ANDYARA LENA PAIVA DE BARROS CAMARGO

CARACTERIZAÇÃO DE BETA-LACTAMASES DE ESPECTRO

ESTENDIDO E DETERMINAÇÃO DE GRUPOS FILOGENÉTICOS

EM ISOLADOS DE Escherichia coli RECUPERADOS DE

PACIENTES EM UM HOSPITAL UNIVERSITÁRIO DE SÃO PAULO

Tese apresentada ao Programa de Pós-Graduação em Microbiologia do Instituto de Ciências Biomédicas da Universidade de São Paulo, para a obtenção do Título de Doutor em Ciências.

São Paulo

2011 


\title{
CARACTERIZAÇÃO DE BETA-LACTAMASES DE ESPECTRO ESTENDIDO E DETERMINAÇÃO DE GRUPOS FILOGENÉTICOS EM ISOLADOS DE Escherichia coli RECUPERADOS DE PACIENTES EM UM HOSPITAL UNIVERSITÁRIO DE SÃO PAULO
}

\begin{abstract}
Tese apresentada ao Programa de Pós-Graduação em Microbiologia do Instituto de Ciências Biomédicas da Universidade de São Paulo, para a obtenção do Título de Doutor em Ciências.
\end{abstract}

Área de Concentração: Microbiologia

Orientador: Prof. Dr. Antonio José Piantino Ferreira.

Co-orientador: Prof. Dr. Nilton Lincopan 
DADOS DE CATALOGAÇÃO NA PUBLICAÇÃO (CIP)

Serviço de Biblioteca e Informação Biomédica do

Instituto de Ciências Biomédicas da Universidade de São Paulo

() reprodução parcial

Paiva, Andyara Lena de Barros Camargo.

Caracterização de beta-lactamases de espectro estendido e determinação de grupos filogenéticos em isolados de Escherichia coli recuperados de pacientes em um Hospital Universitário de São Paulo I Andyara Lena Paiva de Barros Camargo . -- São Paulo, 2011.

Orientador: Antonio José Piantino Ferreira.

Tese (Doutorado) - Universidade de São Paulo. Instituto de Ciências Biomédicas. Departamento de Microbiologia. Área de concentração: Microbiologia. Linha de pesquisa: Estudo de fatores de virulência de enterobactérias aviárias.

Versão do título para o inglês: Characterization of extendedspectrum $\beta$-lactamases and phylogenetic groups in Escherichia coli strains recovered from patients at a university hospital in São Paulo.

Descritores: 1. Escherichia coli 2. Infecção extra-intestinal 3. Infecção do trato urinário 4. ESBL 5. CTX-M 6. Grupo filogenéticos I. Ferreira, Antonio José Piantino II. Universidade de São Paulo. Instituto de Ciências Biomédicas. Programa de Pós-Graduação em Microbiologia III. Título. 


\section{UNIVERSIDADE DE SÃO PAULO \\ INSTITUTO DE CIÊNCIAS BIOMÉDICAS}

Candidato(a):

Andyara Lena Paiva de Barros Camargo.

Título da Tese:

Caracterização de beta-lactamases de espectro estendido e determinação de grupos filogenéticos em isolados de Escherichia coli recuperados de pacientes em um Hospital Universitário de São Paulo.

Orientador(a): $\quad$ Antonio José Piantino Ferreira.

A Comissão Julgadora dos trabalhos de Defesa da Tese de Doutorado, em sessão pública realizada a considerou

\section{( ) Aprovado(a) ( ) Reprovado(a)}

$\begin{array}{ll}\text { Examinador(a): } & \begin{array}{l}\text { Assinatura: } \\ \text { Nome: ........ } \\ \text { Instituição: }\end{array} \\ \text { Examinador(a): } & \begin{array}{l}\text { Assinatura: } \\ \text { Nome: ....... } \\ \text { Instituição: }\end{array} \\ \text { Examinador(a): } & \text { Assinatura: } \\ & \begin{array}{l}\text { Nome: ........ } \\ \text { Instituição: }\end{array} \\ \text { Examinador(a): } & \text { Assinatura: } \\ & \text { Nome: ........ } \\ & \text { Instituição: } \\ & \text { Assinatura: } \\ \text { Presidente: } & \text { Nome: ........ } \\ & \text { Instituição: }\end{array}$




\section{CERTIFICADO DE ISENÇÃO}

Certificamos que o Protocolo CEP-ICB N ${ }^{\circ} \mathbf{2 7 5}$, referente ao projeto intitulado: "Caracterização de B-Lactamases de espectro estendido (ESBL) em isolados clínicos de Escherichia coli do Hopital Universitário da USP“ sob a responsabilidade de Andyara Lena dos Santos Costa, foi analisado na presente data pela CEEA - COMISSÃO DE ÉTICA EM EXPERIMENTAÇÃO ANIMAL e pela CEPSH - COMISSÃO DE ÉTICA EM PESQUiSA COM SERES HUMANOS, tendo sido deliberado que o referido projeto não envolve manipulação animal ou humana que justifique uma aprovação quanto aos princípios éticos exigidos por ambas as Comissões.

São Paulo, 19 de novembro de 2008.

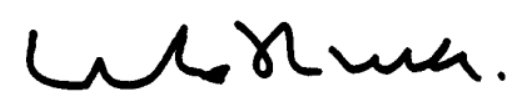

PROF. DR. WOTHAN TAVARES DE LIMA Coordenador da CEEA - ICB/USP

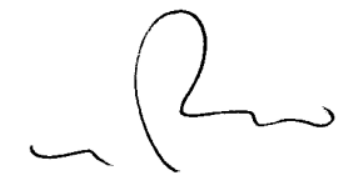

PROF. DR. LUIZ VICENTE RIZZO Coordenador da CEPsh - ICB/USP 
Aos meus avós-pais, Martinho Paiva e Cleonice Paiva (in memorian) por todo amor e ensinamentos recebidos.

A minha mãe Sheila Regina pelo amor incondicional e por sempre apoiar-me em todas as decisões.

Ao meu tio-pai José Henrique (in memorian) pelo amor paterno e exemplo de dignidade.

À minha filha Thaynara Lena, razão das minhas conquistas, pela compreensão durante minhas longas ausências.

Ao meu marido Luís Eduardo por todo amor, auxífio e cumplicidade nos momentos finais e ao Pedro pelo carinho e admiração.

Dedico. 


\section{AGRADECIMENTOS}

A Deus que sempre esteve comigo, e graças a ele tive força para alcançar esta conquista.

Aos meus orientadores, Professor Dr. Antonio Piantino e Professor Dr. Nilton Lincopan por terem me recebido em seus laboratórios, pelos valiosos ensinamentos e, sobretudo pela paciência durante todos esses anos.

À Professora Dra. Claudete Astolfi Ferreira, pelo auxílio científico, e colaboração nas correções finais da tese.

Ao Professor Dr. José Guerra pela atenção e por ter me direcionado ao Laboratório de Ornitopatologia.

À minha família, em especial a minha tia Wandete Paiva por todo o amor recebido, e aos meus primos-irmãos Shantuzza, Alberth e Júnior pelo amor fraternal que existe entre nós.

Ao meu afilhado André Henrique, pelo amor que tem a sua didinha, e ao meu cunhado Neife, pelo carinho e consideração.

Aos meus sogros Conceição Pastore e Nelson Eduardo de Barros Camargo pelo carinho e amável atenção para comigo e com a Thaynara.

A família do Luís Eduardo, em especial a Cé, Anginha e Renata pelo carinho.

Aos meus amigos de infância Eliana Cantanhêde, Welter Cantanhêde, Fábio Cantanhêde, Flávio Cantanhêde e Hamilton Cantanhêde, e aos tios Francisco Ximenes e Gracinha Cantanhêde por estarem sempre presentes em todos os momentos da minha vida.

À Concetta Pappalardo e ao Rafael Barros por todo o apoio.

À Adriana Pereira, por ter sido uma verdadeira colaboradora deste trabalho e pela amizade durante esses anos.

Ao John McCulloch, por todo o auxílio científico e por sempre ter sido um amigo presente nas horas mais difíceis.

À Juliana Amhaz, pela amizade e companheirismo em todos os momentos.

À Patrícia Neves, pelo auxílio valioso na realização dos experimentos, pela 
atenção constante e, principalmente, pela amizade.

Á Professora Dra. Marina Baquerizo Martinez, Diretora do Laboratório de Análises Clínicas do Hospital Universitário por gentilmente ter cedido as cepas para este estudo e às profissionais do laboratório Lilian e Silvia.

Aos amigos Marlilde Abreu, Alexandre Abreu, Ana Reyjane, Paulinho Fernandes e Nathalie Brigatto, por toda a torcida.

Ao Malta e a Dora pelos incentivos e pelo imenso apoio nos momentos finais.

À Jacinta, por ter direcionado meus primeiros passos no ICB.

À Professora Dra. Elsa Mamizuka, por permitir a utilização de seu laboratório e pela imensa atenção dispensada.

À Professora Dra. Andréa Moreno e Dra Renata Paixão (FMVZ/USP), por terem colaborado com este trabalho na realização do PFGE.

A todos os colegas dos Laboratórios de Ornitopatologia, Farmácia e Microbiologia, pelos auxílios na execução dos experimentos, em especial a Luciana Allegretti, Luciana Scanavini, Dennis Zannatto e Ketrin C. da Silva.

Aos amigos Rodrigo Assunção e Jean Zukorosvki, pelos conhecimentos compartilhados e convívio agradável.

Às amigas Patrícia Cristina, Katiuska Azevedo, Rosana Freire e Heloísa Almeida por todo o apoio nas Universidades FMU e ANHEMBI e pela amizade.

À Alice, da secretaria da pós-graduação do ICB-II, por sempre ter sido paciente e pela atenção dada aos alunos.

Aos membros da banca por enobrecerem este trabalho.

À FAPESP, pelo financiamento do projeto junto ao Laboratório de Ornitopatologia da FMVZ/USP.

Enfim, a todos que contribuíram para a realização deste trabalho. 


\section{RESUMO}

PAIVA, A. L. B. C. Caracterização de beta-lactamases de espectro estendido e determinação de grupos filogenéticos em isolados de Escerichia coli recuperados de pacientes em um Hospital Universitário de São Paulo. 2011. 116 f. Tese (Doutorado em Microbiologia) - Instituto de Ciências Biomédicas, Universidade de São Paulo, São Paulo, 2011.

Escherichia coli pode causar infecção intestinal e extra-intestinal, de origem comunitária ou hospitalar, prevalecendo como agente de infecção do trato urinário (ITU). O objetivo do presente estudo foi caracterizar a produção de $\beta$-lactamases de espectro estendido (ESBL), grupos filogenéticos, e a relação clonal em isolados clínicos de E. coli recuperados de pacientes ambulatoriais e internados atendidos em um Hospital Universitário de São Paulo, no período de 2005 a 2007. Seis por cento (34/562) dos isolados de E. coli estudados foram caracterizados como produtores de ESBL, sendo associados exclusivamente a infecções extra-intestinais, tanto nos pacientes ambulatoriais (10/28, 36\%) como nos internados (18/28, 64\%), dos quais 56\% (19/34) foram recuperados de uroculturas. Os isolados produtores de ESBL exibiram um fenótipo multirresistente apresentando um perfil de resistência a ampicilina (100\%), cefalotina $(100 \%)$, cefotaxima $(100 \%)$, ceftazidima $(79 \%)$, sulfametoxazol-trimetoprim (62\%), gentamicina (56\%), ciprofloxacina (50\%) e amicacina (6\%) e permanecendo suscetíveis ao imipinem. A produção de ESBL esteve associada com a presença de genes do tipo bla $a_{\mathrm{CTX}-\mathrm{M}-2}(94 \%, 32 / 34)$, bla $a_{\mathrm{CTX}-\mathrm{M}-15}(3 \%, 01 / 34)$ e bla produtores de ESBL, os grupos filogenéticos B1 $(53 \%, 18 / 34)$ e A $(18 \%, 6 / 34)$, de baixa virulência, foram predominantes sobre os grupos filogenéticos, de alta virulência, B2 $(12 \%, 4 / 34)$ e D (18\%, 6/34). De fato, os genes de virulência pap, cnf1, sfa, hly, e iuc, associados com adesão, invasão e disseminação, não foram identificados. Finalmente, a tipagem genotípica por PFGE (utilizando a enzima Xbal) com posterior análise em dendrograma, identificou a presença de 31 clusters entre os 34 isolados produtores de ESBL. Em resumo, a alta incidência de isolados clonalmente não relacionados, pertencentes aos grupos filogenéticos A e B1, de baixa virulência, sugere que cepas comensais de $E$. coli podem adquirir genes de resistência do tipo blacTX-M por transferência horizontal, contribuindo no estabelecimento e no prognóstico de infecções extra-intestinais, principalmente do trato urinário.

Palavras-chave: Escherichia coli. Infecções extra-intestinais. Infecções do trato urinário (ITU). ESBL. CTX-M. Fatores de virulência. Grupos filogenéticos. 


\begin{abstract}
PAIVA, A. L. B. C. Characterization of extended-spectrum $\beta$-lactamases and phylogenetic groups in Escherichia coli strains recovered from patients at a university hospital in São Paulo. 2011. 116 p. Ph. D. Thesis (Microbiology) - Instituto de Ciências Biomédicas, Universidade de São Paulo, São Paulo, 2011.
\end{abstract}

Escherichia coli can produce both intestinal and extraintestinal community- or nosocomialacquired infection, being the main agent of urinary tract infection (UTI). The aim of this study was to characterize the extended-spectrum beta-lactamase (ESBL) production, phylogenetic groups, and clonal relationship among E. coli clinical isolates recovered from inpatients and outpatients admmited at a university hospital in São Paulo, during 2005 to 2007. Six percents (34/562) E. coli isolates were characterized as ESBL producers, being associated exclusively to extraintestinal infections in both inpatients $(10 / 28,36 \%)$ and outpatients (18/28, 64\%), of which 56\% (19/34) were recovered from urine cultures. ESBL-producing E. coli exhibited a multidrug-resistant phenotype with a resistance profile to ampicillin (100\%), cephalotin (100\%), cefotaxime (100\%), ceftazidime (79\%), sulphamethoxazole-trimethoprim (62\%), gentamicin (56\%), ciprofloxacin (50\%), and amikacin (6\%), and remaining susceptible to imipenem. In this regard, ESBL production was associated with the presence of bla $a_{\mathrm{CTX}-\mathrm{M}-2}(94 \%, 32 / 34)$, bla $\mathrm{C}_{\mathrm{CTX}-\mathrm{M}-15}(3 \%, 1 / 34)$ and bla $a_{\text {СтX-м-1 }}(94 \%, 32 / 34)$ genes. On the other hand, low-virulence phylogenetic groups B1 $(53 \%, 18 / 34)$ and $A(18 \%, 6 / 34)$ were predominant over high-virulence phylogenetic groups B2 $(12 \%, 4 / 34)$ and D $(18 \%, 6 / 34)$, among ESBL-producing $E$. coli isolates studied. In fact, pap, cnf1, sfa, hly, and iuc virulence genes associated with adhesion, invasion and dissemination were not identified. Finally, genotyping by PFGE (using Xbal restriction) with subsequent cluster analysis (dendrogram) revealed the presence of 31 cluster among 34 ESBL-producing E. coli. In summary, the high prevalence of clonally unrelated ESBL-producing $E$. coli belonging to low-virulence phylogenetic groups $A$ and

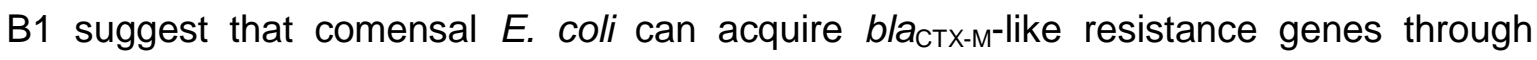
horizontal gene tranfer, contributing to the establishment and outcome of extraintestinal infections, mainly in the urinary tract.

Key-words: Escherichia coli. Extraintestinal infections. Urinary tract infections (UTIs). ESBL. CTX-M. Virulence factors. Phylogenetic groups. 


\section{LISTA DE ABREVIATURAS E SIGLAS}
AK- $\quad$ Amicacina
AMC- $\quad$ Amoxicilina + Ácido clavulânico
AMP- Ampicilina
ATCC- Coleção de Culturas da América ("American Type Culture Collection")
ATM- Aztreonam
BHI- Infusão de cérebro e coracao ("Brain-Heart-Infusion")
Bla- $\quad$ Gene codificador de $\beta$-lactamases de espectro estendido
CAZ- $\quad$ Ceftazidima
CC- Centro Cirúrgico
CIP- Ciprofloxacina.

CLSI- Instituto de Padrões Clínicos e de Laboratório ("Clinical and Laboratory Standards Institute")

CIM- Concentração inibitória mínima

CRO- Ceftriaxona

CTX- Cefotaxima

CTL- Cefotaxima/Ácido clavulânico

CXM- Cefuroxima

DDST- Método da dupla difusão em disco

DHFR- Dihidrofolato redutase

DHPS- Dihidropteroato sintetase

DNA- Ácido desoxiribonucleico ("Deoxyribonucleic Acid")

dNTPp- Deoxinucleotideo trifosfato

EDTA- Ácido etilenodiamino tetra-acetico

EM- Emergência

ESBL- Beta-lactamases de espectro estendido

FEP- Cefepima

FOX- Cefotaxima

GEN- Gentamicina

ITU- Infecção do trato urinário

IMP- Imipenem 
Intl- Gene codificador da integrase

KF- Cefalotina

LBA- Lavado bronco-alveolar

McFarland- Escala que representa concentrações de bactéria por $\mathrm{ml}$

MH- Mueller-Hinton

mL- Mililitro

mm- Milímetro

NAL- $\quad$ Ácido nalidixico

NE- $\quad$ Não encontrado

NIT- Nitrofurantoína

NOR- Norfloxacina

Orf- "Open Reading Frame"

OXA- oxacilina

pb- $\quad$ Pares de bases

PBP- $\quad$ Proteínas de ligação a penicilina ("Penicillin Binding Protein")

PCR- Reação em cadeia pela polimerase ("Polymerase Chain Reaction")

PFGE- Eletroforese em campo pulsado ("Pulsed Field Gel Electrophoresis")

QD- Quinupristina-Dalfopristina

RNA- Ácido ribonucléico ("Ribonucleic Acid")

SAM- Ampicilina/sulbactam

SEMI- $\quad$ Unidade de Terapia Semi-Intensiva

SXT- Sulfametoxazol-Trimetropim

TIM- Ticarcina/Ácido clavulânico

Tris- $\quad$ Tris-hidroximetilaminometano (2-amino-2-(hidroximetil) propano-1,3-

diol)

UV- Ultra-violeta

UFC- $\quad$ Unidades formadoras de colônias

UTI- Unidade de Terapia Intensiva

Van- Gene da vancomicina

Xbal- gene Xbal de Xanthomonas badrii (ATCC 11672). 


\section{LISTA DE FIGURAS}

Figura 1. Patogenia da infecção do trato urinário (ITU) causada por Escherichia coli uropatogênica (UPEC). A figura mostra os diferentes estágios de uma ITU ...25

Figura 2. Patotipos de E. coli e grupos filogenéticos 28

Figura 3. Árvore dicotômica da classificação dos grupos filogenéticos de $E$. coli na presença e ausência dos genes chuA, yjaA e do fragmento TspE4.C2

Figura 4. Mecanismos de resistência do antibiótico

Figura 5. Detecção de ESBL in vitro pelo método de dupla difusão em disco (DDST) e E-test

Figura 6. PCR específico dos grupos filogenéticos de Escherichia coli com os genes chuA, yjaA e o fragmento TspE4.C2

Figura 7. Dendograma dos grupos filogenéticos com os isolados clínicos de Escherichia coli produtores de beta-lactamases de espectro estendido 64

Figura 8. Relação clonal de 34 isolados clínicos de E. coli produtores de ESBL definidos pela técnica de eletroforese em campo pulsado (PFGE), com a enzima $X b a l$, associada aos genótipos de resistência e virulência e grupos filogenéticos de pacientes hospitalizados no Hospital Universitário, São Paulo, Brasil..... 


\section{LISTA DE TABELAS}

Tabela 1- Antibióticos e mecanismos comuns de resistência

Tabela 2- Características dos isolados clínicos de beta-lactamases de espectro estendido de Escherichia coli utilizadas neste estudo

Tabela 3- Origem de Escherichia coli isoladas de um mesmo paciente

Tabela 4- Iniciadores utilizados para a detecção de genótipos de resistência de ESBL

Tabela 5- Iniciadores utilizados para a detecção de genótipos de virulência de Escherichia coli

Tabela 6- Perfil de resistência e detecção in vitro de ESBL dos isolados clínicos de E. coli.

Tabela 7- Grupos filogenéticos, amostras clínicas, perfil de resistência e genótipos de beta-lactamases nos isolados de $E$. coli estudados

Tabela 8- Características de genes de resistência, virulência, grupos filogenéticos, PFGE dos 34 isolados clínicos de Escherichia coli produtores de ESBL e dados das amostras e pacientes 


\section{LISTA DE GRÁFICOS}

Gráfico 1. Perfil da faixa etária dos pacientes internados no Hospital Universitário considerando-se ambos os sexos

Gráfico 2. Frequência de cepas de E.coli e E.coli (ESBL) no período de 2005 a 2007 no Hospital Universitário. .59

Gráfico 3. Frequência dos genótipos de virulência dos isolados clínicos de $E$. coli produtores de ESBL de um Hospital Universitário 


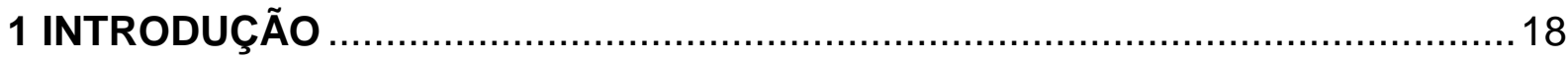

1.1 Escherichia coli E INFECÇÕES EXTRA-INTESTINAIS ...................................19

1.2 PERFIL DOS GENÓTIPOS DE VIRULÊNCIA DE Escherichia coli EXTRA-

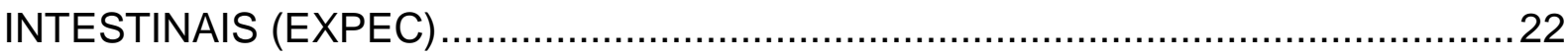

1.3 GRUPOS FILOGENÉTICOS DE Escherichia coli ..........................................27

1.4 RESISTÊNCIA BACTERIANA MEDIADA POR $\beta$-LACTAMASES DE ESPECTRO ESTENDIDO (ESBL - EXTENDED-SPECTRUM $\beta$-LACTAMASES). ..29

1.4.1 A epidemiologia molecular de variantes de $\beta$-lactamases de espectro estendido (ESBL) do tipo CTX-M, TEM, SHV, OXA produzidas por patógenos

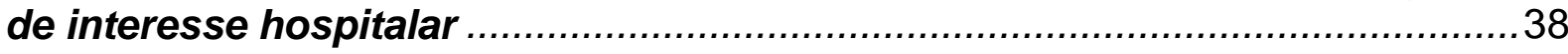

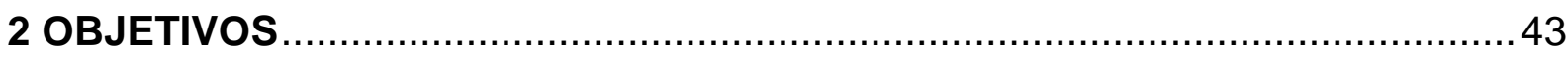

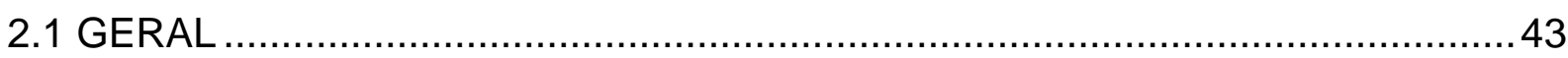

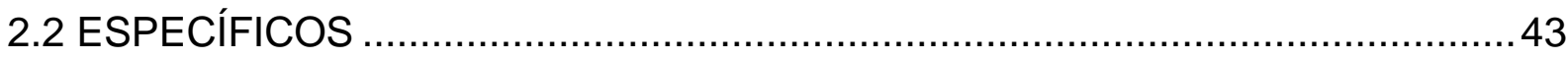

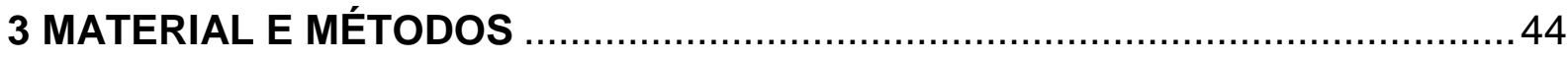

3.1 AMOSTRAS CLÍNICAS E CEPAS BACTERIANAS ….....................................4

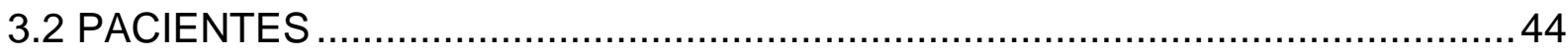

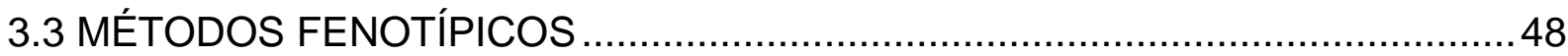

3.3.1 Testes de susceptibilidade aos antimicrobianos pelo método de

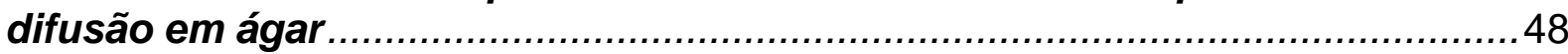

3.3.2 Determinação de $\beta$-lactamases de espectro estendido (ESBLs), pelo método da dupla difusão em disco (DDST- double-disk synergy test) .............. 48

3.3.3 Detecção da concentração inibitória mínima (CIM) de E. coli produzindo $\beta$-lactamases de espectro estendido (ESBL) ...............................................4

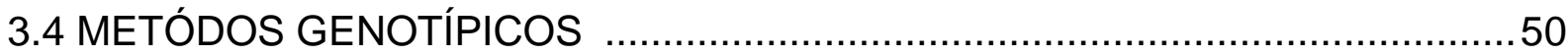

3.4.1 Determinação dos genótipos de resistência bla $a_{E S B L}$ através da Reação

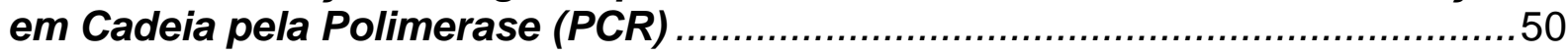

3.4.2 Determinação dos genótipos de virulência para as análises filogenéticas por meio da PCR-multiplex... 
3.5.2 Análise do DNA cromossomal por eletroforese em gel por campo pulsado (PFGE).

4 RESULTADOS

4.1 CARACTERÍSTICAS CLÍNICAS E MICROBIOLÓGICAS DOS ISOLADOS DE Escherchia coli ASSOCIADAS À INFECÇÃO EXTRA-INTESTINAL DOS PACIENTES DE UM HOSPITAL UNIVERSITÁRIO ..............................................56

4.2 MÉTODOS FENOTÍPICOS

4.2.1 Perfil de susceptibilidade dos isolados de Escherichia coli associada com infecção extra-intestinal.

4.2.2 Confirmação dos fenótipos ESBL nos isolados de Escherichia coli associada com infecção extra-intestinal.

4.2.3 Determinação da CIM para cefalosporina de terceira geração (cefotaxima) na presença/ausência de inibidor de ESBL

4.3 MÉTODOS GENOTÍPICOS

4.3.1 Detecção dos genótipos de $\beta$-lactamases de espectro estendido (bla $\left.a_{E S B L}\right)$ em E. coli.....

4.3.2 Determinação de genótipos de virulência, grupos filogenéticos e sua associação com a produção de ESBL nos isolados clínicos de Escherichia coli......61

4.4 TÉCNICAS DE TIPAGEM MOLECULAR PARA ANÁLISE EPIDEMIOLÓGICA . 65

4.4.1 Identificação do sorogrupo 025 nos isolados de Escherichia coli associada com infecção extra-intestinal.

4.2 RELAÇÃO CLONAL DOS ISOLADOS DE Escherchia coli PRODUTORA DE ESBL, SUA RELAÇÃO EPIDEMIOLÓGICA COM O GRUPO FILOGENÉTICO E GENÓTIPO ESBL

5 DISCUSSÃO

6 CONCLUSÕES

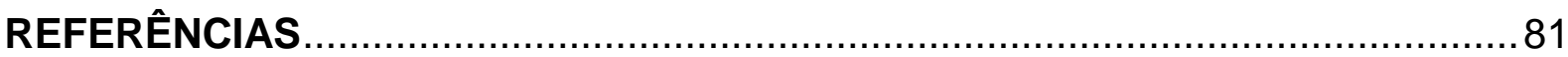




\section{INTRODUÇÃO}

Escherichia coli é um bacilo Gram-negativo, anaeróbio facultativo que faz parte da microbiota intestinal do homem e da maioria dos animais, pertencente à família Enterobacteriaceae (ORSKOV e ORSKOV, 1992).

$O$ processo de colonização intestinal inicia-se ao nascimento, quando bactérias presentes na mucosa vaginal, na pele da mãe e proveniente de fontes ambientais são adquiridas pelo recém-nascido. Uma vez estabelecido o processo de colonização, este microrganismo convive com seu hospedeiro durante toda a vida, sendo a principal bactéria integrante do trato gastrintestinal (GYLES, 1993).

Algumas cepas de E. coli podem causar uma ampla variedade de doenças intestinais e extra-intestinais, como: diarréia, infecções do trato urinário, septicemia e meningite neonatal (CLERMONT; BONACORSI; BINGEN, 2000; GALES; SADER; JONES, 2002; TRABULSI e ALTERTHUM, 2004), o que demonstra a sua variabilidade genética quanto à presença de fatores de virulência e que permite classificá-las em diferentes patotipos (GYLES, 1993; DOZOIS e CURTISS 1999; NOUGAYRÈDE; FERNANDES; DONNENBERG, 2003; WILSON e GAIDO, 2004).

E. coli é classificada em vários patotipos e sorotipos, identificados por antisoros específicos preparados contra os antígenos O:K:H que se encontram presentes na sua membrana externa, denominados antígenos somáticos ("O" - do alemão "Ohne Hauch" que se traduz ou significa "sem bafo"), antígenos capsulares ("K" - do alemão "Kapsel" que significa cápsula) e antígenos flagelares ("H"- do alemão "Hauch" que significa bafo) (KAUFFMANN, 1947). São conhecidos 181 antígenos somáticos (lipossacarídeos constituintes da membrana externa), 80 antígenos capsulares (antígenos polissacarídeos) e 53 antígenos flagelares (antígenos protéicos) (KONEMAN, 2001).

Os sorogrupos mais comumente encontrados em E. coli isoladas de infecções do trato urinário incluem os antígenos somáticos: $\mathrm{O} 1, \mathrm{O} 2, \mathrm{O} 4, \mathrm{O}, \mathrm{O} 7, \mathrm{O} 15, \mathrm{O} 18$, O25, $\mathrm{O} 75$ e O83, os antígenos capsulares: $\mathrm{K} 1$ e K2 e os antígenos flagelares: H31, H10 e H1 (HUGHES, PHILLIPS e ROBERTS, 1982; KUSECEK et al., 1984; YAMAMOTO et al., 1995; DONNENBERG e WELCH, 1996; BLANCO et al., 1997; TERAl et al., 1997; GUYER et al., 2000; MARRS; ZHANG; FOXMAN, 2005; 
ESPARIS et al., 2006).

A combinação entre eles possibilita a discriminação de $E$. coli em mais de 50.000 sorotipos. No entanto, dentre estes, poucos são considerados patogênicos (SCHEUTZ et al., 2004; MOLENDA, 1994; YAMAMOTO, 2007).

\subsection{Escherchia coli E INFECÇÕES EXTRA-INTESTINAIS}

A infecção do trato urinário (ITU) é definida como um conjunto de alterações patológicas conseqüentes a multiplicações de microrganismos neste local. A região periuretral pode ser colonizada por bactérias aeróbicas e anaeróbicas, em conseqüência de modificações da microbiota normal e da colonização por cepas Gram-negativas, principalmente Escherichia coli uropatogênicas que expressam combinações de antígenos e fatores de virulência (LINCOLN, 1974; DICK e FELDMAN, 1996; SALZER, 2000; CAMARGO; BARATELLA; MASCHIETO, 2001; BIANCO; MACHADO; PETRY, 2002; KOCH et al., 2003; KOCH e ZUCCOLOTTO, 2003; MENEZES et al., 2005).

$O$ agente etiológico varia de acordo com a idade, sexo e as condições clínicas dos pacientes (DICK e FELDMAN, 1996; DIEKEMA et al., 1999; GARCIA; CAMPONOVO; TRIANTAFILO, 2001; VILA et al., 2002; DALBOSCO; SROUGl; DALL'OGLIO, 2003). No entanto, Escherichia coli é o principal agente etiológico responsável pelas infecções do trato urinário (ITU), incluindo cistites e pielonefrites (PATERSON, 2006). A maioria das ITU é causada por bactérias Gram-negativas, sendo que $E$. coli é responsável por $80 \%$ a $90 \%$ destas infecções adquiridas na comunidade e por aproximadamente $50 \%$ das infecções nosocomiais (RONALD, 2003; KALSI et al., 2003) e são mais comuns que as infecções respiratórias (TWAIJ, 2000; MEDEIROS et al., 2003).

Andreu et al. (2005), relataram que E. coli foi o principal uropatógeno isolado na comunidade (73\%). Assim como, Almeida, Simões e Raddi em 2007, observaram que $E$. coli foi o agente mais comum nessas infecções $(74,1 \%)$. As infecções do trato urinário (ITU) constituem uma das principais causas de consulta na prática médica (ANDREU et al., 2005). 
Várias bactérias podem também causar ITU como: Staphylococcus saprophyticus, Klebsiella pneumoniae, Proteus mirabilis, Pseudomonas aeruginosa, Enterococcus spp, Providencia spp, Serratia marcescens, Salmonella spp, Enterobacter spp, Staphylococcus aureus, dentre outras. Caracteriza-se como infecção urinária, o crescimento bacteriano de pelo menos $10^{5}$ unidades formadoras de colônias por $\mathrm{mL}$ de urina (100.000 UFC/mL) colhida em jato médio e de forma asséptica. Esse número é necessário para se considerar uma infecção urinária positiva (BACHUR e HARPER, 2001).

A ITU é classificada em infecção urinária baixa e infecção urinária alta. A infecção baixa é a invasão da uretra e bexiga, sendo denominada de cistite. A infecção alta é a invasão dos rins, denominada pielonefrite e glomerulonefrite (RUSHTON, 1997; TWAIJ, 2000). Em relação à patogenia, a via ascendente é a principal forma de infecção do trato urinário, sendo um dos fatores predisponentes para a mulher, devido as suas características anatômicas, como uretra curta e sua maior proximidade com vagina e com o ânus (POLETTO e REIS, 2005; HEILBERG e SCHOR, 2003). Escherichia coli é responsável por cerca de $80 \%$ das infecções em meninas e cerca de $40 \%$ nos meninos, devido ao maior número de malformações congênitas, especialmente a válvula da uretra posterior. Proteus sp. é o responsável pela colonização do prepúcio, isolado em $30 \%$ dos casos de ITU nos meninos (BAILEY, 1993; DICK e FELDMAN, 1996; KOCH e ZUCCOLOTTO, 2003; BRIAN e CURRY, 2005).

A bacteriúria sintomática foi observada igualmente em ambos os sexos $(1,2 \%$ nos meninos e 1,1\% nas meninas). Entretanto, 3,7\% dos meninos e 2,0\% das meninas apresentaram bacteriúria durante o primeiro ano de vida, sendo que a incidência foi maior em meninos nos primeiros meses de vida em estudos realizados nos Estados Unidos (GINSBURG e McCRACKEN, 1982; KUNIN, 1987; MAJD et al., 1991).

Outros estudos revelaram que a incidência de ITU aumenta nas meninas após o primeiro ano em função de características anatômicas que favorecem a colonização da uretra por microrganismos da microbiota intestinal (FARHAT e KHOURY, 2004). Dessa forma, durante toda a infância e principalmente na fase préescolar, as meninas são acometidas por ITU de 10 a 20 vezes mais que os meninos (HEILBERG e SCHOR, 2003). 
As ITU são relatadas com certa freqüência em mulheres jovens sexualmente ativas (STROM et al., 1987), existindo episódios durante a menopausa (NICOLLE, 2001; HEILBERG e SCHOR, 2003) ou na gestação, onde $2 \%$ a $10 \%$ desenvolvem algum tipo de infecção urinária (DASHE e GILSTRAP, 1997; GRAHAM et al., 2001).

Gupta et al. (2001), afirmaram que 50\% a 70\% das mulheres apresentarão ao menos um episódio de ITU durante a sua vida, e que $20 \%$ a $30 \%$ destas poderiam ter episódios recorrentes. Estima-se que 40\% das mulheres adultas poderão sentir os sintomas de cistite, sendo Escherichia coli uropatogênica (UPEC) o agente etiológico responsável por 75 a 80\% dos casos (BAHRANI-MOUGEOT et al., 2002).

Estudos com amostras de infecções do trato urinário entre 1997 e 1999 com 1.430 isolados e em 2000 com 531 isolados, em pacientes hospitalizados, na América Latina - SENTRY, 1997-2000 (SADER et al., 2001), verificaram nesses dois períodos quatro patógenos mais importantes: $E$. coli $(56,0 \% / 60,3 \%)$ como o mais freqüentemente isolado, seguido de Klebsiella spp. (11,6\%/11,5\%), P. aeruginosa $(8,0 \% / 6,2 \%)$, e P. mirabilis $(5,2 \% / 5,1 \%)$ (GALES; SADER; JONES, 2002). Leblebicioglu e Esen (2003) identificaram E. coli (32,4\%), seguido por Klebsiella spp. (17\%), Candida spp. (12,8\%) e Pseudomonas aeruginosa (11,7\%). Almeida, Simões e Raddi (2007) detectaram E. coli $(29,1 \%)$ e Klebsiella spp. (29,1\%). No entanto, Merle et al. (2002), avaliando a incidência de ITU de origem hospitalar em pacientes internados em um Serviço de Urologia observaram que, dentre os microrganismos isolados, $23,9 \%$ foram $P$. aeruginosa, 20,4\% Enterococcus spp., $13,4 \%$ E. coli e $11,1 \%$ Staphylococcus aureus.

Foi demonstrado que a incidência de infecção do trato urinário, em mulheres, pode variar de acordo com a condição socioeconômica, a presença de diabete mellitus, condições de higiene após as relações sexuais, presença de automedicação e de alterações anatômicas do trato urinário (MENEZES et al., 2003).

E. coli pode causar doenças em consequência da presença de fatores de virulência que afetam uma ampla variedade de processos celulares e permitem uma adaptação da bactéria a diferentes sítios de infecção (KAPER; NATARO; MOBLEY, 2004). A designação ExpEC (E. coli patogênica extra-intestinal) abrange os seguintes patotipos: UPEC (E. coli uropatogênica), SePEC (E. coli associada à septicemia), MNEC (E. coli associada à meningite neonatal) e APEC (E. coli 
patogênica para aves) (MOKADY; GOPHNA; RON, 2005). A maioria dos fatores de virulência presente em ExPEC são distintos daqueles encontrados em cepas patogênicas intestinais (PICARD; GARCIA; GOURIOU, 1999; RUSSO e JOHNSON 2000; JOHNSON e RUSSO, 2002; RUSSO e JOHNSON, 2003; JOHNSON, 2003).

E. coli é um dos agentes mais importantes nas infecções extra-intestinais em humanos (KARISIK et al., 2008) e a segunda espécie $(17,7 \%)$ mais prevalente em bacteremias (BIEDENBACH; MOET; JONES, 2004).

As cepas de $E$. coli patogênicas intestinais podem ser classificadas nos patotipos: EPEC (E. coli enteropatogênica), A-EPEC ( $E$. coli enteropatogênica atípica), ETEC (E. coli enterotoxigênica), EIEC ( $E$. coli enteroinvasora), EHEC ( $E$. coli enterohemorrágica; STEC ( $E$. coli produtora de toxina de Shiga), EAEC (E. coli enteroagregativa) e DAEC ( $E$. coli difusamente aderente) (NATARO e KAPER, 1998; TENG et al., 2004; VIDAL et al., 2005).

A presença de fatores de virulência é fundamental para se estabelecer um processo infeccioso por E. coli (GREENE, 2006; SOUSA, 2006), onde diferentes adesinas foram descritas mediando infecções do trato urinário (SADOWSKA et al., 2003).

1.2 PERFIL DOS GENÓTIPOS DE VIRULÊNCIA DE Escherchia coli EXTRAINTESTINAIS (EXPEC)

E. coli causa doenças em humanos devido à expressão de genes que estão localizados em plasmídeos de alto peso molecular e/ou em regiões particulares, denominadas: "Ihas de patogenicidades" que ficam no cromossomo (BLANCO et al., 1996; HACKER e KAPER, 2000; VILA et al., 2002). O conceito de ilha de patogenicidade (pathogenicity islands - PAl) foi introduzido por Hacker et al. (1990) e a presença destas regiões cromossômicas contribui para a evolução de bactérias patogênicas ou não-patogênicas (OELSCHLAEGER; DOBRINDT; HACKER, 2002a; OELSCHLAEGER; DOBRINDT; HACKER, 2002b).

Escherichia coli uropatogênica cepa 536 isolada de paciente com infecção do trato urinário, sorotipo $06: \mathrm{K} 15: \mathrm{H} 31$, revelou cinco elementos genéticos, os quais 
estão inseridos em diferentes locais do cromossomo presentes nas ilhas: PAI $\mathrm{I}_{536}$, PAI II ${ }_{536}$, PAI III ${ }_{536}$, PAI IV ${ }_{536}$ e PAI $V_{536}$, exibindo as principais características destas ilhas de patogenicidade. Estas PAls são importantes na determinação da virulência de E. coli 536 (SCHUBERT et al., 1999; DOBRINDT et al., 2002; MIDDENDORF et al., 2004).

A evolução do quadro clínico depende do potencial de virulência da bactéria que pode ser determinado pelo conjunto de genes localizados nessas ilhas (HACKER et al., 1997; KARIYAWASAM et al., 2006).

UPEC está epidemiologicamente associada à pielonefrite aguda que incluem expressões da fimbria P, codificada pelo gene pap (pyelonephritis-associated pili), fímbria $S$, codificada pelo gene sfa (sialic acid(S)-fimbriae adhesins), hemolisina codificada pelo gene hly (hemolysin A) fator citotóxico necrotizante codificado pelo gene CNF (cytotoxic necrotising factor), aerobactina codificada pelo gene iuc (iron uptake chelate), e outros fatores de virulência (LLOYD; RASKO; MOBLEY, 2007). Dessa forma, cerca de $80 \%$ das amostras de E. coli de pacientes com cistites e pielonefrite possuem a fimbria $P$ (pili manose-resistente), freqüentemente observada no patotipo UPEC, permitindo uma aderência muito maior a células uroepiteliais do que em amostras da microbiota intestinal (BAHRANI-MOUGEOT et al., 2002; RUIZ et al., 2002; JOHNSON e RUSSO, 2005).

Estudos revelaram que as ilhas de patogenicidades (PAls) de E. coli cepa 536 (UPEC) codificam genes para a fímbria P (PAI II ${ }_{536}$ ), fímbria S (PAI III $I_{536}$ ), a-hly (PAI $I_{536}$ e PAI $I_{536}$ ). PAI IV $5_{536}$ é idêntica a ilha de alta patogenicidade (HIP- highpathogenicity island) de espécies de Yersinia, enquanto PAI $I_{536}$ e PAI $V_{536}$ estão associados aos genes que codificam RNA transportadores (REITTER et al., 1989; HOU, 1999; HACKER e KAPER, 2000; HOCHHUT et al., 2006).

Outro estudo verificou a presença de fímbria do tipo I (pili manose sensível) em $91,8 \%$ de Escherichia coli isolada de ITU, sendo que esta fímbria existia em $66,6 \%$ dos isolados de origem fecal (PERUGINI e VIDOTTO, 1992).

A fimbria $S$ é composta pela subunidade principal Sfa e três subunidades menores denominadas: SfaG, SfaH e SfaS. A subunidade SfaS se localiza na extremidade da fímbria, responsável pela ligação da bactéria a resíduos de ácido siálico, presentes em receptores localizados nas células endoteliais e renais. $O$ pili $\mathrm{S}$, parece facilitar a disseminação bacteriana dentro dos tecidos do hospedeiro e 
está freqüentemente associado à $E$. coli que causam septicemia, meningite e infecções ascendentes do trato urinário, incluindo pielonefrite (JOHNSON; GOULLET; PICARD, 1991; OELSCHLAEGER; DOBRINDT; HACKER, 2002a; RUIZ et al., 2002).

O gene hly codifica a síntese da a-hemolisina, uma proteína citolítica formadora de poros, de $110 \mathrm{kDa}$, secretada por muitas cepas virulentas de E. coli (HIRSH e ZEE, 2003), e dependente de íons cálcio para assumir a sua estrutura funcional e se ligar à membrana celular, causando hemólise (BOEBM; WELCH; SNYDER, 1990). Possui capacidade de lisar eritrócitos, leucócitos, granulócitos, fibroblastos e células uroepiteliais. A hemólise aumenta a disponibilidade do íon ferro para o microrganismo, o que ocorre em altas concentrações de $\alpha$-hly, no entanto, pequenas concentrações são suficientes para provocar a lise de leucócitos, monócitos e linfócitos T periféricos (ISLAND et al., 1998).

Existem dois tipos de fatores citotóxicos necrotizantes, CNF1 e CNF2, de pesos moleculares similares. O CNF1 é codificado por um único gene de 3042 pb localizado no cromossomo bacteriano, localizado na ilha de patogenicidade II (PAI-II) (BLUM et al., 1995) e posteriormente denominada de PAI-V (SWENSON et al., 1996). O gene que codifica CNF2 está localizado no plasmídeo (BOQUET, 2001; HIRSH e ZEE, 2003). CNF são proteínas de aproximadamente 110 a 115 kDa, capazes de induzir o rearranjo dos microfilamentos de actina nas células eucarióticas. Trata-se de uma citotoxina com configuração molecular do tipo A-B, dividida em três domínios: a) N-terminal, responsável pela ligação celular; b) região intermediária, formada por duas hélices hidrofóbicas, que permitem a translocação da toxina através da membrana; e c) C-terminal, região catalítica da toxina (BLANCO et al., 1996; KEANE et al., 1987).

Sat (serine autotransporter toxin) é uma protease presente em amostras de UPEC (OTTO et al., 1998; KUKKONEN e KORHONEN, 2004; PARHAM et al., 2004) codificada pelo gene sat que possui uma atividade citotóxica vacuolizante nas células epiteliais da bexiga e rins, in vitro e in vivo (GUYER et al., 2000; GUYER et al., 2002; ANDERSON et al., 2004).

Na patogênese da ITU causada por UPEC, como ilustrada na figura 1, são descritos os mecanismos de patogenicidade que possibilitam a colonização, invasão e/ou evasão do sistema imunológico do hospedeiro (BOWER et al., 2005; 
JOHNSON; GOULLET; PICARD, 1991; MULVEY et al., 2000; KAPER; NATARO; MOBLEY, 2004).

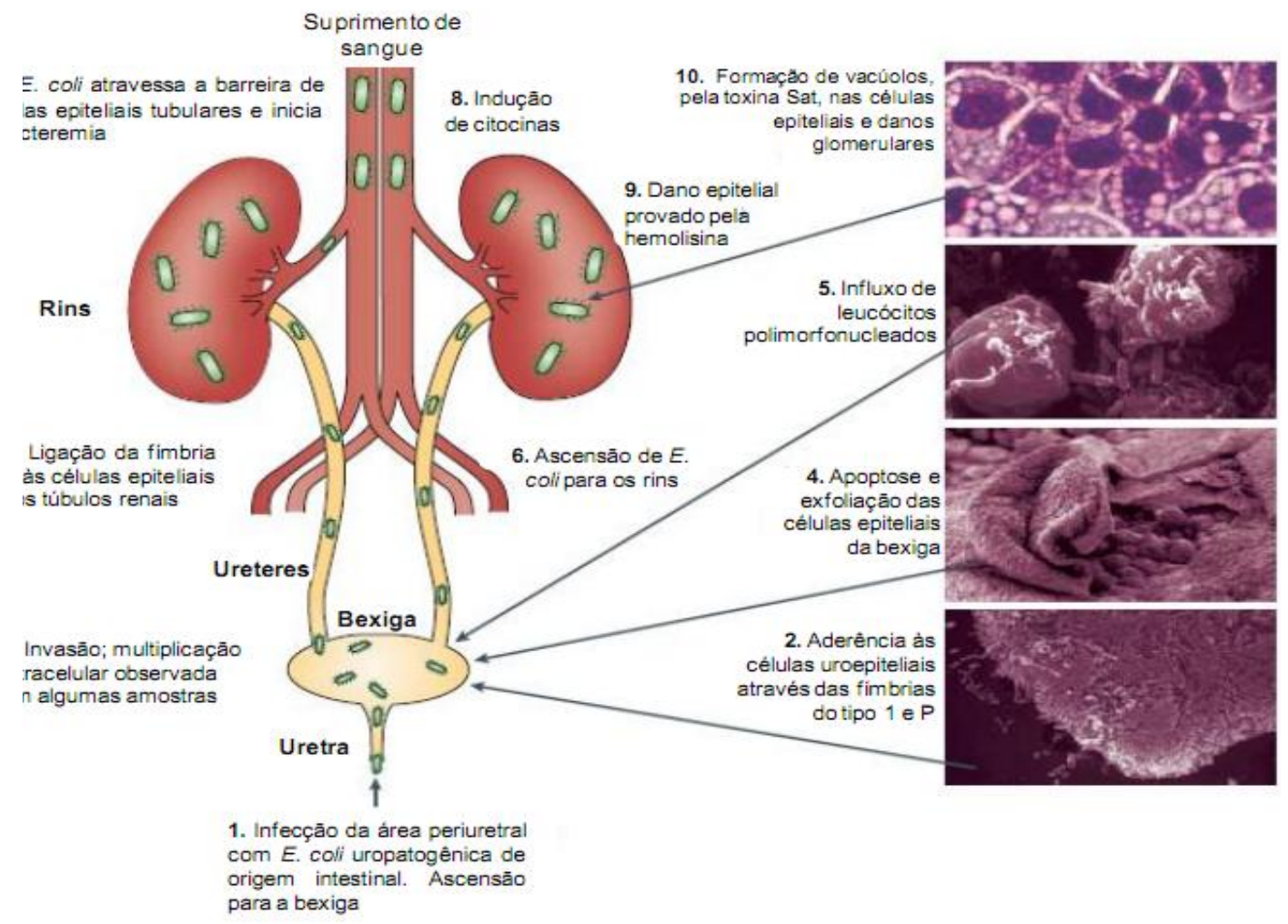

Figura 1. Patogenia da infecção do trato urinário (ITU) causada por Escherichia coli uropatogênica (UPEC). A figura mostra os diferentes estágios de uma ITU.

Fonte: Kaper, Nataro e Mobley (2004), adaptada por Osugui (2008).

UPEC possui um sistema de captação e transporte do íon ferro. A captação de ferro é realizada por proteína codificada pelo gene iuc (iron uptake chelate), enquanto o transporte, por proteína codificada pelo gene iut (iron uptake transport). Estas proteínas são denominadas sideróforos (do grego: transportador de ferro), e são fundamentais para a sobrevivência da bactéria no organismo. O ferro é essencial para o funcionamento de enzimas em todos os organismos, e pode ser seqüestrado no corpo humano por uma variedade de ligações protéicas, conseqüentemente a bactéria que invade os tecidos do hospedeiro deve produzir sideróforos para resgatar este elemento (JOHNSON, 2003b; EWERS et al., 2005; MOKADY; GOPHNA; RON, 2005; EWERS et al., 2009).

A aerobactina (aerobactin system), codificada pelo gene iuc, é um sistema bacteriano que capacita à bactéria crescer em ambientes pobres em ferro, tais como a urina e o soro depletado de complemento (MONTGOMERIE et al., 1984). Os 
genes que codificam a aerobactina podem estar localizados tanto em plasmídeos como no cromossomo bacteriano (TIBA; YANO; LEITE, 2008).

Carbonetti et al. (1986) verificaram uma alta incidência de aerobactina entre os isolados de $E$. coli de pacientes com septicemia $(68,8 \%)$, pielonefrite $(74,6 \%)$, pacientes sintomáticos $(59,8 \%)$ e de pacientes com cistite assintomática $(63,2 \%)$ do que em E. coli isolada de fezes de indivíduos normais (34.3\%). Foi observado que a capacidade para produzir aerobactina era mais freqüente entre isolados de urina de pacientes com ITU do que nas amostras isoladas de fezes de pacientes sem predisposição urológica ou condições médicas (JOHNSON; ROBERTS; STAMM, 1988), assim como, ocorre para a fímbria P (BAHRANI-MOUGEOT et al., 2002) e fimbria tipo I (PERUGINI e VIDOTTO,1992). A aerobactina pode ser considerada um fator de virulência relevante para a disseminação bacteriana do trato urinário para a corrente sangüinea (GARCIA e LE BOUQUÉNEC, 1996).

Estudo com fatores de virulência de $E$. coli isolada de sangue encontrou a presença de gene para a aerobactina em $78 \%$ dos isolados, e em $21 \%$ este gene estava presente em plasmídeo. O gene para a fimbria $\mathrm{P}$, a hemolisina e a fímbria tipo I estava presente no cromossomo em 74,43 e $98 \%$ dos isolados, respectivamente. Os genes para aerobactina, fímbria $\mathrm{P}$ e hemolisina presentes em cromossomos foram detectados em pacientes sem predisposição urológicas ou condições médicas. Os isolados que apresentavam o gene para aerobactina em plasmídeo e ausência de gene para fímbria $\mathrm{P}$ e hemolisina foram encontrados em pacientes com comprometimento do trato urinário e associados a genes de resistência a antimicrobianos (JOHNSON; ROBERTS; STAMM, 1988).

O gene tsh (temperature sensitive haemagglutinin) é uma adesina que possui uma alta homologia com as proteases de IgA de Neisseria gonorrhoeae, Neisseria meningitidis e Haemophilus influenzae (PROVENCE e CURTISS, 1994; HENDERSON e NATARO, 2001). O gene thr (thrW tRNAgene) é responsável pela citotoxina denominada Vat (vacuolating autotransporter toxin) de peso molecular de $56 \mathrm{kDa}$, pertencente à categoria de proteínas SPATE (serine protease autotransporters of the Enterobacteriaceae) que são secretadas e pode contribuir para a virulência de E. coli (HENDERSON e NATARO, 2001; PARREIRA e GYLES, 2003; HENDERSON et al., 2004). 


\subsection{GRUPOS FILOGENÉTICOS DE Escherchia coli}

Estudo filogenético tem mostrado que cepas de Escherichia coli podem ser classificadas em quatro grupos filogenéticos, denominados A, B1, B2 e D. As cepas patogênicas extra-intestinais (ExPEC) classificam-se no grupo filogenético B2 e, em menor escala, no grupo filogenético D (WYCKOFF et al., 1998). Clermont, Bonacorsi e Bingen (2000), usaram dois (02) genes, chuA (outer membrane hemin receptor) e yjaA (uncharacterized protein yjaA genome of E.coli K-12) e um fragmento de DNA, denominado TspE4.C2 (anonymous DNA fragment) de 14,9Kb, como marcadores específicos desses grupos filogenéticos.

As amostras que se classificam nos grupos filogenéticos $B 2$ ou $D$ são freqüentemente responsáveis por infecções aguda do trato urinário (KARISIK et al., 2008), enquanto a maioria das amostras de $E$. coli comensais pertencem aos grupos filogenéticos A e B1 (LECOINTRE et al., 1998). As amostras dos grupos filogenéticos, $B 2$ e $D$ possuem mais fatores de virulência do que aquelas dos grupos filogenéticos A e B1 (KARISIK et al., 2008).

Através de estudos epidemiológicos, clínicos e de caracterização genética as cepas de E. coli podem ser de três categorias: comensal, patógeno intestinal e patógeno extra-intestinal (Figura 2) (PICARD; GARCIA; GOURIOU, 1999; KAPER; NATARO; MOBLEY, 2004; EWERS et al., 2007). Amostras de ExPEC são epidemiologicamente e filogeneticamente distintas das comensais e patogênicas intestinais (RUSSO e JOHNSON; JOHNSON e STELL, 2000), entretanto podem colonizar assintomaticamente o trato intestinal, correspondendo a $20 \%$ da população da microbiota em indivíduos normais (SMITH; FRATAMICO; GUNTHER, 2007). 


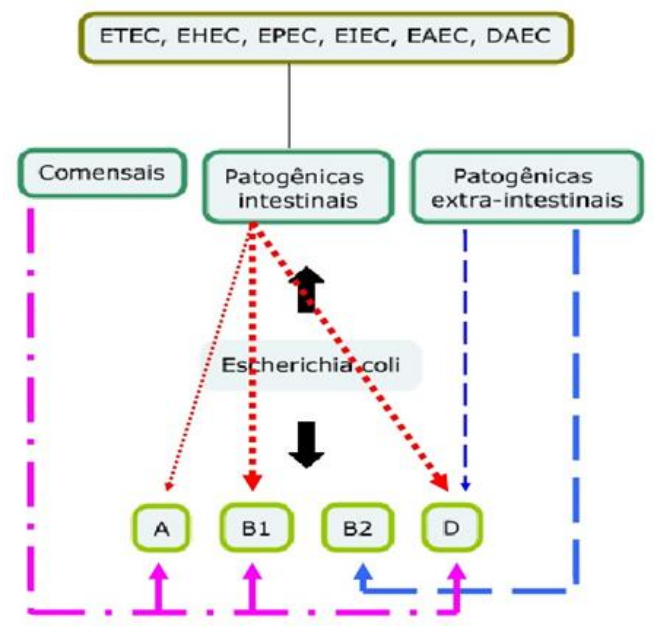

Figura 2. Patotipos de E. coli e grupos filogenéticos Fonte: Ferreira (2010).

A presença do gene chuA foi evidenciada nos grupos B2 ou D, e ausente nos grupos $A$ e $B 1$, permitindo a distinção entre os grupos filogenéticos $B 2$ e $D$ dos grupos filogenéticos A e B1. O gene yja possibilita a separação entre os grupos B2 e $\mathrm{D}$, ou seja, este só é detectado no grupo B2. A presença do fragmento TspE4.C2 caracteriza a amostra como do grupo filogenético B1, enquanto a sua ausência ao grupo filogenético A (CLERMONT; BONACORSI; BINGEN, 2000) (Figura 3).

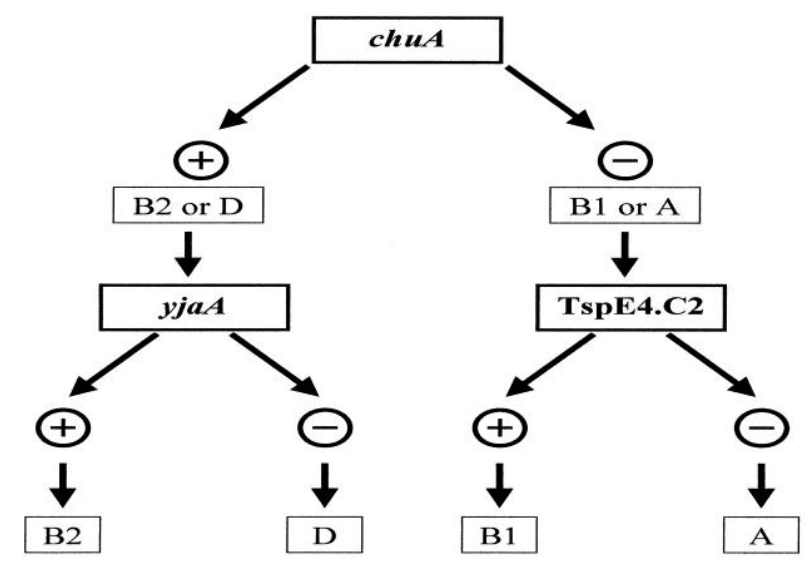

Figura 3. Árvore dicotômica da classificação dos grupos filogenéticos de E. coli na presença e ausência dos genes chuA, yjaA e do fragmento TspE4.C2.

Fonte: Clermont, Bonacorsi e Bingen (2000). 


\subsection{RESISTÊNCIA BACTERIANA MEDIADA POR $\beta$-LACTAMASES DE ESPECTRO ESTENDIDO (ESBL - EXTENDED-SPECTRUM $\beta$-LACTAMASES)}

A resistência bacteriana pode ser definida como um conjunto de mecanismos de adaptação das bactérias contra os efeitos nocivos ou letais aos quais estão sendo expostas (LIVERMORE, 1995). A freqüência de resistência a antimicrobianos varia segundo a região, o tipo de hospital, de paciente e, mesmo dentro da mesma instituição, segundo a unidade (JONES et al., 2000; GALES et al., 2001).

A disseminação de microrganismos resistentes resulta da combinação de múltiplos fatores, tais como: mutações dos genes de resistência que aumentam seu espectro de atividade; troca de informações genéticas nas quais os genes de resistência são transferidos para novos microrganismos; pressão seletiva exercida pelas condições do meio, as quais favorecem a proliferação de clones de pátogenos multiresistentes em todo o mundo (BUSH; JACOBY; MEDEIROS, 1995).

Historicamente, desde a introdução do primeiro antimicrobiano, a resistência bacteriana a estes agentes vêm sendo descrita, sendo observada uma ampla variedade de mecanismos de resistência em agentes bacterianos de origem comunitária ou nosocomial (WICK e PRESTON, 1972; EYKYN et al., 1973; KAISER; GORMAN; WEBBER, 1978; SANDERS e SANDERS Jr, 1979; POWERS, 2004) (Figura 4).

Os patógenos produtores de ESBL são a maior causa de falha terapêutica nos centros de saúde, pois a pressão seletiva ocasionada pelo uso de antimcrobianos, especialmente as cefalosporinas, contribui para o aparecimento e disseminação de microrganismos resistentes (RICE et al., 1990; COUNDRON; MOLAND; SANDERS, 1997)

A resistência aos antimicrobianos por bacilos Gram-negativo é um grande obstáculo na conduta terapêutica contra infecções por estes microrganismos em pacientes hospitalizados (COSGROVE et al., 2002; D'AGATA, 2004; TUMBARELLO et al., 2006), devido a produção de ESBL por estas bactérias (MONNET et al. 1997). Escherichia coli, Klebsiella pneumoniae, Pseudomonas aeruginosa e Enterobacter spp. são os patógenos Gram-negativos que estão mais associados às infecções hospitalares (SADER et al., 1998; SADER et al., 2001; FLUIT; VERHOEF; 
SCHMITZ, 2001).

O conhecimento da epidemiologia da colonização ou infecção por E. coli produtoras de $\beta$-lactamases de espectro estendido nas infecções hospitalares é fundamental para que se desenvolvam medidas que previnam a disseminação destas ESBL nos hospitais brasileiros. Por outro lado, o reconhecimento destes clones auxilia na identificação dos fatores de risco para sua aquisição e disseminação em áreas hospitalares (MENDES et al., 2000; GALES et al., 2001; KIFFER et al., 2005).

$\mathrm{Na}$ América Latina, as beta-lactamases de espectro estendido (ESBL) estão sendo amplamente disseminadas em isolados clínicos de Escherichia coli, e a sua produção é a maior causa de resistência a esta classe de antimicrobianos (STURENBURG e MACK, 2003).

As $\beta$-lactamases são enzimas que catalisam a hidrólise do anel betalactâmico, inativando o antimicrobiano e impedindo que ele apresente atividade contra as proteínas responsáveis pela síntese da parede celular bacteriana (BUSH, 1988; LIVERMORE, 1995; ROSSOLINI, 2005),

Os antibióticos $\beta$-lactâmicos, in vitro, são agentes bactericidas que se caracterizam por possuírem um anel $\beta$-lactâmico ligado a um anel de tiazolidina, e ainda uma cadeia lateral variável. As diferenças estruturais levaram ao agrupamento dos $\beta$-lactâmicos em penicilinas, cefalosporinas, carbapenens e monobactâmicos (BABIC; HUJER; BONOMO, 2006). Os $\beta$-lactâmicos são amplamente usados para combater infecções dos isolados da família Enterobacteriaceae e representam a classe de antimicrobianos mais utilizados clinicamente (MURRAY et al., 2004). 


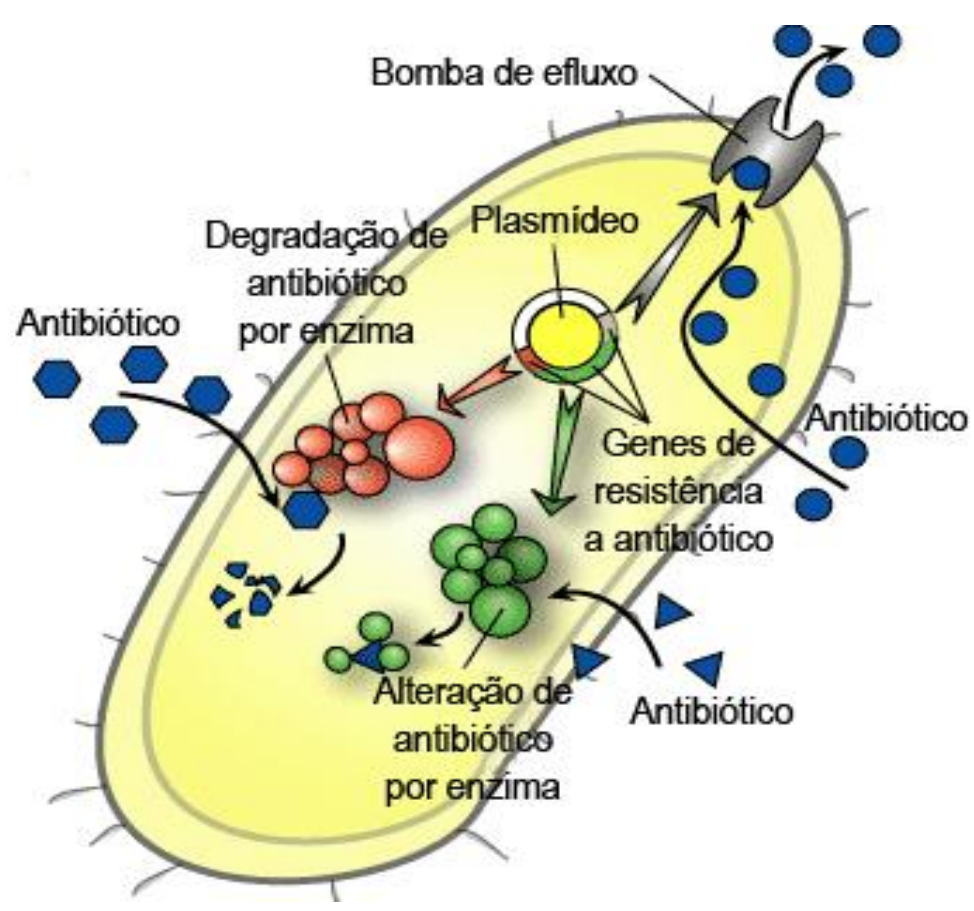

Figura 4. Mecanismos de resistência do antibiótico.

Fonte: Todar (2009).

Existem duas classificações igualmente aceitas para as $\beta$-lactamases: a de Ambler, que as agrupa em quatro classes de $A$ e $D$, de acordo com a sua estrutura primária e seqüências de aminoácidos, podendo ainda ser classificadas dentro de dois grupos serina- $\beta$-lactamases - classes $A, C, D$ e metalo- $\beta$-lactamases - classe $B$ (AMBLER, 1980; BUSH; JACOBY; MEDEIROS, 1995; ROSSOLINI, 2005), e a de Bush-Jacoby-Medeiros, que as divide em grupos de 1 a 4 , segundo as suas semelhanças estruturais, propriedades bioquímicas e seqüências de aminoácidos (BRADFORD, 2001).

$A$ classe $A$ de Ambler corresponde às penicilinases, a $B$ às metalo- $\beta$ lactamases, a $C$ às cefalosporinases e a $D$ às oxacilinases. $O$ grupo 1 de BushJacoby-Medeiros consiste nas cefalosporinases, que hidrolisam cefalosporinas de largo espectro e são resistentes ao ácido clavulânico. $O$ grupo 2 inclui as $\beta$ lactamases susceptíveis ao ácido clavulânico. $O$ grupo 3 consiste nas metalo- $\beta$ lactamases, que hidrolisam 0 antibiótico imipenem (um carbapenem), que são inibidas por ácido etilenodiamino tetraacético (EDTA) e resistentes ao ácido clavulânico. O grupo 4 inclui as restantes $\beta$-lactamases (MULVEY et al., 2004; BABIC; HUJER; BONOMO, 2006).

As enzimas $\beta$-Lactamases de espectro estendido (ESBL) hidrolisam 
oximinocefalosporinas (ceftazidima e cefotaxima, por exemplo) e são inibidas pelo ácido clavulânico. Por este motivo, pertencem à classe $A$ de Ambler e ao grupo 2 be de Bush-Jacoby-Medeiros (BRADFORD, 2001; MULVEY et al., 2005).

A designação 2 be indica que estas enzimas são derivadas das $\beta$ lactamamses do grupo 2b (TEM-1, TEM-2 e SHV-1); o "e" de 2be indica que estas enzimas têm um espectro estendido (BUSH; JACOBY; MEDEIROS, 1995).

TEM-1 é a $\beta$-lactamase mediada por plasmídeo mais comum dos bacilos Gam-negativos entéricos resistentes à ampicilina (por exemplo, Escherichia coli), enquanto SHV-1 é freqüentemente produzida por Klebsiella pneumoniae (LIVERMORE, 1995). As ESBL derivadas das $\beta$-lactamases TEM-1, TEM-2 e SHV-1 diferem de suas progenitoras por no mínimo um aminoácido. Isto resulta em uma profunda mudança na atividade enzimática, tanto que elas passam a hidrolisar as cefalosporinas de terceira geração e o aztreonam (PHILIPPON; ARLET; LAGRANGE, 1994; PATERSON e BONOMO, 2005).

Ainda na classificação de Bush, em comum com as ESBL existem outros grupos de $\beta$-lactamases ( $2 d, 2$ e e $2 f$ ) que hidrolisam cefalosporinas e são inibidas pelo ácido clavulânico. O grupo $2 e$ não apresenta boa atividade hidrolítica a penicilinas e o grupo $2 f$ é fracamente inibido pelo ácido clavulânico. Entretanto, foi observado uma extensão do espectro das $\beta$-lactamases do grupo 2d (tipo OXA) conferindo resistência às cefalosporinas de espectro estendido e muitos autores se referem a algumas enzimas como ESBL (MEDEIROS, 1997).

Na presença de ESBL, os inibidores de $\beta$-lactamases têm efeito sinergístico com as cefalosporinas (GIAMARELLOU, 2005). E, ainda podem ser inibidas in vitro e in vivo utilizando-se os inibidores beta-lactâmicos, como, por exemplo, sulbactam, tazobactam, e o ácido clavulânico, todavia, nem toda beta-lactamase é inibida de forma igual por estes inibidores (GALES et al., 2003; LINCOPAN et al., 2005; SADER et al., 2005; LINCOPAN et al., 2006). A tabela 1 mostra os diferentes $\beta$ lactâmicos e os mecanismos de resitência.

Os efeitos das enzimas variam conforme os seguintes fatores: a distribuição nas diferentes espécies bacterianas, a prevalência da produção de $\beta$-lactamase dentro de cada espécie, e a prevalência em espécies patogênicas. Considerando estes três fatores, as enzimas da classe A são consideradas as mais importantes por seus efeitos na prática clínica (NICOLAS-CHANOINE, 1996), e por apresentarem 
uma resistência muito heterogênea, ocorrendo $20 \%$ a $90 \%$ de similaridade entre as suas seqüências de aminoácidos (BONNET, 2004).

Os genes que codificam as $\beta$-lactamases podem estar contidos no cromossomo bacteriano ou em plasmídeos, sendo que o número de plasmídeos é variável: podem ser apenas um (01), dois (02) ou mais de 100 para cada célula bacteriana (MADIGAN; MARTINKO; PARKER, 2003). Nas bactérias Gramnegativas, o plasmídeo $\mathbf{R}$ ( $\mathbf{R}=$ resistência), possui genes que promovem resistência aos antimicrobianos (SOUSA, 2005). 
Tabela 1- Antibióticos e mecanismos comuns de resistência.

\begin{tabular}{|c|c|}
\hline Antibióticos & Mecanismos de resistência \\
\hline$\beta$-Lactâmicos & $\beta$-Lactamases (ESBL,carbapenemases) \\
\hline Penicilinas (ampicilina, amoxicilina) & - Mutações na PBP \\
\hline $\begin{array}{l}\text { Cefalosporinas } \quad \text { (cefotaxima, } \\
\text { ceftazidima) }\end{array}$ & - Diminuição da permeabilidade da membrana \\
\hline Monobactâmicos (aztreonam) & - Expulsão ativa do antibiótico (bomba de efluxo) \\
\hline Carbapenêmicos (imipenem) & \\
\hline $\begin{array}{l}\text { Glicopeptídios } \quad \text { (vancomicina, } \\
\text { teicoplanina) }\end{array}$ & - Alteração do alvo do antibiótico (genes van) \\
\hline Tetraciclina & $\begin{array}{l}\text { - Expulsão ativa do antibiótico } \\
\text { - Proteção do alvo (ribossomos) } \\
\text { - Inibicão enzimática }\end{array}$ \\
\hline Cloranfenicol & - Inibição enzimática \\
\hline $\begin{array}{l}\text { Aminoglicosídeos (estreptomicina, } \\
\text { gentamicina, canamicina) }\end{array}$ & - Modificação enzimática (transferases) \\
\hline Macrolídeos (eritromicina) & - Modificação do alvo (metilação dos ribossomas) \\
\hline e Lincosamidas & $\begin{array}{l}\text { - Expulsão ativa do antibiótico } \\
\text { - Inibição enzimática }\end{array}$ \\
\hline Sulfametoxazol e Trimetoprim & $\begin{array}{l}\text { - Modificação do alvo [mutação em DHFR e } \\
\text { DHPS (Sul1, Sul2)] }\end{array}$ \\
\hline Quinolonas & $\begin{array}{l}\text { - Modificação do alvo (mutações na DNA girase } \\
\text { e na topoisomerase IV), inibição alósterica do } \\
\text { alvo (codificada pelo gene qnr), acetilação } \\
\text { (codificada pelo gene } \operatorname{aac}\left(6^{\prime}\right)-(b-c r) \text {, bomba de } \\
\text { efluxo }\end{array}$ \\
\hline Rifampicinas & $\begin{array}{l}\text { - Modificacao do alvo (mutação na RNA } \\
\text { polimerase) }\end{array}$ \\
\hline Quinupristina-dalfopristina & - Modificação enzimática \\
\hline Linezolida & Mutação no domínio V do RNAr 23S \\
\hline
\end{tabular}

As ESBL codificadas por genes plasmidiais, estão localizadas dentro de elementos móveis, particularmente transposons e integrons (LAUTENBACH et al., 
2001a), uma vez que as mutações nos genes de resistência aumentam o espectro da atividade enzimática (PHILIPPON; LABIA; JACOBY, 1989). A mobilidade genética pode ser ampliada por meio de transposons, os quais transportam os genes desde os plasmídeos até os cromossomos. Esta mobilidade é importante, pois permite que os genes das $\beta$-lactamases, que conferem resistência, se disseminem através de diversas comunidades bacterianas (WILLIAMS, 1999; BOU et al., 2002).

As $\beta$-lactamases de espectro estendido foram observadas inicialmente em bacilos Gram-negativos isolados em pacientes da Europa e foram em seguida, encontradas nos Estados Unidos (QUINN et al., 1989). As primeiras $\beta$-lactamases de espectro estendido foram descritas em 1983, a partir de isolados clínicos de Klebsiella pneumoniae e Serratia marcenses (KNOTHE et al., 1983). Nesse mesmo ano, foram detectados os primeiros isolados clínicos de Klebsiella pneumoniae e Escherichia coli resistentes às cefalosporinas de terceira geração na Alemanha (Frankfurt) (SOUSA JÚNIOR et al., 2004).

Essas enzimas são descritas mundialmente (PHILLIPPON et al., 1994), e essa resistência é comum, principalmente, em Klebsiella pneumoniae e Escherichia coli (LAUTENBACH et al., 2001), sendo observadas em outras Enterobacteriaceae, como: Citrobacter diversus, Citrobacter freundii, Enterobacter cloacae, Enterobacter aerogenes, Proteus mirabilis, Klebsiella oxytoca, Serratia marcescens, Salmonella spp. e em Pseudomonas aeruginosa, (JACOBY, 2000).

As hipóteses para explicar a alta prevalência desse padrão de resistência de amostras de Escherichia coli e Klebsiella sp. produtoras de $\beta$-lactamases mais elevada no Brasil, quando comparada com amostras dos EUA e Europa, deve-se ao fato de que as amostras isoladas no Brasil podem ser resistentes às cefalosporinas de $3^{\mathrm{a}}$ e $4^{\mathrm{a}}$ gerações mediante produção de beta-lactamases da classe A (ESBLs) (penicilínicos - ampicilina, amoxicilina) e/ou por alteração de permeabilidade, pois, esse mecanismo de resistência é mediado por genes plasmidiais (JONES et al., 1994; GALES et al., 1997)

Por outro lado, cepas de E. coli e Klebsiella spp apresentaram uma resistência ao sulfametoxazol/trimetoprim (100\%), e eram isolados clínicos de pacientes hospitalizados com infecções do trato urinário (ALMEIDA et al., 2007).

Estudo envolvendo E. coli isolada de urina, no período de 1992 a 1996, 
verificou que ocorreu um aumento da resistência ao trimetroprim e trimetroprimsulfamethoxazol, ou seja, de 9\% em 1992 para 18\% em 1996 (GUPTA et al., 1999; GUPTA; SCHOLES; STAMM, 1999a).

A freqüência da resistência de isolados clínicos de E. coli produtores de ESBL aos carbapenems nas Américas e na Europa têm aumentado drasticamente, sendo um sério problema de saúde pública, uma vez que, os carbapenems apresentam ampla e potente atividade antimicrobiana contra Gram-negativos, pois têm alta afinidade pelas PBPs (penicillin-binding proteins), as quais são resistentes à grande maioria das $\beta$-lactamases (SADER e JONES, 1993; PFALLER et al., 1998; FLUIT et al., 2000; SADER et al., 2003; GALES et al., 2003; SADER et al., 2004; ROSSOLINI et al., 2005; LINCOPAN et al., 2005; LINCOPAN et al., 2006).

O perfil de resistência a antimicrobianos das amostras nosocomiais de E. coli isoladas de sangue de quatro (04) regiões geográficas: Brasil (SADER et al., 2004), América Latina (SADER et al., 2003), Europa (FLUIT et al., 2000), EUA e Canadá (PFALLER et al., 1998), apresentaram, respectivamente, os seguintes percentuais de sensibilidade usando os antimicrobianos: ceftazidima (96,1\%, 95,6\%, 98,5\% e $98,0 \%$ ); ceftriaxona $(95,6 \%, 94,2 \%, 98,8 \%$ e $98,3 \%$ ); cefotaxima (informação não disponível nas três (03) primeiras regiões e 98,3\% nos EUA e Canadá); cefoxitina (92,8\%, 92,1\%, 96,6\% e 93,0\%); aztreonam (95,6\%, 94,4\%, 98,3\% e $97,6 \%$ ); cefepime (97,2\%, 97,1\%, 99,5\% e 99,3\%); amoxicilina/clavulanato (informação não disponível nas duas (02) primeiras regiões, 80,4\% e 68,8\%); ticarcilina/clavulanato (70,5\%, 65,3 e informação não disponível nas duas (02) últimas regiões); imipenem (99,8\%, 100,0\%, 99,9\% e 99,5\%); ciprofloxacina (85,8\%, 85,4\%, 91,9\% e 97,2\%); piperacilina/tazobactam $(95,0 \%, 91,4 \%, 96,0 \%$ e $95,5 \%)$ e gentamicina $(89,3 \%$, $90,5 \%, 95,0 \%$ e $96,0 \%)$.

Os dados epidemiológicos brasileiros mostram que a freqüência de cepas produtoras de ESBL pode variar significativamente de região para região ou mesmo de hospital para hospital, dentro de uma mesma região geográfica, sendo que o Brasil vem apresentando índices altos destas cepas em relação a outros países (SADER et al., 2001), onde a disseminação de patógenos nosocomiais produtores de $\beta$-lactamases está sendo relatada com uma freqüência cada vez maior (GALES et al., 2003; LINCOPAN et al., 2005; SADER et al., 2005; LINCOPAN et al., 2006). Em hospitais brasileiros, estudos multicêntricos têm reportado que para $K$. 
pneumoniae existe uma alta freqüência de produção de ESBL $(48,4 \%)$, enquanto que para $E$. coli esta prevalência tem sido mais baixa (8,9\%) (SADER et al., 2001). Infelizmente, a produção de ESBL não está restrita aos hospitais, pois foi encontrada em $1,48 \%$ entre as enterobactérias isoladas de pacientes ambulatoriais (MINARINI et al., 2007).

Além disso, outros estudos reportam que dentre os países da América Latina, a resistência no Brasil parece estar mais acentuada, conforme sugerido por Andrade et al. (2003). Estes autores estudaram amostras isoladas no período de 1997 a 2001, e observaram que $90 \%$ das amostras com resistência simultânea a várias classes de antimicrobianos eram procedentes do Brasil. Este perfil de multiresistência aumentou, em média, em 5,4\% ao ano, neste período (ANDRADE et al., 2003).

O surgimento dessas enzimas é conseqüência a introdução das cefalosporinas de terceira geração no início dos anos 80, demonstrando a capacidade de adaptação por parte desses patógenos (PATERSON e BONOMO, 2005), como ocorreu com as ESBL do tipo CTX-M (BOU et al., 2002), sendo que mutações nos genes de resistência aumentaram o espectro da atividade enzimática (PHILIPPON; LABIA; JACOBY, 1989), como ocorre nas amostras de ExPEC, onde a alta incidência da resistência antimicrobiana muitas vezes são disseminadas por plasmídeos (RON, 2006).

$A$ evolução da resistência associadas às $E S B L$ foi demonstrada por diversos estudos conduzidos no país, identificando entre os isolados clínicos brasileiros cepas produtoras de uma grande diversidade de ESBL, entre elas, as do tipo CTX-M, TEM, SHV e GES (CORKILL et al., 2001; MENDES et al., 2004a; MENDES et al., 2004b; MARTINS et al., 2006; LINCOPAN et al., 2005; LINCOPAN et al., 2006; MINARINI et al., 2007; MINARINI et al., 2008; GARCIA et al., 2007; DROPA et al., 2009; PICÃO; POIREL; NORDMANN, 2009; DROPA et al., 2010; CERGOLE-NOVELLA et al., 2010; TOLLENTINO et al., 2010;).

Contudo, a produção de $\beta$-lactamases é a causa predominante de resistência aos antimicrobianos por bactérias Gram-negativas, limitando as opções terapêuticas (BONNET, 2004; BRADFORD, 2001). As cefalosporinas de $3^{\mathrm{a}}$ geração (cefotaxima, ceftazidima e ceftriaxona) foram especificamente desenvolvidos para serem resistentes à ação hidrolítica das $\beta$-lactamases, porém a cada novo $\beta$-lactâmico 
empregado na conduta terapêutica, novas $\beta$-lactamases foram produzidas pelos microrganismos, causando assim uma resistência a esses novos agentes antimicrobianos. Assim, a pressão seletiva do uso excessivo de novos antimicrobianos no tratamento de pacientes tem selecionado novas variantes de $\beta$ lactamases (BRADFORD, 2001).

\subsubsection{A epidemiologia molecular de variantes de $\beta$-lactamases de espectro estendido (ESBL) do tipo CTX-M, TEM, SHV, OXA produzidas por patógenos de interesse hospitalar}

Seeberg et al. (1983) relataram que as $\beta$-lactamases respondem pela resistência bacteriana devido a sua grande atividade intrínseca frente aos diferentes antimicrobianos, podendo mostrar uma significante discrepância in vitro e in vivo entre os testes de susceptibilidade aos antimicrobianos (SANDERS e SANDERS Jr, 1979; KNOTHE et al.,1983).

As ESBL geralmente são derivadas de pontos de mutações comuns entre as $\beta$-lactamases TEM, que foi relatada pela primeira vez em 1965, em uma amostra de Escherichia coli de um paciente grego Temoniera (BRADFORD, 2001) e em SHV-1, comumente encontrada em Klebsiella pneumoniae, responsável por mais de $20 \%$ de resistência à ampicilina mediada por plasmídeo nesta espécie (TZOUVELEKIS ET al., 1999). Em muitas amostras de K. pneumoniae, bla $\mathrm{SHV}_{\mathrm{H}-1}$ ou outro gene encontrase integrado ao cromossomo bacteriano (LIVERMORE, 1995). Outros membros dessas enzimas foram descritos em todo o mundo com este fenótipo de resistência (PHILLIPON, 1989; PEIRANO e PITOUT, 2010).

Bauernfeind, Grimm e Schweighart (1990) encontraram um novo plasmídeo codificando uma enzima para cefotaxima, presente em E. coli e denominada CTX-M, pois se relacionava às famílias TEM e SHV de $\beta$-lactamase de espectro estendido, descritas, respectivamente, por Medeiros (1984) e Kliebe et al. 1985. Estas também foram encontradas em amostras de Salmonella enterica serovar Typhimurium e Escherichia coli (BRADFORD et al., 1997; BONNET et al., 2000). Esta enzima foi descrita em outras espécies da família Enterobacteriaceae, mas a sua grande 
prevalência têm se confirmado em amostras de Escherichia coli (PAGANI, 2003; BONNET, 2004; PATERSON e BONOMO, 2005; MUGNAIOLI et al., 2006; LIVERMORE, 2007; PITOUT et al., 2007).

As cefotaximases CTX-M emergiram como as ESBL mais prevalentes na Europa e na América do Sul (CANTÓN e COQUE, 2006; MUGNAIOLI et al., 2006; PEREZ et al., 2007). Verificou-se que ESBL específica parece predominar em determinada região, assim, TEM-10 foi responsável por infecções nos Estados Unidos por diversos anos (RICE et al., 1990; NAUMOVSKI et al., 1992; BRADFORD et al., 1994; URBAN et al., 1994; BRADFORD, 2001) e foi descrita na Europa por Liu et al. (1992).

No Brasil, a ocorrência de CTX-M foi relatada pela primeira vez em 2000, tendo sido descrita uma nova CTX-M, a CTX-M-8, produzida por isolados clínicos de Enterobacter cloacae, Enterobacter aerogenes e Citrobacter amalonaticus. Em 2001, foi descrita outra enzima isolada de Escherichia coli, variante da CTX-M-9 e denominada CTX-M-16, ambas detectadas no Rio de Janeiro (BONNET et al., 2000; BONNET et al., 2000).

As CTX-M não apresentam relação próxima com as ESBL TEM ou SHV (BRADFORD, 2001), e seu potencial hidrolítico sobre as cefalosporinas de amplo espectro constitui uma característica intrínseca desta família, e não resultante de mutações em enzimas precursoras (BUSH et al., 1993; BONNET, 2004; BABIC; HUJER; BONOMO, 2006).

Estas enzimas hidrolisam preferencialmente cefotaxima, e de forma geral apresentam baixa capacidade de hidrólise da ceftazidima. Entretanto, alguns organismos produtores de variantes de CTX-M com alta capacidade hidrolítica sobre a ceftazidima já foram descritos (BONNET et al., 2000; POIREL et al., 2001; PITOUT e LAUPLAND, 2008).

As CTX-M atualmente disseminadas entre diversas espécies bacterianas apresentam uma identidade de aminoácidos com as $\beta$-lactamases cromossômicas encontradas no gênero Kluyvera (BONNET, 2004). Acredita-se que estas enzimas originaram-se da aquisição de um plasmídeo com um gene cromossomal préexistente em Kluyvera spp. (BONNET, 2004), e que as enzimas dos grupos CTX-M1 e CTX-M-2 são provavelmente originadas de Kluyvera ascorbata, que produz uma enzima cromossomal AmpC (ampicilinase de classe C), designada Klu-1 e Klu-2 
(HUMENIUK et al., 2002), enquanto os grupos CTX-M-8 e CTX-M-9 foram originadas de Kluyvera georgiana (OLSON et al., 2005).

Estudos preliminares apontaram que a $\beta$-lactamase cromossômica CTX-M-25 (de origem desconhecida) apresentava grande semelhança com a enzima KluG-1, originária da espécie Kluyvera georgiana, sugerindo que foi originada de alguma variante de KluG-1 ou de outra $\beta$-lactamase produzida intrinsecamente por Kluyvera sp. (OLSON et al., 2005). Assim como, Kluyvera cryocrescens produz uma enzima, denominada KluC-1 (DECOUSSER; POIREL; NORDMANN, 2001), que possui identidade com as enzimas do grupo CTX-M-1 (OLIVER et al., 2001; RODRIGUEZ et al., 2004; OLSON et al., 2005).

Já foram descritas mais de 100 enzimas do tipo CTX-M (http://www.lahey.org/studies/), classificadas de acordo com a seqüência de aminoácidos, em cinco grupos distintos: CTX-M-1; CTX-M-2; CTX-M-8; CTX-M-9 e CTX-M-25.

O grupo CTX-M-1, inclui as seguintes enzimas: CTX-M-1, CTX-M-3, CTX-M10, CTX-M-11, СTX-M-12, СTX-M-15, СTX-M-22, СТX-M-23, СTX-M-28, СТХ-М-29, CTX-M-30, СTX-M-32, CTX-M-33, СTX-M-36, СTX-M-54, СTX-M-55, СTX-M-57 е UOE-1.

O grupo CTX-M-2, possui as enzimas: CTX-M-2, CTX-M-4, CTX-M-7, CTX-M20, CTX-M-31, e CTX-M-44; o grupo CTX-M-8, apresenta as enzimas: CTX-M-8, CTX-M-40 e CTX-M-63; o grupo CTX-M-9, contém as enzimas: CTX-M-9, CTX-M13, CTX-M-14, CTX-M-16 a CTX-M-19, CTX-M-21, СTX-M-27 e CTX-M-45 a СTXM-50; e o grupo CTX-M-25, as enzimas: CTX-M-25, CTX-M-26, CTX-M-39 e CTX-M41 (BONNET, 2004; CANTÓN e COQUE, 2006).

A similaridade das enzimas em um mesmo grupo de CTX-M é superior a $94 \%$, e entre enzimas de grupos diferentes é inferior a 90\% (BONNET, 2004), porém com a CTX-M-45, pertencente ao grupo CTX-M-9, foi observada uma similaridade entre $86,3 \%$ a $88 \%$ com as demais enzimas pertencentes ao grupo, mas o gene blacTX-M-

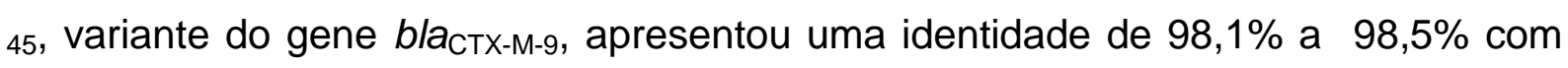
os genes que codificam as enzimas do grupo CTX-M-9 (WALTHER-RASMUSSEN e HOIBY, 2004; BONNET, 2004).

Algumas enzimas são encontradas, em $E$. coli, de maneira específica, em determinados países, como as CTX-M-9 e CTX-M-14 na Espanha, Canadá e China, 
CTX-M-1 na Itália, CTX-M-2 na América do Sul, Japão e Israel, CTX-M-3 na Polônia. No entanto, a $\beta$-lactamase CTX-M-15 é disseminada mundialmente (LIVERMORE e HAWKEY, 2005; CANTÓN e COQUE, 2006; LIVERMORE et al., 2007; PITOUT e LAUPLAND, 2008; CERGOLE-NOVELLA et al., 2010), e freqüentemente associada com outras $\beta$-lactamases: TEM-1 e OXA-1 (PITOUT, 2009; PEIRANO e PITOUT, 2010).

As cepas bacterianas que produzem as enzimas da classe A: TEM-1, SHV-1, ROB-1 ou PC-1 são resistentes à amoxicilina e à ticarcilina e apresentam susceptibilidade reduzida a piperacilina (JACOBY e SUTTON, 1985; LIVERMORE e YANG, 1987). Entre as enzimas da classe A mediadas por plasmídeos, as penicilinases destacam-se porque ocorrem numa grande variedade de patógenos, incluindo Staphylococcus sp., Enterococcus sp., Moraxella catarrhalis, Neisseria sp., Haemophilus sp., Bacteroides sp., Pseudomonas sp., Acinetobacter sp., e membros da família Enterobacteriaceae (NICOLAS-CHANOINE, 1996).

A $\beta$-lactamase TEM-1 foi considerada uma enzima altamente totalmente eficiente (BUSH; JACOBY; MEDEIROS, 1995) por hidrolisar a penicilina e seus derivados, tais como: ampicilina, carbenicilina e piperacilina. É bastante ativa contra cefalotina e cefuroxima, porém apresenta atividade insignificante contra cefotaxima, ceftazidima, ceftriaxona ou aztreonam, e não possui nenhuma ação contra as cefamicinas (cefoxitina ou cefotetan). O grupo OXA contém uma série menos comum de $\beta$-lactamases codificados por plasmídeos, caracterizadas por hidrolisar oxacilina, floxacilina e meticilina, mas que não apresentam qualquer atividade contra os substratos oximino: TEM-1, TEM-2 e SHV-1. As enzimas do grupo OXA, são rapidamente inibidas pelo ácido clavulânico, sulbactam e tazobactam. Já foram descritas 183 ESBL da família TEM-1, 137 ESBL da família SHV e 161 ESBL da família das OXA (http://www.lahey.org/studies/).

O monitoramento da ocorrência de cepas produtoras de ESBL em enterobactérias de interesse clínico contribui para delinear a amplitude do problema e para definir opções de tratamento e medidas de corretivas adequadas (LUZZARO et al., 2006).

O rápido surgimento e a disseminação da resistência desses microrganismos a várias drogas levam à necessidade do controle imediato destes patógenos em ambientes hospitalares no mundo inteiro, pois estas cepas também estão 
associadas às infecções na comunidade. Representando, assim, um sério problema de saúde pública e um grande desafio terapêutico em função da múltipla resistência as drogas antimicrobianas disponíveis (BISSON et al., 2002). A Sociedade Americana de Infectologia alertou que novas terapias são urgentemente necessárias (TALBOT et al., 2006).

E. coli produzindo $\beta$-lactamases de espectro estendido (ESBL) do tipo CTX$M$, especialmente CTX-M-15, foi isolada tanto de amostras de pacientes hospitalizados como de indivíduos da comunidade (CERGOLE-NOVELLA et al., 2010). Um clone, denominado ST131, do subtipo molecular O25b, produzindo essa $\beta$-lactamase, isolado de infecções do trato urinário, do grupo filogenético B2 e com alto potencial de virulência foi encontrado no mundo todo, inclusive no Brasil, representando um grande problema de saúde pública (CLERMONT et al., 2008; KARISIK et al., 2008; NICOLAS-CHANOINE et al., 2008; LAU; KAUFMANN; LIVERMORE, 2008; CLERMONT et al., 2009; MORA et al., 2010; PEIRANO e PITOUT, 2010). 


\section{OBJETIVOS}

\subsection{GERAL}

A proposta deste estudo foi caracterizar a produção de beta-lactamases de espectro estendido (ESBL), os grupos filogenéticos, os genótipos de virulência, e a relação clonal em isolados clínicos de Escherichia coli de amostras de pacientes de diferentes faixas etárias, internados no período de janeiro de 2005 a julho de 2007, em um Hospital Universitário (USP) de São Paulo, SP, Brasil.

\subsection{ESPECÍFICOS}

1. Investigar a ocorrência de isolados de $E$. coli produtores de beta-lactamases de espectro estendido associados às infecções extra-intestinais, com ênfase à infecção do trato urinário.

2. Avaliar o perfil fenotípico e genotípico de resistência aos antibióticos de uso clínico, nos isolados de Escherichia coli produtores de ESBL.

3. Caracterizar os genótipos de virulência e grupos filogenéticos dos isolados clínicos de Escherichia coli produtores de ESBL.

4. Identificar a presença do sorogrupo O25 (internacional) entre os isolados clínicos de Escherichia coli produtores de ESBL

5. Estudar a relação clonal entre os isolados clínicos de Escherichia coli produtores de ESBL por PFGE.

6. Estabelecer a relação epidemiológica entre o tipo de infecção, genótipo ESBL, grupo filogenético, perfil de susceptibilidade, e similaridade genética entre os isolados clínicos de Escherichia coli produtores de ESBL. 


\section{MATERIAL E MÉTODOS}

\subsection{AMOSTRAS CLÍNICAS E CEPAS BACTERIANAS}

No período de janeiro de 2005 a julho de 2007 foram isoladas 562 Escherichia coli, de diferentes origens, de pacientes da unidade de terapia intensiva (UTI) e semi-intensiva (SEMI), unidade de terapia intensiva pediátrica (UTIP), centro cirúrgico (CC), pronto socorro (PS), clínica médica (CM), berçário (BER) e ambulatório $(\mathrm{AMB})$ de um Hospital Universitário de São Paulo - SP, pelo laboratório de microbiologia clínica deste hospital, e gentilmente cedidas pela Profa. Dra. Marina Baquerizo Martinez, da Faculdade de Ciências Farmacêuticas, da Universidade de São Paulo (USP), para este estudo.

Como cepa controle, para os estudos fenotípicos utilizou-se Escherichia coli ATCC 25922 (American Type Culture Collection). Escherichia coli DRC5.4 e Escherichia coli DRC5.5, pertencentes ao Laboratório de Ornitopatologia, do Departamento de Patologia, da Faculdade de Medicina Veterinária e Zootecnia (FMVZ)-(USP), foram usadas para a correlação do perfil de virulência com os isolados clínicos de ESBL de Escherichia coli de pacientes hospitalizados.

A identificação dos 562 isolados clínicos $(n=562)$ de Escherichia coli $(n=562)$ foi realizada usando a metodologia convencional bioquímica, ou um sistema automatizado VITEK (BioMérieux Vitek Inc., Hazelwood, Mo., EUA), pelo laboratório clínico do hospital universitário.

\subsection{PACIENTES}

Considerando os resultados obtidos no teste de susceptibilidade aos antimicrobianos, foram selecionados 34 isolados clínicos de E. coli (obtidos de 28 pacientes) para a detecção de $\beta$-lactamases de espectro estendido (ESBL). Desses pacientes, doze estavam internados na UTI, SEMI ou UTIP, três (03) pacientes eram 
do centro cirúrgico, um (01) paciente era do berçário, oito (08) do pronto socorro, dois (02) do ambulatório e um (01) da clínica médica, sendo que uma (01) paciente foi primeiramente atendida no ambulatório no dia 15.02.2007 e hospitalizada no dia 28.02.2007.

A tabela 2 apresenta as características destes isolados clínicos. A figura 8 mostra o perfil dos pacientes hospitalizados de ambos os sexos, de diferentes faixas etárias, em diversas clínicas, dos quais se originaram os 34 isolados clínicos de Escherichia coli produtoras de ESBL. A correlação entre as diferentes faixas etárias de ambos os sexos estão ilustrados no gráfico 1.

A análise das fichas dos pacientes hospitalizados, permitida pelo laboratório de microbiologia clínica, revelou que dentre os 34 isolados clínicos estudados, alguns eram provinientes do mesmo paciente. Dessa forma, foram estudadas $E$. coli isoladas de 28 pacientes, sendo que em cinco pacientes foram coletadas duas (02) ou três (03) amostras. As amostras 770/5 (urina), 753/5 (urina) e 756/5 (prega inguinal) foram isoladas do paciente 1. As amostras 713/5 (secreção traqueal) e 712/5 (LBA) do paciente 2. As amostras 601/5 (sangue) e 602/5 (urina) do paciente 3. As amostras 03/07 e 14/07 foram isoladas do paciente 4, ambas de urina. As amostras $321 / 5$ e 323/5 foram isoladas do paciente 5 e também eram de urina. $A$ tabela 3 mostra a idade destes pacientes, a identificação da amostra, a unidade de internação e sua origem. Dentre os 28 pacientes, 64\% (18/28) eram de indivíduos hospitalizados e dez (10) eram de unidades ambulatoriais, sendo $28 \%(8 / 28)$ do pronto socorro (PS) e 7\% (2/28) do ambulatório (AMB).

Com relação aos pacientes hospitalizados $(n=18), 28 \%(8 / 28)$ eram da UTI, $3,5 \%$ (01/28) da SEMI, $11 \%$ (03/28) da UTIP, $11 \%$ (03/28) do centro cirúrgico (CC), 3,5\% (01/28) do berçário (BER), 3,5\% (01/28) da clínica médica (CM) e 3,5\% (01/28) de uma paciente atendida no pronto socorro (PS), mas que foi internada no dia 28/03/2007. 
Tabela 2- Características dos isolados clínicos de beta-lactamases de espectro estendido de Escherichia coli utilizadas neste estudo.

\begin{tabular}{|c|c|c|c|c|}
\hline N. & Amostra & Clínica & Origem & Data de coleta \\
\hline 1 & $333 / 6$ & UTI & Abscesso & $12 / 06 / 2006$ \\
\hline 2 & $154 / 6$ & $\mathrm{CC}$ & Secreção coto & 27/03/2006 \\
\hline 3 & $814 / 5$ & AMB & Urina & $27 / 12 / 2005$ \\
\hline 4 & $248 / 6$ & PS & Urina & 04/05/2006 \\
\hline 5 & $681 / 5$ & UTIP & Secreção traqueal & 29/09/2005 \\
\hline 6 & $249 / 6$ & PS & Urina & 07/05/2006 \\
\hline 7 & $770 / 5$ & UTI & Urina & $22 / 11 / 2005$ \\
\hline 8 & $217 / 6$ & $\mathrm{CC}$ & Secreção biliar & $27 / 04 / 2006$ \\
\hline 9 & $740 / 5$ & UTI & Prega axilar & 09/11/2005 \\
\hline 10 & $753 / 5$ & UTI & Urina & $18 / 11 / 2005$ \\
\hline 11 & $720 / 5$ & UTI & Secreção peritoneal & 03/11/2005 \\
\hline 12 & $713 / 5$ & UTI & Secreção traqueal & 28/10/2005 \\
\hline 13 & $601 / 5$ & UTI & Sangue & 08/08/2005 \\
\hline 14 & $658 / 5$ & BER & Prega inguinal & 03/09/2005 \\
\hline 15 & $602 / 5$ & UTI & Urina & 08/08/2005 \\
\hline 16 & $712 / 5$ & UTI & LBA & $27 / 10 / 2005$ \\
\hline 17 & $152 / 6$ & PS & Urina & $31 / 03 / 2006$ \\
\hline 18 & $756 / 5$ & UTI & Prega inguinal & $18 / 11 / 2005$ \\
\hline 19 & $473 / 5$ & UTI & LBA & $16 / 05 / 2005$ \\
\hline 20 & $195 / 5$ & UTI & Lavado cavitário & $12 / 02 / 2005$ \\
\hline 21 & $321 / 5$ & $\mathrm{CC}$ & Urina & 06/03/2005 \\
\hline 22 & $323 / 5$ & $\mathrm{CC}$ & Urina & $10 / 03 / 2005$ \\
\hline 23 & $366 / 5$ & PS & Urina & $28 / 03 / 2005$ \\
\hline 24 & $311 / 6$ & UTIP & Urina & 02/06/2006 \\
\hline 25 & $1 / 7$ & SEMI & Urina & $11 / 03 / 2007$ \\
\hline 26 & $2 / 7$ & PS & Urina & $18 / 02 / 2007$ \\
\hline 27 & $3 / 7$ & PS & Urina & $15 / 02 / 2007$ \\
\hline 28 & $4 / 7$ & PS & Urina & $15 / 02 / 2007$ \\
\hline 29 & $5 / 7$ & PS & Urina & $12 / 04 / 2007$ \\
\hline 30 & $8 / 7$ & $\mathrm{CM}$ & Prega inguinal & $20 / 02 / 2007$ \\
\hline 31 & $10 / 7$ & PS & Urina & $10 / 02 / 2007$ \\
\hline 32 & $11 / 7$ & UTIP & Secreção traqueal & $26 / 05 / 2007$ \\
\hline 33 & $13 / 7$ & AMB & Urina & $15 / 02 / 2007$ \\
\hline 34 & $14 / 7$ & PS & Urina & $28 / 03 / 2007$ \\
\hline
\end{tabular}


Tabela 3- Origem de Escherichia coli isoladas de um mesmo paciente.

\begin{tabular}{|c|c|c|c|c|c|}
\hline Paciente/Unidade & Idade & Sexo & Amostras & Origem & Data de coleta \\
\hline & & & $770 / 5$ & Urina & 22.11 .2005 \\
\hline \multirow[t]{2}{*}{$1 /$ UTI } & 84 & M & $753 / 5$ & Urina & 18.11 .2005 \\
\hline & & & $756 / 5$ & Prega inguinal & 18.11.2005 \\
\hline \multirow{2}{*}{2 / UTI } & 79 & $M$ & $713 / 5$ & Secreção traqueal & 28.10 .2005 \\
\hline & & & $712 / 5$ & LBA & 27.10 .2005 \\
\hline \multirow{2}{*}{3 / UTI } & & & $601 / 5$ & Sangue & 08.08 .2005 \\
\hline & & & $602 / 5$ & Urina & 08.08 .2005 \\
\hline \multirow{2}{*}{$4^{\star} / \mathrm{PS}$} & & & $03 / 7$ & Urina & 15.02 .2007 \\
\hline & vo & 1 & $14 / 7$ & Urina & 28.03.2007 \\
\hline \multirow{2}{*}{$5 / \mathrm{CC}$} & 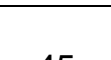 & 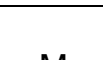 & $321 / 5$ & Urina & 06.03 .2005 \\
\hline & & & $323 / 5$ & Urina & 10.03 .2005 \\
\hline
\end{tabular}

* Paciente atendida pelo ambulatório no dia 15.02.2007 e hospitalizada no dia 28.03.2007.

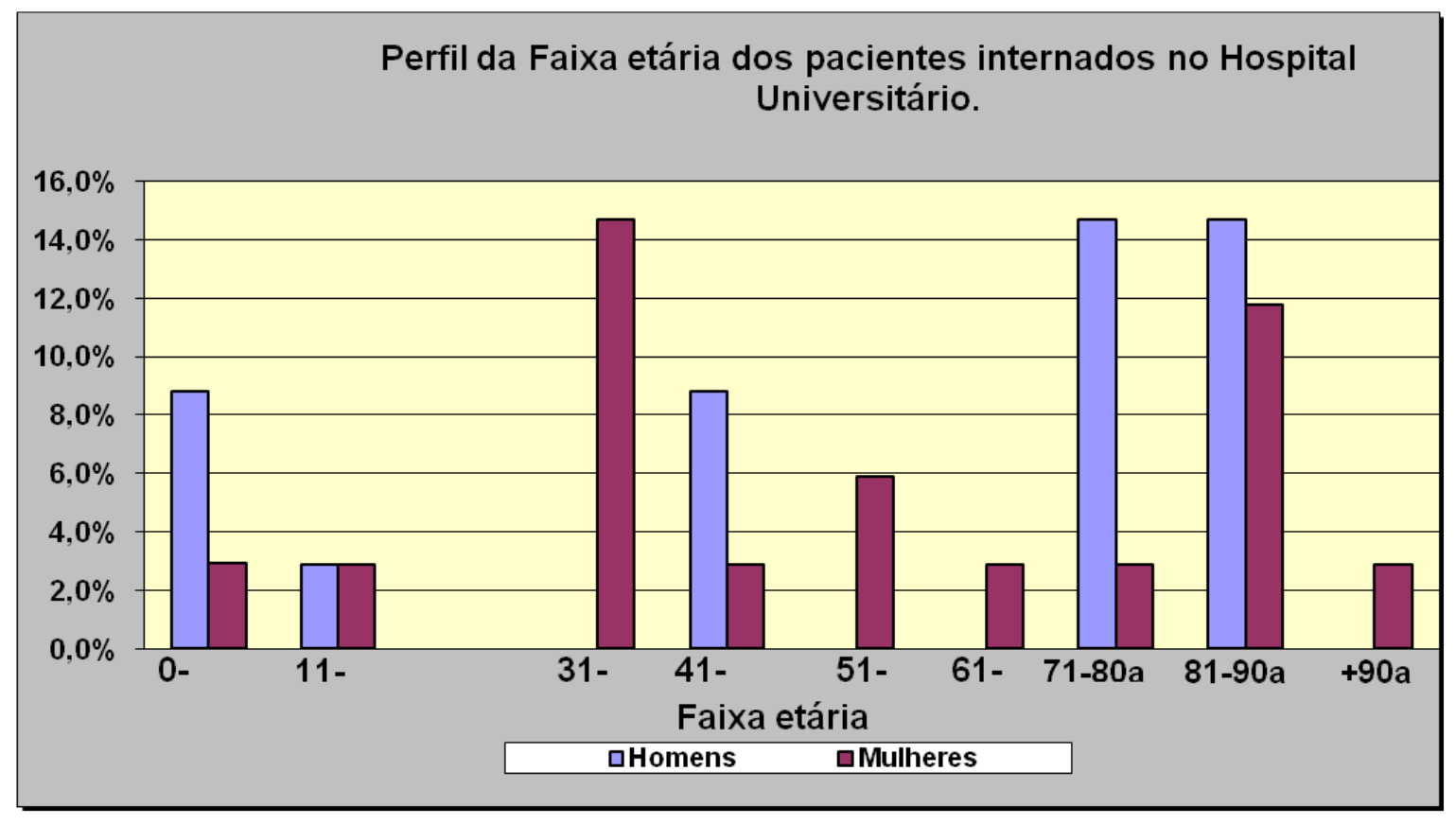

Gráfico 1. Perfil da faixa etária dos pacientes internados no Hospital Universitário considerando-se ambos os sexos. 


\subsection{MÉTODOS FENOTÍPICOS}

\subsubsection{Testes de susceptibilidade aos antimicrobianos pelo método de difusão em ágar}

As amostras de E. coli foram testadas, pelo laboratório de microbiologia clínica, quanto à sensibilidade aos antimicrobianos. O inóculo dos isolados, bem como dos controles, foi preparado fazendo-se uma suspensão direta, em solução salina, de colônias isoladas, selecionadas de uma placa de ágar tríptico de soja (TSA) após cultivo de 18 a 24 horas a $37^{\circ} \mathrm{C}$. A suspensão foi ajustada com auxílio de densitômetro (Densimat, Biomerieux), em comprimento de onda de $625 \mathrm{~nm}$, para uma absorbância de 0,08 a 0,13, assim, esta concentração bacteriana correspondia a turbidez do tubo 0,5 da escala de McFarland (1,5 × $10^{8} \mathrm{UFC} / \mathrm{mL}$ ). Em seguida, se realizou a semeadura do inóculo em meio ágar Mueller-Hinton (Difco, Laboratories, Detroit, Mich. EUA), acrescentou-se os discos com antimicrobianos na superfície do meio de cultura, de acordo com a técnica de Kirby-Bauer (BAUER; KIRBY; SHERRIS, 1966), a placa foi incubada por 24 horas a $37^{\circ} \mathrm{C}$.

Foram testados neste estudo: ampicilina (AMP), ampicilina/sulbactam (SAM), aztreonam (ATM), cefepima (FEP), cefotaxima (CTX), cefoxitina (FOX), ceftazidima (CAZ), cefalotina (KF), gentamicina (GEN), ciprofloxacina (CIP), ceftriaxona (CRO), ácido nalidíxico (NAL), norfloxacina (NOR), sulfametoxazol/trimetoprim (SXT), cefuroxima (CXM), nitrofurantoína (NIT), ticarcillina/clavulanato (TIM), amoxicillina/clavulanato (AMC), amicacina (AK) e o imipenem (IMP) (Probac,Brasil), interpretados conforme as recomendações do CLSI, 2006, como "resistente", "intermediário" ou "sensível.

\subsubsection{Determinação de $\beta$-lactamases de espectro estendido (ESBLs), pelo método da dupla difusão em disco (DDST- double-disk synergy test)}

Os isolados que apresentaram resistência múltipla aos antimicrobianos, foram 
selecionados $(n=34)$ para a determinação de $\beta$-lactamases de espectro estendido (ESBL), através do método idealizado por Jalier et al. (1988), também denominado de double-disk synergy test (DDST).

Utilizou-se, no ágar Mueller-Hinton, cefotaxima (CTX), ceftazidima (CAZ) e aztreonam (ATM) como substratos, e o ácido clavulânico como inibidor. No centro da placa foi colocado o disco com amoxicilina $(30 \mu \mathrm{g}) /$ ácido clavulânico $(1 \mu \mathrm{g})$ (Oxoid,

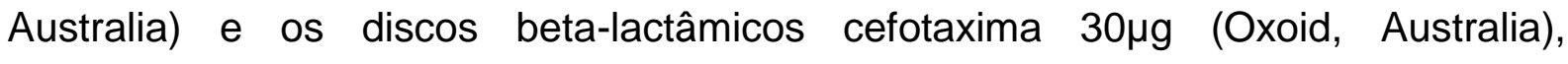

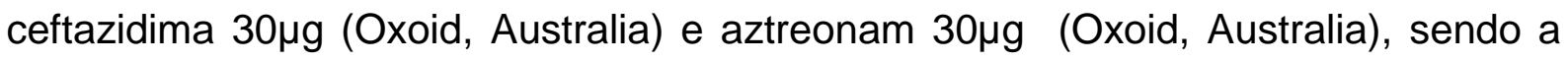
distância entre os discos de 20 a 30 mm (SOUSA JÚNIOR et al., 2004).

$O$ teste foi considerado positivo sempre que se detectaram fenômenos de sinergismo, isto é, quando se observou um aumento no(s) halo(s) de inibição ao redor do(s) disco(s) de cefalosporinas de amplo espectro e/ou aztreonam ou ainda o aparecimento de uma terceira zona de inibição de crescimento designada por "ghost zone" (SOUSA JÚNIOR et al., 2004).

A detecção fenotípica das amostras estudadas permitiu a visualização da inibição do halo de crescimento, conforme normas de padronização do CLSI, 2006.

\subsubsection{Detecção da Concentração Inibitória Mínima (CIM) de E. coli produzindo $\beta$-lactamases de espectro estendido (ESBL)}

A CIM (concentração inibitória mínima) da Cefotaxima foi determinada através da metodologia do E-tes $\AA^{\circledR}$ (AB Biodisk, Probac Brasil).

Foram utilizadas fitas de E-test $\circledast$ ESBL Screen (AB Biodisk, Probac Brasil) para as $\beta$-lactamases de espectro estendido. A fita consistia de cefotaxima $(0,25-$ $16 \mu \mathrm{g} / \mathrm{mL})$ /cefotaxima $(0,016-1 \mu \mathrm{g} / \mathrm{mL})$ associada ao ácido clavulânico $(4 \mu \mathrm{g} / \mathrm{mL})$. A CIM (concentração inibitória minima) foi interpretada no ponto de intersecção entre a zona elíptica de inibição do crescimento e a extremidade da fita do E-test. O teste foi considerado positivo, quando a CIM de cefotaxima foi reduzida $\geq$ três (03) vezes (log2) de diluições na presença do ácido clavulânico (CLSI/2006). 


\subsection{METÓDOS GENOTÍPICOS}

\subsubsection{Determinação dos genótipos de resistência bla ${ }_{E S B L}$ através da reação em cadeia pela polimerase (PCR)}

As amostras de Escherichia coli que apresentaram um fenótipo positivo para ESBL, foram submetidas à extração do DNA pelo método de fervura (CHAPMAN et al., 2001). A amplificação do DNA ocorreu por meio da PCR, usando os iniciadores específicos para os genes bla $a_{\mathrm{ESBL}}$ : bla $a_{\mathrm{CTX}-\mathrm{M}}$, bla $a_{\mathrm{CTX}-\mathrm{M}-1}, b / a_{\mathrm{CTX}-\mathrm{M}-2}$, bla $a_{\mathrm{CTX}-\mathrm{M}-9}, b / a_{\mathrm{CTX}-\mathrm{M}-15}$, bla $a_{T E M-l i k e}, b / a_{S H V-l i k e}, b / a_{P E R-2}$ e bla $a_{G E S-l i k e}$.

Para cada reação da PCR foi usado um mix com os seguintes reagentes: água ultra pura estéril $(14,9 \mu \mathrm{L})$, tampão $10 x$ concentrado $(5,0 \mu \mathrm{L})$; dATP $0,1 \mathrm{mM}$, dCTP $0,1 \mathrm{mM}$, dGTP $0,1 \mathrm{mM}$ e dTTP $0,1 \mathrm{mM}(1,25 \mu \mathrm{L}) ; \mathrm{MgCl}_{2} 2,0 \mathrm{mM}(0,75 \mu \mathrm{L})$,

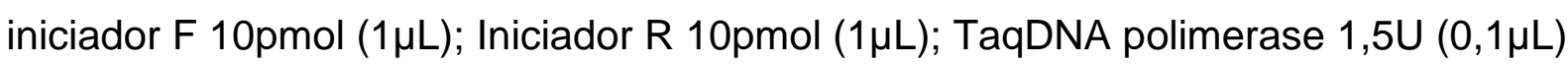
(Invitrogen, Carlsbad, CA), para um volume final de reação de $25 \mu \mathrm{L}$ e $1 \mu \mathrm{L}$ do DNA da amostra. A amplificação foi realizada em termociclador (Perkin Elmer GeneAmp PCR 2400 ou Biometra T3000), sob as seguintes condições: desnaturação inicial a $94{ }^{\circ} \mathrm{C}$ por 5 minutos; 30 ciclos de $94{ }^{\circ} \mathrm{C}$ por 30 segundos, adequando-se a temperatura de hibridização (n) (específica para cada par de iniciadores), conforme a Tabela 3 , e extensão a $72{ }^{\circ} \mathrm{C}$ por 30 segundos, seguidos de uma extensão final a $72{ }^{\circ} \mathrm{C}$ por 5 minutos.

Os produtos da PCR foram submetidos à eletroforese em gel de agarose 1,0 a 1,5\%, em relação ao tamanho dos fragmentos esperados. O tampão utilizado foi o TBE 1X (composto por: TBE 5X: Tris (hidroximetil) aminometano - 54g/L; ácido bórico - 27,5g/L; EDTA 0,5M, pH 8 - 20mL). Após a solidificação do gel, depositaram-se nos poços $10 \mu \mathrm{L}$ do produto amplificado com cerca de $2 \mu \mathrm{L}$ de tampão de corrida (sacarose 10\%, azul de bromofenol 0,0025\% em TE [Tris (hidroximetil) aminometano $10 \mathrm{mM}$, EDTA $1 \mathrm{mM}, \mathrm{pH} 8$ ). Na corrida eletroforética utilizou-se um marcador de peso molecular de 100pb (Gibco BRL, Invitrogen) para se comparar seu peso molecular com o do fragmento amplificado.

A eletroforese foi conduzida por 45 minutos, com corrente de 96 Volts (V). 
Após a eletroforese, o gel foi corado com solução de brometo de etídeo $0,5 \mu \mathrm{L} / \mathrm{mL}$, por aproximadamente 15 minutos. Os produtos da amplificação foram visualizados sob luz ultravioleta em transiluminador (Macro Vue UV-20 Hoefer) e o gel foi fotografado num capturador de imagem (modelo Image Store 5000).

A presença do gene blacTX-M foi confirmada por seqüenciamento, através do método padrão de dideoxinucleotídeo de Sanger (SANGER; NICKLEN; COULSON, 1992). As seqüências foram analisadas utilizando o banco de dados de nucleotídeos (blast database) (http://www.ncbi.nlm.nih.gov/blast/Blast.cgi) editado pela versão BioEdit v.7.0.9 (http://www.mbio.ncsu.edu/BioEdit/BioEdit.html) e alinhado com o módulo ClustalW. Os genes bla tabela 4.

\subsubsection{Determinação dos genótipos de virulência para as análises filogenéticas por meio da PCR-multiplex}

Os isolados clínicos de Escherichia coli apresentando ESBL foram investigados para a detecção dos seguintes genes de virulência: pap, cnf, sfa, hly, iuc, iss, tsh, thr, chuA, yjA e para o fragmento de DNATspE4.C2. Essas amostras foram submetidas à extração do DNA pelo método de fervura (CHAPMAN et al., 2001) e submetidas a técnica da PCR multiplex, usando iniciadores específicos. As reações de amplificação foram feitas em um volume final de $25 \mu \mathrm{L}$. Neste volume havia: água ultra-pura estéril $(14,9 \mu \mathrm{L})$, tampão $10 \mathrm{x}$ concentrado $(5,0 \mu \mathrm{L})$; dATP

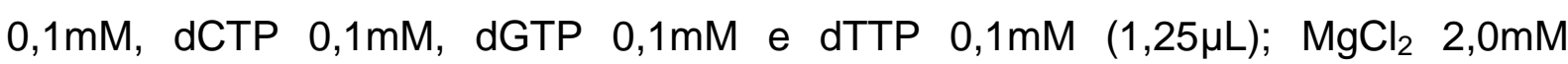
$(0,75 \mu \mathrm{L})$, Iniciador F 10pmoL $(1 \mu \mathrm{L})$; Iniciador R 10pmoL (1 $\mu \mathrm{L})$; TaqDNA polimerase $1,5 \mathrm{U}(0,1 \mu \mathrm{L})$ (Invitrogen, Carlsbad, CA) e $1 \mu \mathrm{L}$ de DNA da amostra. A amplificação foi realizada em termociclador (Perkin Elmer GeneAmp PCR 2400 ou Biometra T3000), sob as seguintes condições: desnaturação inicial a $94{ }^{\circ} \mathrm{C}$ por 3 minutos; 30 ciclos de $94{ }^{\circ} \mathrm{C}$ por 1 minuto; $63{ }^{\circ} \mathrm{C}$ por 30 segundos e extensão de $72{ }^{\circ} \mathrm{C}$ por 3 minutos, seguido de extensão de $72{ }^{\circ} \mathrm{C}$ por 7 minutos (YAMAMOTO et al., 1995), para os genes iss etsh se utilizou 25 ciclos de $94 \stackrel{\circ}{\circ}$ por 1 minuto, $63^{\circ} \mathrm{C}$ por 1 minuto e 30 segundos para a hibridização dos primers e $72 \stackrel{\circ}{\circ}$ por 1 minuto e 30 segundos para 
a extensão final do DNA (EWERS et al., 2005). Os produtos amplificados foram submetidos à eletroforese em gel de agarose 1,0 a $1,5 \%$, conforme os procedimentos descritos acima. Escherichia coli cepas DRC5.4 e DRC5.5 foram usadas como controle positivo para os genes pap, cnf, sfa, hly, iuc, iss, tsh, vat, chuA, yjA e o fragmento de DNA TspE4.C2. Os genes de virulência estudados estão descritos na tabela 5 .

Tabela 4- Iniciadores utilizados para a detecção de genótipos de resistência de ESBL.

\begin{tabular}{|c|c|c|c|c|c|c|}
\hline $\begin{array}{l}\text { Nome do } \\
\text { iniciador }\end{array}$ & Seqüência de nucleotídeos 5'-3' & Gene & $\begin{array}{l}\text { Produto } \\
(\mathrm{pb})\end{array}$ & $\mathbf{T}\left({ }^{\circ} \mathrm{C}\right)$ & $\begin{array}{l}\text { Acesso } \\
\text { GenBank }\end{array}$ & Referência \\
\hline $\begin{array}{l}\text { CTX-M F } \\
\text { CTX-M R }\end{array}$ & $\begin{array}{l}\text { TTT GCG ATG TGC AGT ACC AGT AA } \\
\text { CGA TT CGT TGG TGG TGC CAT A }\end{array}$ & blactX-м & 544 & 56,8 & EF374097 & $\begin{array}{l}\text { Edelstein et } \\
\text { al., } 2003 .\end{array}$ \\
\hline $\begin{array}{l}\text { CTX-M-1F } \\
\text { CTX-M-1R }\end{array}$ & $\begin{array}{l}\text { GACGATGTCACTGGCTGAGC } \\
\text { AGCCGCCGACGCTAATACA }\end{array}$ & blactX-M-1 & 498 & 55 & HM138652.1 & $\begin{array}{l}\text { Frye e } \\
\text { Fedarka -Cray, } \\
2007\end{array}$ \\
\hline $\begin{array}{l}\text { CTX-M 2F } \\
\text { CTX-M 2R }\end{array}$ & $\begin{array}{l}\text { ATG ATG ACT CAG AGC ATT CG } \\
\text { TGG GTT ACG ATT TTC GCC GC }\end{array}$ & blactX-M-2 & 876 & 52,2 & AY750915 & $\begin{array}{l}\text { Hopkins et al., } \\
2005\end{array}$ \\
\hline $\begin{array}{l}\text { CTX-M 9F } \\
\text { CTX-M 9R }\end{array}$ & $\begin{array}{l}\text { ATG GTG ACA AAG AGA GTG CA } \\
\text { CCC TTC GGC GAT GAT TCT }\end{array}$ & blactX-M-9 & 905 & 54,1 & DQ849332 & $\begin{array}{l}\text { Wu et al., } \\
2007\end{array}$ \\
\hline $\begin{array}{l}\text { CTX-M 15F } \\
\text { CTX-M 15R }\end{array}$ & $\begin{array}{l}\text { CACACGTGGAATTTAGGGACT } \\
\text { GCCGTCTAAGGCGATAAACA }\end{array}$ & blactX-м-15 & 996 & 54,8 & HQ157357.1 & $\begin{array}{l}\text { Muzaheed et } \\
\text { al., } 2008\end{array}$ \\
\hline $\begin{array}{l}\text { SHV F } \\
\text { SHV R }\end{array}$ & $\begin{array}{l}\text { ATG CGT TAT ATT CGC CTG TG } \\
\text { GTT AGC GTT GCC AGT GCT CG }\end{array}$ & blasHv & 573 & 53,1 & DQ449578 & $\begin{array}{l}\text { Chen et al., } \\
2006 .\end{array}$ \\
\hline $\begin{array}{l}\text { TEM F } \\
\text { TEM R }\end{array}$ & $\begin{array}{l}\text { ATG AGT ATT CAA CAT TTC CGT G } \\
\text { TTA CCA ATG CTT AAT CAG TGA G }\end{array}$ & blatem & 861 & 51,0 & AJ318094 & $\begin{array}{l}\text { Baraniak et al., } \\
2005 .\end{array}$ \\
\hline $\begin{array}{l}\text { PER F } \\
\text { PER R }\end{array}$ & $\begin{array}{l}\text { GTA GTA TCA GCC CAA TCC CC } \\
\text { CCA ATA AAG GCC GTC CAT CA }\end{array}$ & blapeR & 700 & 54,7 & X93314 & $\begin{array}{l}\text { Bauernfeind et } \\
\text { al., } 1996\end{array}$ \\
\hline $\begin{array}{l}\text { GES F } \\
\text { GES R }\end{array}$ & $\begin{array}{l}\text { ATG CGC TTC ATT CAC GCA C } \\
\text { CTA TTT GTC CGT GCT CAG G }\end{array}$ & bla ${ }_{G E S}$ & 827 & 53,1 & AB113580 & $\begin{array}{l}\text { Wachino et al., } \\
2004\end{array}$ \\
\hline
\end{tabular}


Tabela 5- Iniciadores utilizados para a detecção de genótipos de virulência de Escherichia coli.

\begin{tabular}{|c|c|c|c|c|c|c|}
\hline $\begin{array}{l}\text { Nome do } \\
\text { iniciador }\end{array}$ & Seqüência de nucleotídeos 5'-3' & Gene & $\begin{array}{l}\text { Produto } \\
(\mathrm{pb})\end{array}$ & $\begin{array}{c}T \\
(\stackrel{\circ}{C})\end{array}$ & $\begin{array}{l}\text { Acesso } \\
\text { GenBank }\end{array}$ & Referência \\
\hline $\begin{array}{l}\text { Pap-F } \\
\text { Pap-R }\end{array}$ & $\begin{array}{l}\text { GCA ACA GCA ACG CTG GTT GCA TCA T } \\
\text { AGA GAG AGC CAC TCT TAT ACG GAC A }\end{array}$ & pap & 336 & 60,0 & M20146 & $\begin{array}{l}\text { Yamamoto et } \\
\text { al., } 1995\end{array}$ \\
\hline $\begin{array}{l}\text { Cnf-F } \\
\text { Cnf-R }\end{array}$ & $\begin{array}{l}\text { AAG ATG GAG TTT CCT ATG CAG GAG } \\
\text { CAT TCA GAG TCC TGC CCT CAT TAT T }\end{array}$ & $c n f$ & 498 & 60,0 & X70670 & $\begin{array}{l}\text { Yamamoto et } \\
\text { al., } 1995\end{array}$ \\
\hline $\begin{array}{l}\text { Sfa-F } \\
\text { Sfa-R }\end{array}$ & $\begin{array}{l}\text { CTC CGG AGA ACT GGG TGC ATC TTA C } \\
\text { CGG AGG AGT AAT TAC AAA CCT GGC A }\end{array}$ & sfa & 420 & 60,0 & X16664 & $\begin{array}{l}\text { Yamamoto et } \\
\text { al., } 1995\end{array}$ \\
\hline $\begin{array}{l}\text { HlyA-F } \\
\text { HlyA-R }\end{array}$ & $\begin{array}{l}\text { AACAAGGATAAGCACTGTTCTGGCT } \\
\text { ACCATATAAGCGGTCATTCCCGTCA }\end{array}$ & hly & 1177 & 60,0 & M10133 & $\begin{array}{l}\text { Yamamoto et } \\
\text { al., } 1995\end{array}$ \\
\hline $\begin{array}{l}\text { luc-F } \\
\text { luc- } R\end{array}$ & $\begin{array}{l}\text { TACC GGA TTG TCA TAT GCA GAC CGT } \\
\text { AAT ATC TTC CTC CAG TCC GGA GAA G }\end{array}$ & iuc & 602 & 60,0 & U90207 & $\begin{array}{l}\text { Yamamoto et } \\
\text { al., } 1995\end{array}$ \\
\hline $\begin{array}{l}\text { Iss-F } \\
\text { Iss- } R\end{array}$ & $\begin{array}{l}\text { ATCACATAGGATTCTGCCG } \\
\text { CAGCGGAGTATAGATGCCA }\end{array}$ & iss & 309 & 58,0 & FJ416147 & $\begin{array}{l}\text { Ewers et al., } \\
2005 .\end{array}$ \\
\hline $\begin{array}{l}\text { Tsh-F } \\
\text { Tsh-R }\end{array}$ & $\begin{array}{l}\text { ACTA TTCTCTGCAGGAAGTC } \\
\text { CTTCCGATGTTCTGAACGT }\end{array}$ & tsh & 824 & 58,0 & AY280856 & $\begin{array}{l}\text { Ewers et al. } \\
2005 .\end{array}$ \\
\hline $\begin{array}{l}\text { ThrF } \\
\text { ThrR }\end{array}$ & $\begin{array}{l}\text { GTGTCAGAACGGAATTGT } \\
\text { CTGACCATTATGTCCCAGGA }\end{array}$ & thr & 981 & 55,0 & AY151282 & $\begin{array}{l}\text { Parreira e } \\
\text { Gyles, } 2003\end{array}$ \\
\hline $\begin{array}{l}\text { ChuA-F } \\
\text { Chu-R }\end{array}$ & $\begin{array}{l}\text { GACGAACCAACGGTCAGGAT } \\
\text { TGCCGCCAGTACCAAAGACA }\end{array}$ & chuA & 279 & 55,0 & AM055961 & $\begin{array}{l}\text { Clermont; } \\
\text { Bonacorsi;Bin } \\
\text { gen, 2000. }\end{array}$ \\
\hline $\begin{array}{l}\text { YjA-F } \\
\text { Yja-R }\end{array}$ & $\begin{array}{l}\text { TGAAGTGTCAGGAGATGCTG } \\
\text { ATGAAGAATGCGTTCCTCAAC }\end{array}$ & $y j A$ & 211 & 55,0 & СР000468 & $\begin{array}{l}\text { Clermont; } \\
\text { Bonacorsi;Bin } \\
\text { gen, 2000. }\end{array}$ \\
\hline $\begin{array}{l}T s p E 4 . C 2-\mathrm{F} \\
T s p E 4 . C 2-R\end{array}$ & $\begin{array}{l}\text { GAGTAATGTCGGGGCATTCA } \\
\text { CGCGCCAACAAAGTATTACG }\end{array}$ & TspE4.C2 & 152 & 55,0 & СР000468 & $\begin{array}{l}\text { Clermont; } \\
\text { Bonacorsi;Bin } \\
\text { gen, } 2000 \text {. }\end{array}$ \\
\hline
\end{tabular}

\subsection{TIPAGEM MOLECULAR}

\subsubsection{Sorogrupo por PCR}

A detecção do sorogrupo 025 utilizou os iniciadores: O25ab-F, sendo a seqüência de nucleotídeo 5'-ATACCGACGACGCCGATCTG-3', do gene alvo gndbis, O25a-R, com a seqüência de nucleotídeo 5'-GAGATCCAAAAACAGTTT GTG-3', baseada nos genes do grupo rfb e o O25b-R, com a seqüência de nucleotídeo 5'TGCTATTCATTATGCGCAGC-3' baseada nos genes do grupo rfb. As reações 
ocorreram em temperatura de hibridização de $55{ }^{\circ} \mathrm{C}$ e produziram fragmentos de $274 \mathrm{pb}$ e $300 \mathrm{pb}$, respectivamente, que definiram o sorogrupo O25A e O25B (CLERMONT et al., 2007; CLERMONT et al., 2008).

\subsubsection{Análise do DNA cromossomal por eletroforese em campo pulsado (PFGE)}

A técnica PFGE, desenvolvida por Schwartz et al. (1983) é considerada a ferramenta "padrão ouro" para diferenciação clonal de diversos patógenos bacterianos (TENOVER et al., 1995). O princípio desta técnica consiste na separação de fragmentos de DNA de alto peso molecular, obtidos pela digestão do DNA genômico da bactéria com enzimas de restrição (GOERING, 2004).

A separação destes fragmentos ocorre por corrente eletroforética, na qual a direção e intensidade dos pulsos elétricos aplicados são alteradas em diferentes intervalos de tempo. Para uma melhor reprodutibilidade e uniformidade entre laboratórios foi criado o Prevention PulseNet, por meio da colaboração do U.S. Centers for Disease Control (CDC) (GOERING, 2004; RIBOT et al., 2006).

O perfil de restrição gerado é utilizado para comparação clonal das amostras (SCHWARTZ et al., 1983) e todos os isolados clínicos de E. coli produtores de ESBL foram estudados por PFGE, conforme procedimentos abaixo:

Uma alíquota de $6,0 \mathrm{~mL}$ do cultivo bacteriano foi centrifugada a $4000 \mathrm{rpm}$ por 5 minutos e o pélete lavado com solução Pett IV $(1 \mathrm{M} \mathrm{NaCl}, 10 \mathrm{mM}$ Tris pH $8,10 \mathrm{mM}$ EDTA), posteriormente centrifugada como a alíquota. Este novo pélete foi ressuspendido em $500 \mu \mathrm{L}$ da mesma solução e então misturado com igual volume de agarose de baixo ponto de fusão (BioRad Laboratories) a 2,0\% e, após homogeneização, transferidas para moldes plásticos. Os plugs (blocos) de agarose resultantes, contendo a amostra, foram submetidos a um processo de lise in situ com uma lavagem por 2 horas com solução de lise $(1 \mathrm{M} \mathrm{NaCl}, 10 \mathrm{mM}$ Tris $\mathrm{pH} 8$, 200mM EDTA, 0,5\% Na-laurylsarkosine sodium salt, 0,2\% deoxycholic acid sodium salt, $1 \mathrm{mg}$ lisozima/ ml) a $37^{\circ} \mathrm{C}$, e após submetidos à desproteinização em solução (0,5 M EDTA, pH 8,0, 1\% Na-laurylsarkosine sodium salt, $20 \mathrm{mg}$ de proteinase $\mathrm{K} / \mathrm{ml}$ ) a $56^{\circ} \mathrm{C}$ overnight. Os plugs foram então primeiramente lavados com água ultra pura 
e depois com um tampão de TE (10 mM Tris, $1 \mathrm{mM}$ EDTA) e PMSF (1 mM), por duas vezes. $\mathrm{E}$, em seguida foram novamente lavados com água ultra pura para inativar o PMSF e, por fim, mais duas vezes com tampão TE. Os plugs foram estocados em $900 \mu \mathrm{L}$ tampão TE até o momento da eletroforese e uma fração do plug foi submetida à digestão com a enzima de restrição Xbal (NewEngland, Biolabs), posteriormente adicionada ao gel de agarose $1 \%$ (BioRad Laboratories). A eletroforese foi conduzida num período de 22 horas a 200 volts, $6 \mathrm{~V} / \mathrm{cm}^{3}$, ângulo fixo de $120^{\circ} \mathrm{C}$, com pulso inicial de 2,0 e final de 55 segundos, em tampão TBE 0,5 $\mathrm{X}$, acrescido com tiouréia $50 \mu \mathrm{M}$, mantido a $14{ }^{\circ} \mathrm{C}$, utilizando o sistema de eletroforese CHEF DR III Chiller System (Bio-Rad). O gel foi corado em solução de brometo de etídio a $10 \mathrm{Mm} / \mathrm{mL}$ e visualizados em luz UV. A relação dos perfis de PFGE encontrados foi analisada com o programa Bionumerics (Applied Maths, Kortrijk, Belgium). Foi construído um dendograma UPGMA com índices de similaridades: DICE, linkage completo, otimização: $1 \%$ de tolerância da posição da banda. 


\section{RESULTADOS}

\subsection{CARACTERÍSTICAS CLÍNICAS E MICROBIOLÓGICAS DOS ISOLADOS DE Escherchia coli ASSOCIADA À INFECÇÃO EXTRA-INTESTINAL DOS PACIENTES DE UM HOSPITAL UNIVERSITÁRIO}

No presente estudo, foram identificados 562 isolados clínicos de Escherichia coli de pacientes hospitalizados em um Hospital Universitário, no período de janeiro de 2005 a julho de 2007. Destes isolados, 6\% (34/562) eram isolados que apresentavam resistência a mais de um antimicrobiano e estiveram associados com infecções extra-intestinais. Estes resultados se encontram no gráfico 2.

Dentre estas E. coli, 56\% (19/34) eram de infecções do trato urinário e,44\% (15/34) de outras infecções, sendo isoladas de 28 pacientes do Hospital Universitário. A tabela 6 mostra estes resultados.

Dentre os 28 pacientes, 64\% (18/28) eram de indivíduos hospitalizados e dez (10) eram de unidades ambulatoriais, sendo $28 \%$ (8/28) do pronto socorro (PS) e $7 \%$ (2/28) do ambulatório (AMB).

Com relação aos pacientes hospitalizados $(n=18), 28 \%(8 / 28)$ eram da UTI, 3,5\% (01/28) da SEMI, 11\% (03/28) da UTIP, 11\% (03/28) do centro cirúrgico (CC), 3,5\% (01/28) do berçário (BER), 3,5\% (01/28) da clínica médica (CM) e 3,5\% (01/28) de uma paciente atendida no pronto socorro (PS), mas que foi internada no dia 28/03/2007. Assim, foi observado que em cinco pacientes foram recuperados mais de um isolado clínico de E. coli (ESBL) como demonstrado na tabela 3. 


\subsection{MÉTODOS FENOTÍPICOS}

\subsubsection{Perfil de susceptibilidade dos isolados de Escherichia coli associada com infecção extra-intestinal}

Neste estudo, os isolados de E. coli exibiram um perfil de multiresistência aos seguintes antibióticos: ampicilina (100\%), cefalotina (100\%), cefotaxima (100\%), ceftazidima (79\%), cefepima (94\%), ciprofloxacina (50\%), gentamicina (56\%), sulfametaxazolltrimetroprim (62\%), e amicacina (6\%). Todos os isolados apresentaram susceptibilidade ao imipinem (100\%). As tabelas 6 e 7 apresentam estes resultados.

4.2.2 Confirmação dos fenótipos ESBL nos isolados de Escherichia coli associada com infecção extra-intestinal

A positividade para a triagem de ESBL variou de acordo com o substrato utilizado. Quando se utilizou cefotaxima como substrato, foi obtido 94\% (32/34). Já com aztreonan e ceftazidima esta foi, respectivamente, 91\% (31/34) e 79\% (27/34). Estes resultados encontram-se na figura 5 e tabela 6.

\subsubsection{Determinação da CIM para cefalosporina de terceira geração (cefotaxima) na presença/ausência de inibidor de ESBL}

O E-test foi positivo para todas as amostras de Escherichia coli estudadas, ocorrendo uma concentração inibitória mínima (CIM) reduzida de >16 para 0,064 $\mu \mathrm{g} / \mathrm{mL}$ na presença do ácido clavulânico $(4 \mathrm{ug} / \mathrm{mL})$. A figura 5 e a tabela 6 apresentam estes resultados. 
Tabela 6 - Perfil de resistência e detecção in vitro de ESBL dos isolados clínicos de E. coli ${ }^{*}$.

\begin{tabular}{|c|c|c|c|c|c|c|}
\hline \multirow{3}{*}{ Amostra } & \multirow{3}{*}{ a Fenótipos de Resistência ${ }^{a}$} & \multicolumn{5}{|c|}{ ESBL } \\
\hline & & \multicolumn{3}{|c|}{ DDST $(A M C+)$} & \multicolumn{2}{|c|}{ Etest } \\
\hline & & Caz & Ctx & Atm & Ctx & $\mathrm{Ctx} / \mathrm{Cla}$ \\
\hline $333 / 6$ & AmpSamAtmFepCtxFoxCazKfGen & - & + & + & $>16$ & 0.094 \\
\hline $154 / 6$ & AmpSamAtmFepKfCtxCazCip & + & + & + & $>16$ & 0.094 \\
\hline $814 / 5$ & AmcAmpFepKfCroCipGenNalNorSxtCtx & + & + & + & $>16$ & 0.047 \\
\hline $248 / 6$ & AmpFepCroCxmKfCipNalNorSxtCazCtx & + & + & + & $>16$ & 0.19 \\
\hline $681 / 5$ & AmpSamAtmFepCtxFoxCazKfGenSxt & + & + & + & $>16$ & 0.32 \\
\hline $249 / 6$ & AmcAmpFepCroCxmKfNalSxtCtx & + & + & + & $>16$ & $>1.0$ \\
\hline $770 / 5$ & AmpFepCroCxmKfCipGenNitSxtCtx & + & + & + & $>16$ & 0.094 \\
\hline $217 / 6$ & AmpSamAtmFepCtxFoxCazKfCipTimSxt & + & + & + & $>16$ & 0.094 \\
\hline $740 / 5$ & AkAmpClaAtmFepCtxCazKfGenSxt & + & + & + & $>16$ & $>1.0$ \\
\hline $753 / 5$ & AmpFepCroCxmKfGenSxtCtx & + & + & + & $>16$ & 0.064 \\
\hline $720 / 5$ & AmpAtmFepCtxCazKf & + & + & + & $>16$ & 0.064 \\
\hline $713 / 5$ & AmpSamAtmFepCtxCazKf & + & + & + & $>16$ & 0.064 \\
\hline $601 / 5$ & AmpSamAtmCtxCazKfGenSxt & + & + & + & $>16$ & 0.094 \\
\hline $658 / 5$ & AmpSamAtmFepCtxCazKfGenTim & + & + & + & $>16$ & 0.023 \\
\hline $602 / 5$ & AmcAmpFepCroCxmKfGenNalSxtCazCtx & + & + & + & $>16$ & 0.094 \\
\hline $712 / 5$ & AmpSamAtmFepCtxCazKf & + & + & + & $>16$ & 0.064 \\
\hline $152 / 6$ & AmpCroCxmKfCipNalNorSxtCazCtx & + & + & + & $>16$ & 0.19 \\
\hline $756 / 5$ & AmpSamAtmFepCtxKfGenSxtCaz & + & + & + & $>16$ & 0.032 \\
\hline $473 / 5$ & AmpSamAtmFepCtxCazKfGen & - & - & + & $>16$ & 0.094 \\
\hline $195 / 5$ & AmpAtmFepCtxFoxCazKfCip & + & + & + & $>16$ & 0.064 \\
\hline $321 / 5$ & AmpSamAtmFepCtxFoxCazKfCipGen & + & + & + & $>16$ & 0.064 \\
\hline $323 / 5$ & AmpSamAtmFepCtxFoxCazKfCipGen & + & + & + & $>16$ & 0.064 \\
\hline $366 / 5$ & AmpSamAtmFepCtxCazKfCipGenTim & + & + & + & $>16$ & 0.125 \\
\hline $311 / 6$ & AmcAmpFepCroCxmKfCtx & + & + & + & $>16$ & 0.032 \\
\hline $1 / 7$ & AmpFepCroCxmKfCipGenNalNorSxtCazCtx & - & + & + & $>16$ & 0.094 \\
\hline $2 / 7$ & AmcFepCroCxmKfSxtCazCtx & - & + & + & $>16$ & 0.125 \\
\hline $3 / 7$ & AmcAmpFepCroCxmKfCipNaINorSxtCazCtx & - & + & + & $>16$ & 0.25 \\
\hline $4 / 7$ & AmcAmpFepCroCxmKfCipNorSxtCtx & - & + & + & $>16$ & 0.125 \\
\hline $5 / 7$ & AmcAmpFepCroKfCipGenNalNorSxtCtx & - & + & - & $>16$ & 0.19 \\
\hline $8 / 7$ & AmpAtmFepCtxFoxCazKfCipGenSxt & + & - & - & $>16$ & 0.19 \\
\hline $10 / 7$ & AmcAmpFepCroCxmKfSxtCazCtx & + & + & - & $>16$ & 0.094 \\
\hline $11 / 7$ & AkAmpSamAtmFepCtxCazKfGen & + & + & + & $>16$ & 0.47 \\
\hline $13 / 7$ & AmpFepCroCxmKfCipGenNalNorSxtCazCtx & + & + & + & $>16$ & 0.094 \\
\hline $14 / 7$ & AmcAmpFepCroCxmKfCipNalNorSxtCazCtx & + & + & + & $>16$ & 0.094 \\
\hline
\end{tabular}

*ampicilina (AMP), ampicilina/sulbactam (SAM), aztreonam (ATM), cefepima (FEP), cefotaxima (CTX), cefoxitina (FOX), ceftazidima (CAZ), cefalotina (KF), gentamicina (GEN), ciprofloxacina (CIP), ácido nalidíxico (NAL), norfloxacina (NOR), sulfametoxazol/trimetoprim SXT), cefuroxima (CXM), nitrofurantoína (NIT), ticarcillina/clavulanato (TIM),,ceftriaxona (CRO), amoxicillina/clavulanato (AMC), amicacina (AK), DDST-disco dupla difusão. 


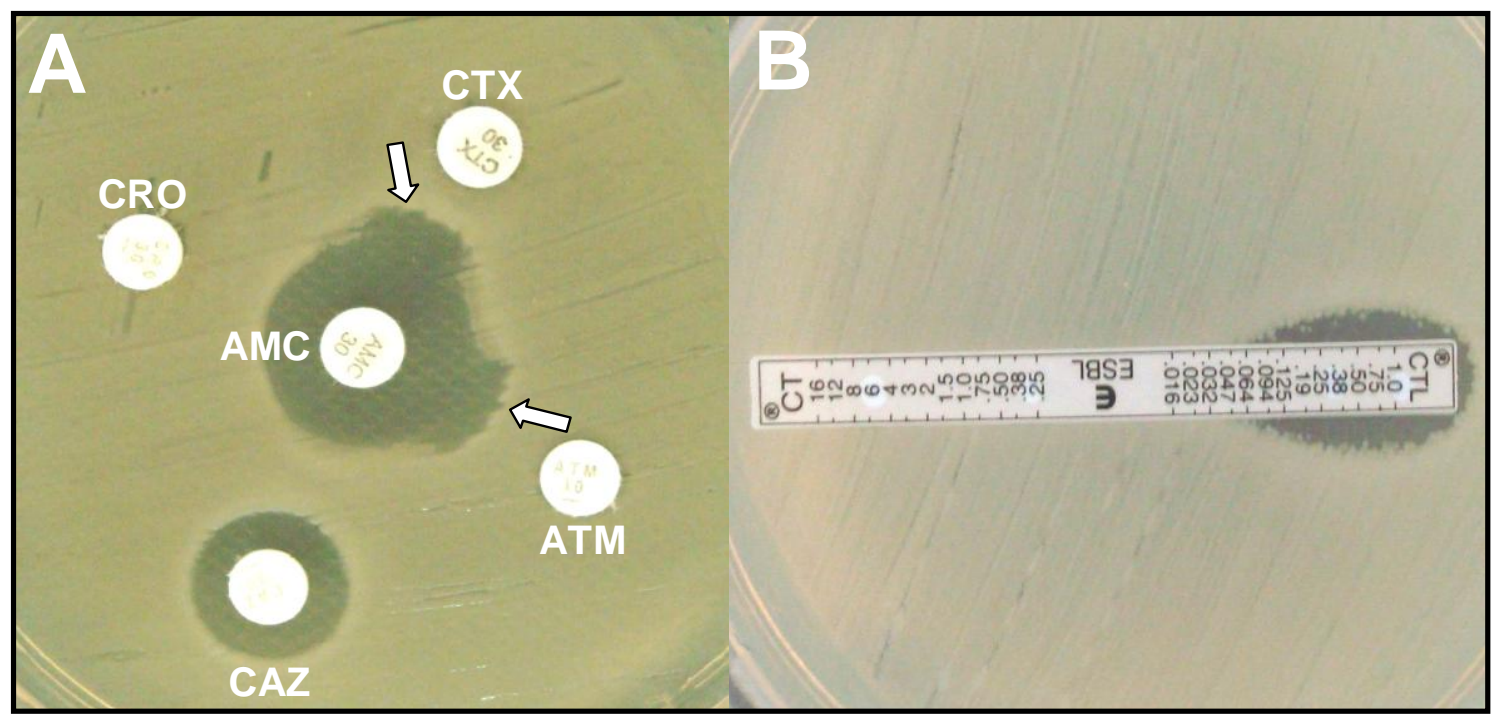

Em A (DDST), se visualiza a zona fantasma ao redor dos discos contendo cefotaxima/ácido clavulânico CTX/AMC e aztreonam/ácido clavulânico, ATM/AMC sugerindo a presença de ESBL. $\mathrm{Em} \mathrm{B}$, a CIM de cefotaxima é reduzida de $>16$ para $0,064 \mathrm{~g} / \mathrm{mL}$ na presença do ácido clavulânico (4ug/mL), confirmando a presença de ESBL.

Figura 5. Detecção de ESBL in vitro pelo método de dupla difusão em disco (DDST) e E-test DDST e E-test.

(\%)

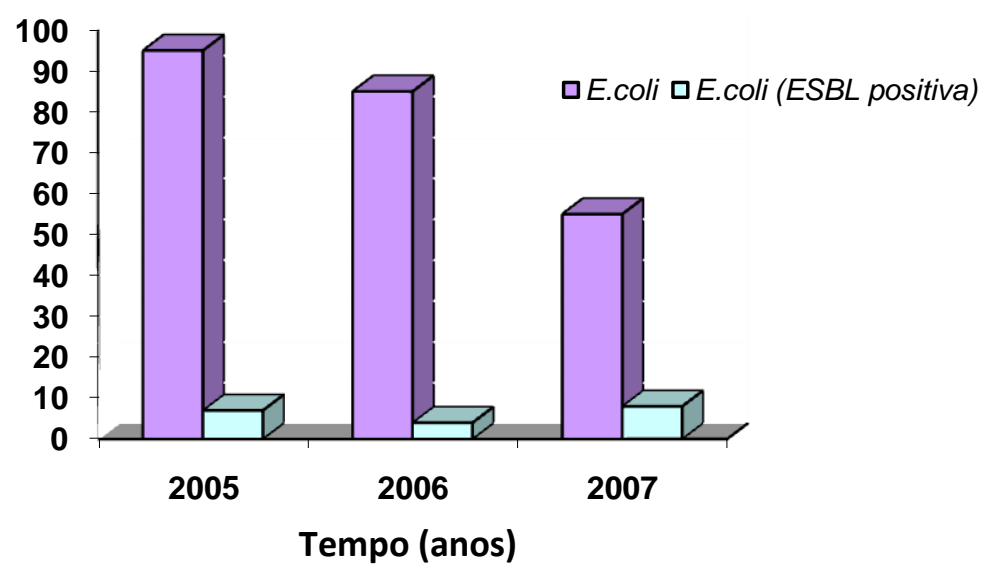

Gráfico 2. Frequência de cepas de E.coli e E.coli (ESBL) no período de 2005 a 2007 no Hospital Universitário. 


\subsection{MÉTODOS GENOTÍPICOS}

\subsubsection{Detecção dos genótipos de $\beta$-lactamases de espectro estendido (bla $\left.a_{E S B L}\right)$ em E. coli}

Dentre os 34 isolados produtores de ESBL estudados, $56 \%$ eram de urina $(19 / 34)$ e $44 \%$ (15/34) de outras infecções. Genes bla que $32(94 \%)$ isolados possuíam o gene blacTX-M-2, um (01) (3\%) o gene bla

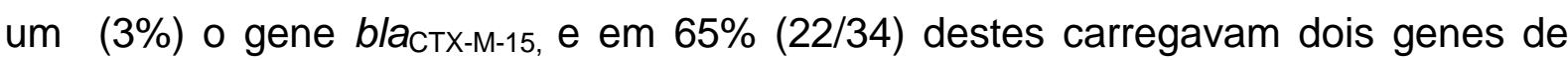
resistência. Analisando as 32 amostras de $E$. coli que apresentavam o gene bla 2 verificou-se que 20 (59\%) apresentavam também o gene bla gene blasHV. No isolado carregando o gene bla $a_{\mathrm{CTX}-\mathrm{M}-1}$ foi também detectada a presença do gene blaTEM, e o isolado carregando o gene bla encontrado outro gene codificando ESBL dentre aqueles utilizados neste estudo. A tabela 7 e figura 8 mostram estes resultados.

Considerando as 19 amostras isoladas de urina, verificou-se que em 18

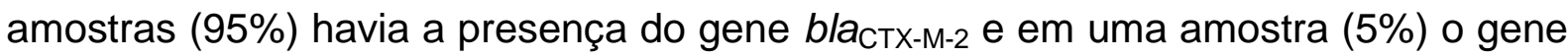

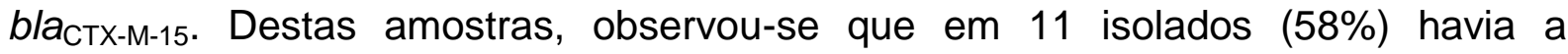
presença dos genes blaCTX-M-2 e bla TEM.

Todos os isolados de outras infecções possuíam o gene bla 10 destes $(66,7 \%)$ possuíam também o gene bla também o gene blasHv (16,7\%). Na tabela 07 e na figura 08 encontram-se estes resultados.

Relacionando a origem dos pacientes hospitalizados com os 34 isolados clínicos de E. coli produtores de ESBL, verificou-se que 35\% (12/34) eram das UTI, SEMI ou UTIP, sendo que $100 \%$ dos isolados (12/12) possuíam o genótipo ESBL bla $a_{\mathrm{CTX}-\mathrm{M}-2}$ e 50\% (6/12) destes apresentavam também o gene bla carregava o gene blasHV. Verificou-se que $9 \%(3 / 34)$ dos isolados eram de pacientes do centro cirúrgico e $100 \%$ apresentavam os genes bla observado em um isolado de paciente do berçário que carregava esses dois genes. Um paciente que estava na clínica médica $(\mathrm{CM})$ e foi hospitalizado possuía um 
isolado com o genótipo bla CTX-M-1 $_{\text {e }}$ bla TEM ,enquanto um isolado de paciente do pronto socorro (PS) carregava o genótipo bla

Nas amostras de E. coli isoladas de pacientes do ambulatório 6\% (02/34), o gene blactX-M-2 foi detectado em um isolado e em outro o gene bla pacientes do pronto socorro observou-se que $18 \%$ (06/34) dos isolados carregavam os genes bla CTX-M-2 $_{\text {e }}$ bla $a_{\text {TEM }}$ e $6 \%(02 / 34)$ o genótipo bla estes resultados.

Os genes bla $a_{\mathrm{CTX}-\mathrm{M}-9,}$, blapER, e bla $a_{\mathrm{GES}}$ não foram encontrados neste estudo.

\subsubsection{Determinação de genótipos de virulência, grupos filogenéticos e sua associação com a produção de ESBL nos isolados clínicos de Escherichia coli}

Este estudo avaliou a presença dos genes de virulência: pap, cnf, sfa, hly, iuc, iss, tsh, thr, os genes chuA, yjA e o fragmento de DNA TspE4.C2 que determinam os grupos filogenéticos. Os genes pap, cnf, sfa, hly e iuc não foram encontrados nas amostras de E. coli estudadas. Detectou-se a presença dos genes iss em $53 \%$,e os genes tsh e thr em $38 \%$ dos 34 isolados clínicos de E. coli (ESBL). Dessa forma, os genes iss, tsh, thr, chuA, yjA e TspE4.C2 permitiu diferenciar os isolados clínicos em 23 genótipos diferentes. A figura 6 mostra o tamanho dos produtos amplificados que classificam os grupos filogenéticos. Duas (02) amostras não apresentavam os genes de virulência estudados e TspE4.C2 e foram classificadas no grupo filogenético A descrito por Clermont, Bonacorsi e Bingen (2000). Estes resultados encontram-se no gráfico 3 e figura 8. 


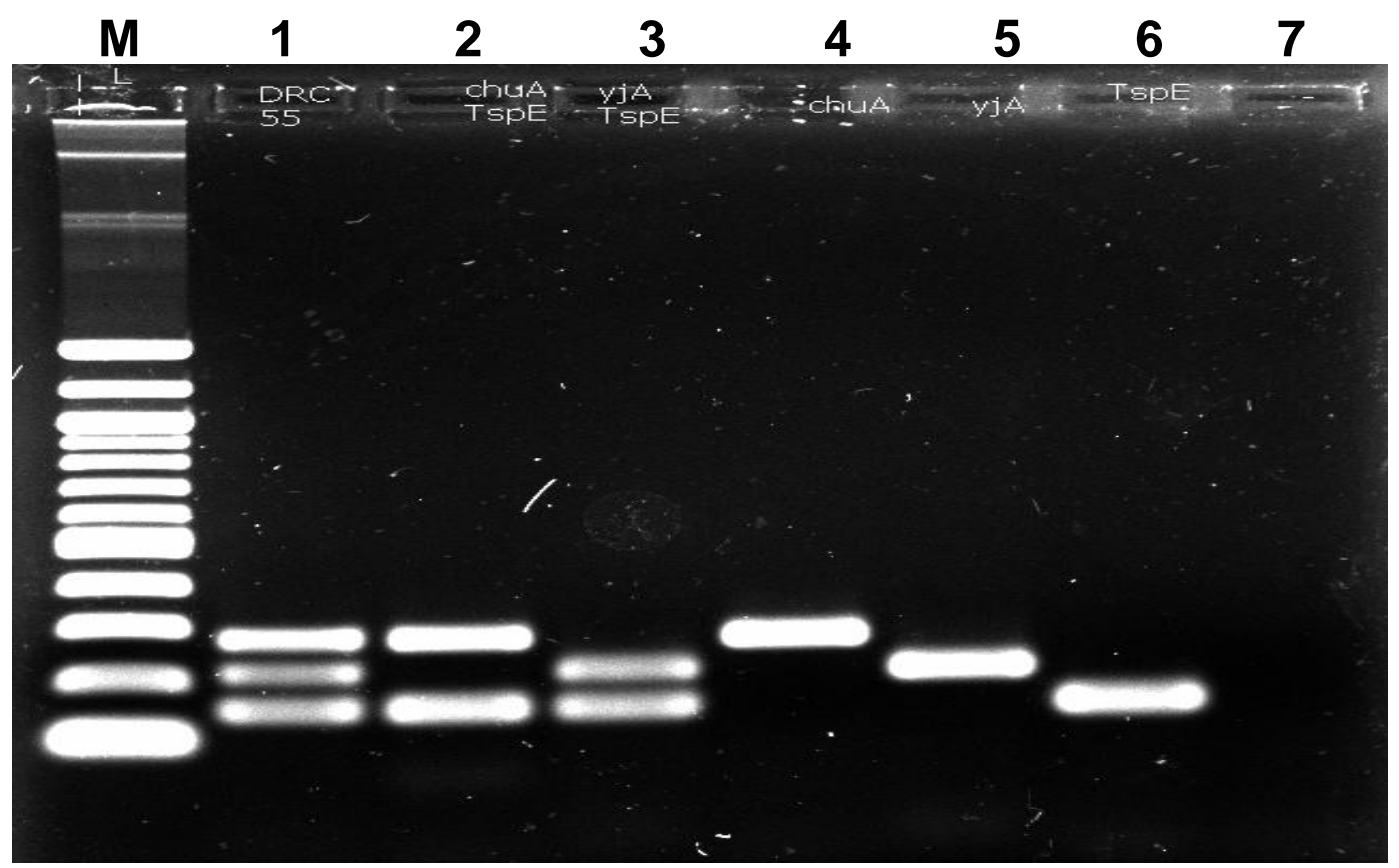

Linha 1, grupo B2 (E. coli carregando os genes chuA, yjaA, e TspE4.C2); Linha 2, grupo A (E. coli carregando os genes chuA e TspE4.C2); Linha 3, grupo B1 (E. coli carregando os genes yjaA e TspE4.C2); Linha 4, grupo D (E. coli carregando o gene chuA); Linha 5, grupo A $(E$. coli carregando o gene $y j a A)$; Linha 6, grupo B1 (E. coli carregando somente o gene TspE4.C2); e Linha 7, controle negativo. Linha M, marcador de peso molecular.

Figura 6. PCR específico dos grupos filogenéticos de Escherichia coli com os genes chuA, yjaA e o fragmento TspE4.C2.

Verificou-se que $18(53 \%)$ amostras de E. coli produtoras de $\beta$-lactamases de espectro estendido classificaram-se no grupo filogenético B1, dessas, em nove (09) amostras não foi detectado nenhum gene de virulência estudado, quatro (04) possuíam o gene iss, duas (02) os genes tsh e trh, duas (02) os genes iss, tsh e trh.

O grupo filogenético A foi definido em 6 isolados clínicos (18\%), sendo que em quatro (04), os genes iss, tsh e thr estavam presentes e em dois (02) os genes de virulência estudados não foram detectados. 


\section{Frequência dos genótipos de virulência de E. coli (ESBL)}
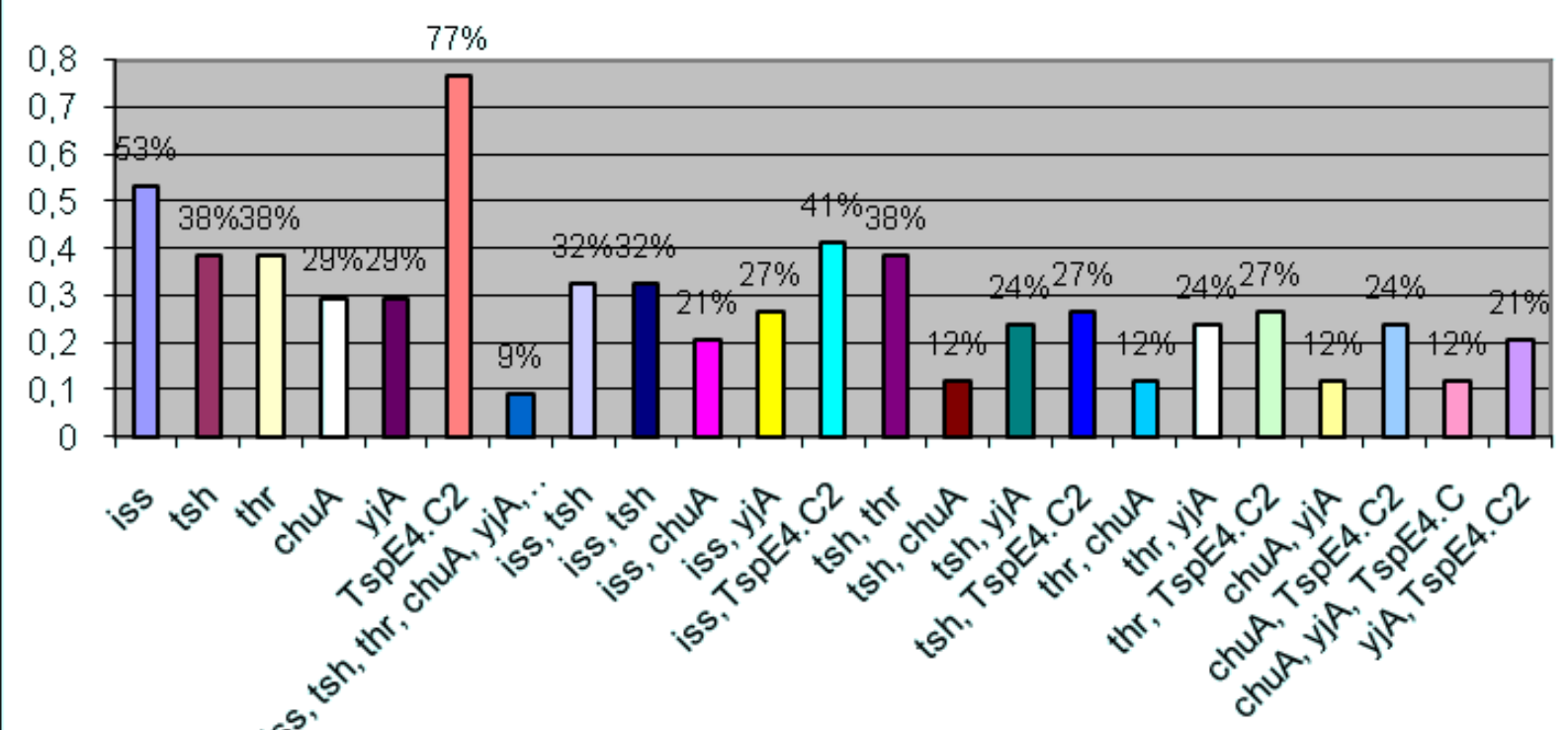

Gráfico 3. Freqüência dos genótipos de virulência dos isolados clínicos de $E$. coli produtores de ESBL de um Hospital Universitário.

O grupo filogenético B2 foi definido em quatro (04) isolados clínicos (12\%), os genes de virulência iss, tsh, thr foram detectados em três (03) E. coli e em uma apenas o gene iss.

O grupo filogenético $D$ foi definido em seis (06) E. coli (18\%) destes, em três (03) amostras os genes de virulência estudados estiveram ausentes, em dois (02) isolados detectou-se a presença do gene iss e em um (01) isolado foram encontrados os genes iss, tsh e trh. A tabela 7 e a figura 8 apresentam estes resultados.

A correlação entre os grupos filogenéticos e os antimicrobianos revelou que entre as $E$. coli classificadas no grupo B1, uma (01/34) possuía os genes bla e bla Tем, uma (01/34) o gene bla que em 11 isolados foi detectado também o gene bla grupo filogenético $\mathbf{A}$ foi definido em seis (06) isolados (18\%) e estes carregavam o

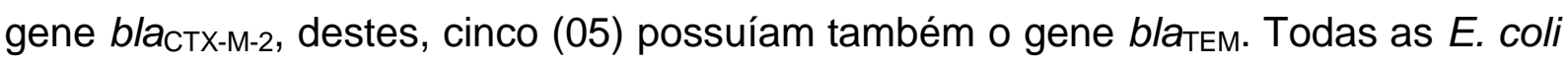
$(\mathrm{n}=03)$ do grupo filogenético B2 tinham o gene bla $a_{\mathrm{CTX}-\mathrm{M}-2}$ e em duas (02) amostras 0 gene blaтем também estava presente. Seis (06) isolados clínicos foram classificados no grupo filogenético $\mathbf{D}$ e $100 \%$ possuíam o gene bla $a_{\mathrm{CTX}-\mathrm{M}-2}$ eem três (03) isolados existia também o gene blaTEM. 
Considerando o grupo filogenético e a origem da amostra, verificou-se que dentre os 18 isolados do grupo B1, 11 (61\%) eram de infecções do trato urinário e 7 $(39 \%)$ de outras infecções. Observou-se que as amostras de urina eram de pacientes da UTI $(n=4)$, da UTIP ( $n=1)$, da SEMI $(n=1)$, do CC $(n=2)$, do AMB $(n=1)$ e do PS $(n=4)$, enquanto as de outras infecções eram de pacientes da UTI $(n=4)$, da CM $(n=1)$ e do CC $(n=2)$. Aqueles definidos no grupo $\mathbf{A}(n=06), 50 \%(03 / 06)$ eram de urina, de pacientes do pronto socorro e 50\% (03/06) de outras infecções, de pacientes da UTIP $(n=1)$, da UTI $(n=1)$ e do BER $(n=1)$. E. coli classificada no grupo filogenético B2 ( $n=04)$, tinha como origem a urina (AM), a secreção traqueal (UTIP), o lavado bronco alveolar (UTI) e o abscesso (UTI). As amostras de E. coli do grupo filogenético $\mathbf{D}(n=06)$, quatro (04) eram de urina, de paciente da UTI $(n=1)$ e do PS $(n=3)$, e duas $(02 / 06)$ de outras infecções, de paciente da UTI. A tabela 7 mostra estes resultados.

\begin{tabular}{lll}
\hline Similaridade & Amostras & Grupos \\
filogenéticos
\end{tabular}

Figura 7. Dendograma dos grupos filogenéticos com os isolados clínicos de Escherichia coli produtores de beta-lactamases de espectro estendido. 
4.4 TÉCNICAS DE TIPAGEM MOLECULAR PARA ANÁLISE EPIDEMIOLÓGICA

4.4.1 Identificação do sorogrupo 025 nos isolados de Escherichia coli associada com infecção extra-intestinal

Dentre os 34 isolados de E. coli (ESBL), uma (3\%) foi classificada no subtipo molecular O25b, classificada no grupo filogenético B2, com a presença do gene de virulência iss e genótipo de resistência blacTX-M-2/blaTEM, isolada de secreção traqueal de paciente hospitalizado na UTI pediátrica. 
Tabela 7- Grupos filogenéticos, amostras clínicas, perfil de resistência e genótipos de beta-lactamases nos isolados de E. coli estudados.

\begin{tabular}{|c|c|c|c|c|c|c|c|c|c|c|c|c|c|c|c|c|}
\hline \multirow[b]{2}{*}{$\begin{array}{c}\text { Grupos } \\
\text { filogenéticos }\end{array}$} & \multicolumn{2}{|c|}{ Amostras } & \multicolumn{9}{|c|}{ Perfis de Resistência (\%) } & \multicolumn{5}{|c|}{ Genótipos ß-lactamase (\%) } \\
\hline & urina & outros ${ }^{\mathrm{a}}$ & Amp & Kf & Ctx & $\mathrm{Caz}$ & Fep & Cip & Gen & Sxt & $\mathrm{Ak}$ & $\begin{array}{l}\frac{n}{1} \\
\sum_{1}^{1} \\
\stackrel{x}{\bullet} \\
\dot{U}\end{array}$ & $\begin{array}{l}\stackrel{N}{1} \\
\sum_{1}^{1} \\
\stackrel{x}{\ominus} \\
\stackrel{U}{U}\end{array}$ & 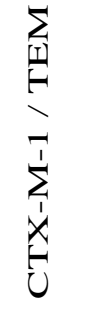 & 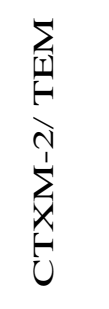 & 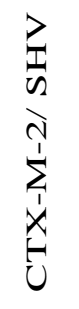 \\
\hline A & $3(9)$ & $3(9)$ & $6(18)$ & $6(18)$ & $6(18)$ & $5(15)$ & $6(18)$ & $4(12)$ & $2(6)$ & $3(9)$ & 1(3) & - & $1(3)$ & & $5(15)$ & - \\
\hline B1 & $11(32)$ & $7(20)$ & $18(53)$ & $18(53)$ & $18(53)$ & $15(44)$ & $17(50)$ & $9(26)$ & $9(26)$ & $11(32)$ & - & $1(3)$ & $5(15)$ & $1(3)$ & $10(29)$ & $1(3)$ \\
\hline B2 & 1(3) & $3(9)$ & $4(12)$ & $4(12)$ & $4(12)$ & $3(9)$ & $4(12)$ & $1(3)$ & $4(12)$ & $2(6)$ & - & - & $2(6)$ & & $2(6)$ & \\
\hline D & $4(12)$ & $2(6)$ & $6(18)$ & $6(18)$ & $6(18)$ & $4(12)$ & $5(15)$ & $3(9)$ & $4(12)$ & $5(15)$ & $1(3)$ & & $3(9)$ & & $3(9)$ & - \\
\hline TOTAL & $19(56)$ & $15(44)$ & $34(100)$ & $34(100)$ & $34(100)$ & $27(79)$ & $32(94)$ & $17(50)$ & $19(56)$ & $21(62)$ & $2(6)$ & $1(3)$ & $11(33)$ & $1(3)$ & $20(59)$ & $1(3)$ \\
\hline
\end{tabular}

a sangue, secreção traqueal, secreção peritoneal, secreção biliar, abscesso, prega axilar, prega inguinal, lavado bronco-alveolar e lavado cavitário. Ampicilina (AMP), ampicilina/sulbactam (SAM), aztreonam (ATM), cefepima (FEP), cefotaxima (CTX), cefoxitina (FOX), ceftazidima (CAZ), cefalotina (KF), gentamicina (GEN), ciprofloxacina (CIP), ceftriaxona (CRO), ácido nalidíxico (NAL), norfloxacina (NOR), sulfametoxazol/trimetoprim (SXT), cefuroxima (CXM), nitrofurantoína (NIT), ticarcillina/clavulanato (TIM), amoxicillina/clavulanato (AMC), amicacina (AK). 


\subsubsection{Relação clonal dos isolados de Escherichia coli produtores de ESBL, sua relação epidemiológica com o grupo filogenético e genótipo ESBL}

Os resultados mostraram a existência de diferentes clones de E. coli, de acordo com os genótipos de resistência e virulência. Através da técnica de PFGE foi possível a identificação de 31 clones entre as 34 amostras de E. coli estudadas, com $90 \%$ de similaridade, denominados I a XXXI. Dessa forma, se observou que o grupo III, o grupo X ou o grupo XXIX foi encontrado em dois isolados. No entanto, analisando o perfil genético de virulência e resistência desses isolados, verificou-se que apenas aqueles do grupo III são iguais, de acordo com os parâmetros estudados, e estas foram obtidas de um mesmo paciente, internado na UTI e foram isoladas de sangue (601/5-UTI) e de urina (602/5-UTI), com a mesma data de coleta, de uma paciente, com 31 anos de idade.

Por outro lado, alguns isolados eram de um mesmo paciente. Assim, os isolados 753/5 (urina, coleta no dia 18/11/05, grupo B1), 756/5 (prega inguinal, coleta no dia 18/11/05, grupo D) e 770/5 (urina, coleta no dia 22/11/05, grupo D), de um paciente da UTI, com 84 anos, eram dos grupos X, XXIX e V, respectivamente, e todos possuíam o gene iss e o gene blacTX-M-2.

E. coli isolada da amostra 712/5 (LBA, coletada no dia 27/10/05, grupo B1) e da amostra 713/5 (secreção traqueal, coletada no dia 28/10/05, grupo B1), de uma paciente da UTI, com 79 anos, foram classificadas nos grupos II e IX, com o genótipo bla $a_{\mathrm{CTX}-\mathrm{M}-2}$ e bla $\mathrm{TEM}_{\mathrm{TEM}}$, apresentavam os genes tsh, thr e iss, respectivamente.

Os isolados 321/5 (urina, amostra coletada no dia 06/03/10, grupo B1) e do 323/5 (urina, amostra coletada no dia 10/03/05, grupo B1), de uma paciente do CC, com 45 anos, definidas nos grupos XXIX e XIII, respectivamente, com o genótipo bla $a_{\text {CTX-M-2 }}$ e bla TEM $_{\text {TE }}$ ausência de genes de virulência estudados.

A amostra 3/7 (urina, coletada no dia 15/02/07, grupo A) e a amostra 14/7 (urina, coletada no dia 28/03/07, grupo A), de uma paciente do PS, com 99 anos, foram classificadas nos grupos XXII e IV, respectivamente, eram do genótipo blactXM-2 e blaTEM, e com os genes de virulência iss, tsh e thr.

Verificou-se que entre os pacientes internados na UTI, SEMI ou UTIP $(n=12)$, foram isoladas $16 \mathrm{E}$. coli, todas com gene de resistência aos $\beta$-lactâmicos. A figura 8 e tabela 8 mostram estes resultados. 


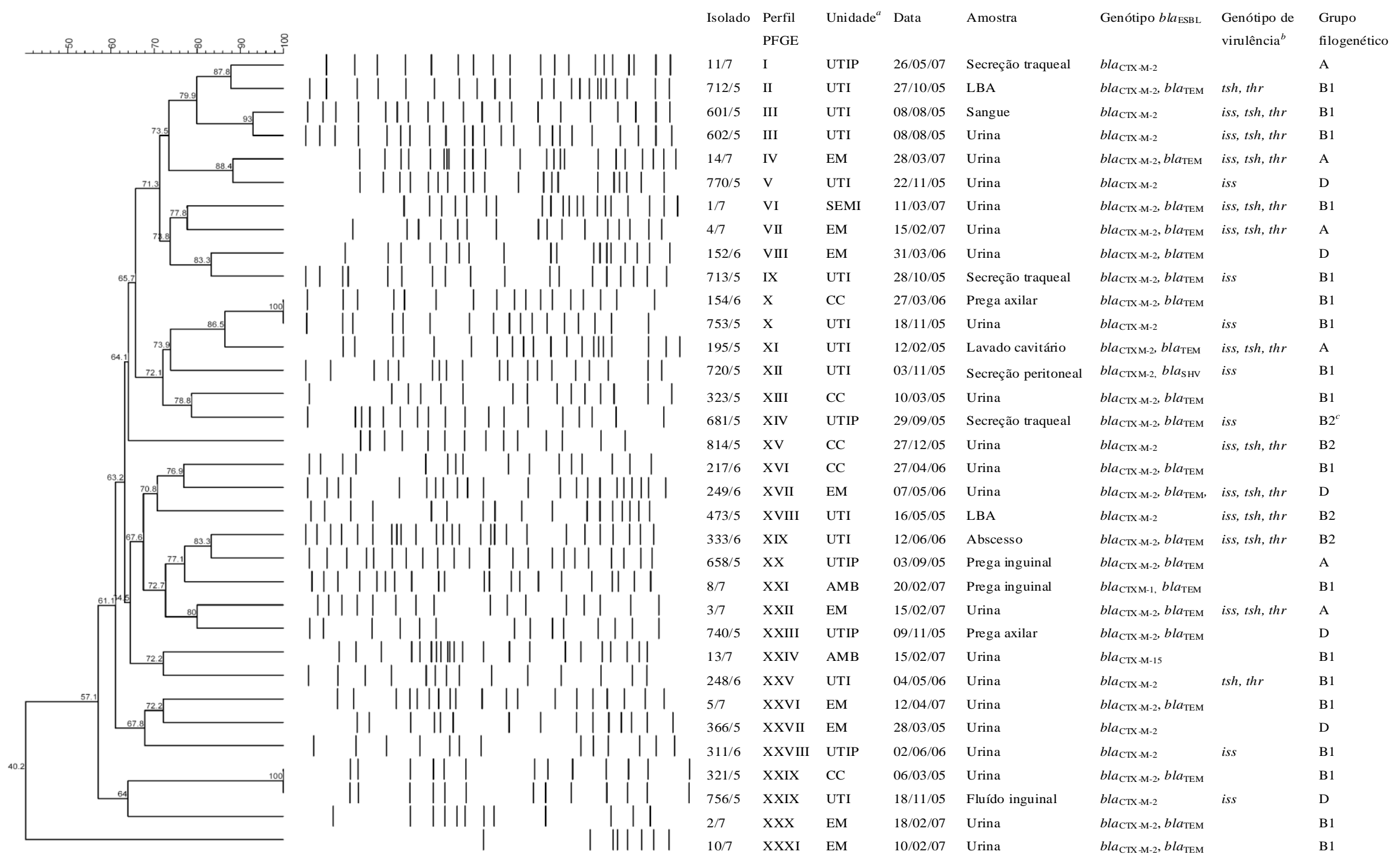

Figura 8. Relação clonal de 34 isolados clinicos de E. coli produtores de ESBL definidos pela técnica de eletroforese em campo pulsado (PFGE), com a enzima Xbal, associada aos genótipos de resistência e virulência e grupos filogenéticos de pacientes hospitalizados no Hospital Universitário, São Paulo, Brasil. ${ }^{a}$ : UTIUnidade de Terapia Intensiva, SEMI-Semi-Intensiva, UTIP-Unidade de Terapia Intensiva Pediátrica CC-Centro Cirúrgico, PS-Pronto Socorro, CM-Clínica Médica, EM-Emergência, BER-Berçário, AMB-Ambulatório. ${ }^{b}:$ iss, tsh e thr - genes de virulência de APEC. ${ }^{c}:$ O25 positivo 
Tabela 8 - Características de genes de resistência, virulência, grupos filogenéticos, PFGE dos 34 isolados clínicos de Escherichia coli produtores de ESBL e dados das amostras e pacientes.

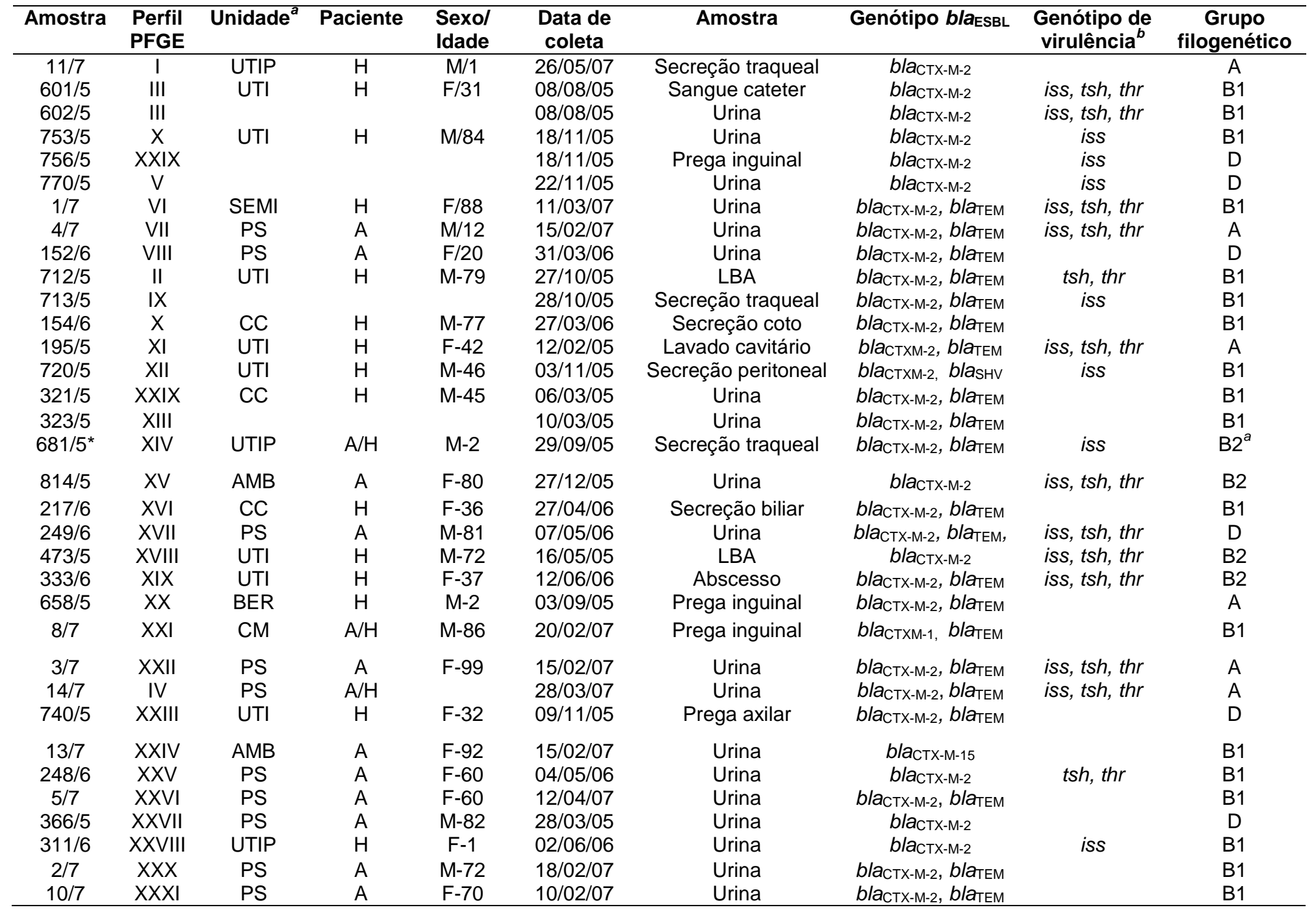

*O25 positivo 


\section{DISCUSSÃO}

Escherichia coli é uma bactéria anaeróbia facultativa predominante na microbiota humana (DRASAR e HILL, 1974; NATARO e KAPER, 1998), pertence à família Enterobacteriaceae, e pode ser classificada em amostra comensal, patogênica intestinal (diarréica) ou extra-intestinal. As amostras de E. coli patogênicas extra-intestinais causam freqüentemente infecções no trato urinário (ITU), septicemia (SePEC) e meningite neonatal (MNEC) (RUSSO e JOHNSON 2000; KAPER; NATARO; MOBLEY, 2004; MOKADY; GOPHNA; RON, 2005; EWERS et al., 2007).

Neste estudo foram analisadas inicialmente 562 amostras de E. coli, pelo laboratório de microbiologia clínica, sendo selecionadas 34 amostras (6\%) com múltipla resistência aos antimicrobianos comumente utilizados na clínica médica, verificou-se que estas eram de origem extra-intestinal, de diferentes unidades de um hospital universitário (Tabela 2 e Gráfico 2).

Com relação à susceptibilidade aos antimicrobianos, os 34 isolados clínicos apresentaram resistência a ampicilina (100\%), a cefalotina (100\%), a cefotaxima $(100 \%)$, a ceftazidima (79\%), a cefepima (94\%), a ciprofloxacina $(50 \%)$, a gentamicina (56\%), a sulfametaxazolltrimetroprim (62\%), e a amicacina (6\%), sendo que $100 \%$ mostraram-se suscetíveis ao imipinem (Tabela 6 e 7). A resistência bacteriana a penicilinas de amplo espectro, fluoroquinolonas e ao sulfametoxazol/trimetoprim constitui um grave problema na América Latina (SADER et al., 1999a; SADER et al., 1999b; GALES; SADER; JONES, 2002; SCHITO et al., 2009). A suscetibilidade ao imipinem e ao meropenem possibilita aos clínicos uma alternativa terapêutica para as infecções graves causadas por Enterobacteriaceae, pois os carbapenêmicos são altamente estáveis à hidrólise de beta-lactamase (LIVERMORE, 1987; EDELSTEIN et al., 2003). Neste estudo, 62\% dos isolados clínicos de E. coli exibiram resistência ao sulfametaxazol/trimetroprim (Tabela 3). Outros autores mostraram, nas amostras de UPEC, uma resistência maior que $30 \%$ a este antimicrobiano (MENEZES et al., 2001; POLETTO e REIS, 2005; BROWN FREEMAN e FOXMAN, 2002) (Tabelas 6 e 7).

A recomendação do CLSI, 2010 (M100-S20), para a detecção de bactérias 
produtoras de $\beta$-lactamases de espectro estendido (ESBL), declara o seguinte: "Cepas de Klebsiella spp. e E. coli que produzem ESBL podem ser clinicamente resistentes a terapia com penicilinas, cefalosporinas, ou aztreonam apesar de uma aparente suscetibilidade in vitro para alguns destes agentes. Em todas as cepas produtoras de ESBL, as CIM para uma ou mais cefalosporinas de espectro estendido ou aztreonam deverão diminuir, na presença de ácido clavulânico. Dessa forma, este resultado deverá ser interpretado como um isolado resistente para todas as penicilinas, cefalosporinas, e aztreonam (NCCLS, 2002).

Considerando essas recomendações, pelo teste da dupla difusão, foi usado o ácido clavulânico como inibidor de $\beta$-lactamase associado à amoxicilina, e determinou-se que $79 \%, 91 \%$ e $94 \%$ das amostras foram positivas para as $\beta$ lactamases que degradam ceftazidima (CAZ), aztreonam (ATM) e cefotaxima (CTX), respectivamente. Assim, verificou-se que os $6 \%$ dos isolados clínicos de $E$. coli, isolados entre 2005 e 2007, eram produtores de ESBL (34/562). Minarini et al. (2007) estudaram 1481 isolados de infecções urinárias, entre 2000 a 2002, de pacientes não hospitalizados, em de Juiz de Fora - MG, destes 1126 eram E. coli e sete (07) isolados eram produtores de ESBL (0,6\%). Em estudo envolvendo 354 isolados clínicos de $E$. coli, de cinco unidades ambulatoriais e hospitalares, no período de outubro de 2002 a maio de 2003, no Rio de Janeiro, foram encontrados 8 isolados produtores de ESBL, ou seja, em 2,2\% desses (DEL PELOSO et al., 2003). Dentre 257 enterobactérias isoladas durante o período de 2000 a 2005, nove (09) eram E. coli produtoras de ESBL (3,5\%) (MINARINI et al., 2009). Nogueira et al.(2006) estudaram 498 isolados de pacientes de hospital universitário, Curitiba $\mathrm{PR}$, no período de 2003 a 2004, e determinaram que 7,2\% eram E. coli produtoras de ESBL. Em 838 isolados bacterianos, de pacientes hospitalizados, Passo Fundo RS, no período de julho a dezembro de 2007, foram identificadas 96 E. coli e 11,4\% destas eram ESBL (LAGO; FUENTEFRIA; FUENTEFRIA, 2010). Estes dados mostram um aumento da porcentagem de isolamento de $E$. coli produtoras de ESBL, no Brasil, durante o período de 2000 a 2007.

A detecção de resistência fenotípica in vitro à ESBL é clinicamente significante, pois organismos que produzem ESBL são resistentes aos antibióticos $\beta$ lactâmicos, incluindo as cefalosporinas de amplo espectro e o aztreonam (MENDES et al., 2000). A resistência varia grandemente entre os países, hospitais, unidades e 
até mesmo pacientes, pois a causa mais comum de resistência bacteriana aos agentes antimicrobianos $\beta$-lactâmicos é a produção de $\beta$-lactamases presente em plasmideo (LIVERMORE e WILLIAMS, 1996; BUSH; JACOBY; MEDEIROS, 1995).

Neste estudo foi detectado, que $100 \%$ dos isolados eram produtores de $\beta$ lactamases, o gene bla A prevalência do grupo CTX-M-2 em países da América Latina é citada por diversos autores (BONNET, 2004; LIVERMORE e HAWKEY, 2005; CANTÓN e COQUE, 2006; LIVERMORE 2007; CANTÓN et al., 2008). Uma alta prevalência deste genótipo foi encontrada em infecções humanas no Brasil e em outros países sulamericanos (SCHITO et al., 2009). Os resultados encontrados concordam com os de Mamlouk et al. (2006) que observaram em 35 isolados clínicos de E. coli, de pacientes em hospital da Tunísia, a presença do genótipo bla

Os resultados deste estudo mostraram também que em 20 isolados (62,5\%) ocorria a presença dos genes bla

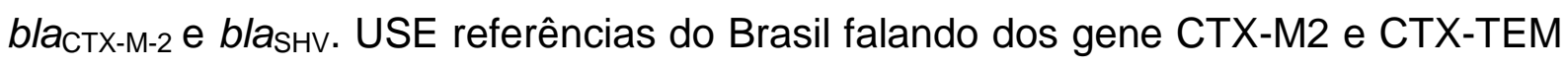
ou CTX-SHV. Estudo anterior revelou em 35 isolados clínicos de E. coli a presença dos genes bla $a_{\mathrm{CTX}-\mathrm{M}-15}$ e bla TEM-1, bla $a_{\mathrm{CTX}-\mathrm{M}-15}$ e blaoXA-1 e de blaCTX-M-16 e bla (MAMLOUK et al., 2006).

As beta-lactamases CTX-M são as ESBL mais amplamente difundidas, devido ao fato destes genes serem os que mais se disseminaram entre as enterobactérias (BONNET, 2004; POWER et al., 2004), em conseqüência do fenômeno da conjugação estas bactérias e a transferência de plasmideo de resistência. A disseminação dos genes bla CTX-M tem se tornado frequente não apenas em ambientes hospitalares, mas também na comunidade acarretando sérias consequências sobre a conduta terapêutica (MINARINI et al., 2007), uma vez que a presença de bactérias produtoras de ESBL podem estar associada ao uso indiscriminado de cefalosporinas de amplo espectro (RICE et al., 1996; RICE, 1999). Assim, é possível que o plasmídeo de resistência aos genes de $\beta$-lactamases seja o responsável por este fenótipo, entre as enterobactérias (WILLIAMS, 1999; BOU et al., 2002; DUVAL et al., 2009; MARCADÉ et al., 2009). O monitoramento da detecção fenotípica de isolados clínicos produtores de ESBL poderia limitar a disseminação desse perfil de resistência (MAMLOUK et al., 2006). Neste estudo, 12 pacientes (12/28) eram das Unidades de Terapias Intensivas (UTI), sendo detectada 
a presença do genótipo bla $\mathrm{C}_{\mathrm{CTX}-\mathrm{M}-2}$ em todos os isolados provenientes desses pacientes. As UTI, provavelmente, representem as áreas de maior risco de disseminação de bactérias Gram-negativas, com perfil de multiresistência aos antimicrobianos (BABINI e LIVERMORE, 2000), devido a freqüência maior do uso de antimicrobianos. Considerando o número de isolados por paciente na UTI, verificouse que ocorreu mais de um isolado por paciente, assim $16 \mathrm{E}$. coli foram isoladas (47\% - 16/34), enquanto 18 isolados eram das demais unidades do hospital (53\% 18/34) (Figura 8 e Tabela 8). Dessa forma, estes isolados clínicos de E. coli produtores de ESBL estavam disseminados em diferentes áreas do Hospital Universitário. Um estudo epidemiológico em hospitais brasileiros revelou que a mortalidade foi significativamente maior entre os pacientes que apresentavam isolados clínicos de Escherichia coli produtores de ESBL (SUPERTI; AUGUSTI; ZAVASCKI, 2009).

Dos isolados clínicos de E. coli produtores de ESBL neste estudo, 56\% eram de urina (19/34) e 44\% (15/34) de outras infecções (Tabela 7). Dos isolados clínicos de urina, 18 (95\%) exibiam o genótipo bla Gales, Sader e Jones (2002), em estudo multicêntrico realizado na América Latina, revelaram que infecções do trato urinário são as doenças mais comumente diagnosticadas em pacientes ambulatoriais. Desse modo, Escherichia coli é o principal uropatógeno dentre as bactérias Gram-negativas que podem causar ITU, incluindo cistites e pielonefrites (PATERSON, 2006), sendo responsável por 40 a $50 \%$ das infecções nosocomiais e por $80 \%$ a $90 \%$ destas infecções adquiridas na comunidade (RONALD, 2003; KALSI et al., 2003).

A disseminação de amostras de $E$. coli patogênicas na comunidade pode contribuir significativamente para a ocorrência de infecções por $E$. coli extraintestinais, incluindo às infecções do trato urinário (EYKYN e PHILLIPS, 1986).

Em um (01) isolado estudado (3\%-01/34), detectou-se a presença do gene blactX-M-15, em amostra de urina, do grupo filogenético B1, ou seja, de baixa virulência. Dessa forma, este isolado não era o clone denominado ST131, do sorogrupo O25, do grupo filogenético B2 e carreando o plasmídeo de multiresistência IncFII, isolado em vários países desde 2003, e associado a infecções comunitária e nosocomial, representando um risco a saúde pública (THOMSON; PREVAN; SANDERS, 1996; THOMSON e SANDERS, 1997; BOYD et 
al., 2004; KARISIK et al., 2008; CLERMONT et al., 2008, NICOLAS-CHANOINE et al., 2008; LAU; KAUFMANN; LIVERMORE, 2008; DUVAL et al., 2009; CLERMONT et al., 2009; PEIRANO e PITOUT, 2010; PEIRANO et al., 2010).

Os resultados deste estudo mostraram a presença do sorogrupo $\mathbf{0 2 5}$, do subtipo molecular b, em uma amostra isolada de secreção traqueal, do grupo filogenético B2, com a presença do gene de virulência iss e genótipo blacTX-M-2 $\mathrm{e}$ blaтем,. Na literatura existe a descrição do sorogrupo O25, freqüentemente associado à infecção urinária (DONNENBERG e WELCH, 1996; BLANCO et al., 1997; GUYER et al., 2000; MARRS; ZHANG; FOXMAN, 2005; ESPARIS et al., 2006), sendo o gene bla $\mathrm{CTX-M-15}$ identificado nestas amostras. Os resultados encontrados não confirmam estes dados.

Dentre as E. coli estudadas, apenas uma (01) (3\% - 1/34), possuía o genótipo bla $a_{\mathrm{CTX}-\mathrm{M}-1}$ e bla $\mathrm{T}_{\mathrm{TEM}}$, estes resultados corraboram com estudo anterior, onde o genótipo bla $a_{\text {CTX-M-1 }}$ não é disseminado com a mesma freqüência que o gene bla indivíduos hospitalizados (GNIADKOWSKI et al., 1998). Contudo, Enterobacteriaceae produtoras de ESBL do tipo CTX-M, com o fenótipo de resistência para cefotaxima, são amplamente relatados em diversas regiões geográficas, incluindo Europa, América do Sul e Oriente Médio (BAUERNFEIND; GRIMM; SCHWEIGHART, 1990; ISHII et al., 1995; BAUERNFEIND et al., 1996).

Um dos mecanismos de transferência horizontal desses genes de resistência é atribuído aos plasmídeos, que podem carrear genes de virulência como por exemplo para aerobactina, resistência sérica e antígeno K1 (BLANCO e BLANCO, 1993). Stawski (1990) demonstrou que a cápsula K1 impedia a fagocitose e podia estar envolvida na resistência sérica. Chuba et al. (1984) observaram que o gene iss aumentava em 20 vezes a capacidade de resistência das células bacterianas ao efeito do soro. O gene tsh é codifcado por plasmídeo de alto peso molecular (DOZOIS et al., 2000; STEHLING 2003; JOHNSON et al., 2006), principalmente pelo plasmídio ColV.

Neste estudo, detectou-se, a presença dos genes iss em $53 \%$,e os genes tsh e thr em 38\% dos 34 isolados clínicos de E. coli (ESBL) (Gráfico 3 e Figura 8). Estudos anteriores demonstraram que amostras de E. coli patogênicas para aves (APEC) têm uma similaridade com amostras de E. coli patogênicas extra-intestinais de humanos (EXPEC), devido ao fato da maioria dos genes de virulência de APEC 
serem semelhantes aos de ExPEC (MOULIN-SCHOULEUR et al., 2006; KARIYAWASAM; SCACCIANOCE; NOLAN, 2007). O gene iss foi encontrado em E. coli patogênica isolada de infecções extra-intestinais de animais e humanos (MINSHEW et al., 1978; BINNS; DAVIES; HARDY, 1979; SMITH e HUGGINS, 1980; AGUERO e CABELLO, 1983; AGUERO et al., 1989; FERNANDEZ-BEROS et al., 1990). Muitos genes de virulência de amostras de APEC também estiveram presentes em isolados de ExPEC de humanos, associados às infecções do trato urinário e meningite neonatal, bem como, amostras de ExPEC associadas às infecções em animais (SCHOULER et al., 2004).

O gene iss (increased serum survival) é comumente detectado em APEC (ELLIS; ARP; LAMONT, 1988; IKE et al., 1990; WOOLEY et al., 1993; FANTINATTI; SILVEIRA; CASTRO, 1994; NGELEKA et al., 1996; PARREIRA; ARNS; YANO, 1998; ELLIS et al., 1988; DOZOIS et al., 2000; NOLAN et al., 2003; JOHNSON; WANNEMUEHLER; NOLAN, 2008a) e os genes iss e tsh foram encontrados em maior proporção em E. coli de aves doentes, do que nos isolados de $E$. coli de aves sadias (PFAFF-MCDONOUGH et al., 2000). Fernandez-Beros et al. (1990) detectaram o gene iss em amostras intestinais e sistêmicas. O gene tsh foi encontrado em $46 \%$ de amostras de APEC, sendo que nove (09) eram amostras comensais (MAURER et al., 1998). Outros estudos revelaram que o gene thr está comumente envolvido na virulência de UPEC (HENDERSON e NATARO, 2001; HENDERSON et al., 2004).

Analisando a presença desses genes com os isolados clínicos associados às infecções do trato urinário, obtidos neste estudo, verificou-se que 53\% (10/19) tinham o gene iss e 42\% (8/19) os genes tsh e thr nos mesmos isolados (Figura 8 e Tabela 8). Estes resultados não corroboram com os de Ewers et al. (2007) que detectaram o gene iss e, o gene tsh em menor porcentagem em amostras de UPEC, respectivamente, $25,8 \%$ e $4,5 \%$, sendo o gene thr determinado em $54,5 \%$ das UPEC, foram estudadas amostras de APEC, UPEC e NMEC.

Os genes de virulência das amostras de ExPEC podem ser transferidos de forma horizontal, entre as cepas, pelo plasmídeo ou pelas ilhas de patogenicidade (PAIs) que contém genes que codificam múltiplos fatores de virulência (JOHNSON et al., 2001; PITOUT et al., 2005; ANANIAS e YANO, 2008), e alguns codificam o autotransporte e secreção de toxinas (BAUER et al, 2002). As amostras de ExPEC 
mostram uma relação genética com amostras de UPEC e APEC, e são provavelmente relacionadas com as amostras de SePEC por apresentarem os mesmos fatores de virulência, comumente encontrados em UPEC e APEC, porém o perfil genético das amostras de SePEC ainda não foi elucidado (ANANIAS e YANO, 2008).

Este estudo verificou que o clone do grupo III (PFGE) foi encontrado na mesma paciente, isolado das amostras de sangue e urina, coletadas no mesmo dia, detectou-se a presença dos genes iss, tsh e thr, portanto, este clone pode ter se disseminado da urina para o sangue, e a presença do gene iss pode ter contribuído para que este isolado tenha escapado dos mecanismos microbicidas presentes no sangue, como o sistema complemento e os peptídeos antimicrobianos, mecanismos estes já descritos na literatura (HACKER et al., 1990; BLUM et al., 1994; HORNE et al., 2000). Além disso, os resultados da PFGE revelaram entre os 34 isolados clínicos de E. coli que havia 31 clones diferentes, e que isolados diferentes foram recuperados de um mesmo paciente (Tabelas 3 e 8 e Figura 8). Estes resultados corroboram os de Minarini et al. (2007) que encontraram, através da técnica do PFGE com Xbal, três (03) clones diferentes em um mesmo paciente, mas não corrobora o resultado encontrado por estes autores, de que um mesmo clone foi detectado em pacientes diferentes. Outro estudo realizado pelo mesmo grupo revelou a presença de perfis diferentes em 21 indivíduos com infecção do trato urinário na comunidade, sendo que a maioria era do sexo feminino $(70 \%)$ e estavam relacionados aos genótipos bla fenótipos de multiresistência (MINARINI et al., 2009). Neste estudo, detectou-se que o genótipo bla СтX-M-2 foi o mais prevalente (94\%) encontrado em 95\% (18/19) dos isolados de infecções do trato urinário, sendo que 58\% (11/19) destes eram do sexo feminino (Tabela 8). Os resultados encontrados neste estudo também não concordam com os de Mamlouk et al. (2006) que revelaram a presença do mesmo clone em diferentes pacientes, usando a técnica de PFGE com a enzima Hpal.

As amostras de Escherichia coli extra-intestinal distinguem-se das amostras de E. coli comensal e de amostras de E. coli patogênicas intestinais, sendo observado por alguns autores distinções na epidemiologia e grupos filogenéticos de E.coli (PICARD; GARCIA; GOURIOU, 1999; RUSSO e JOHNSON, 2000; RUSSO e JOHNSON, 2003; VILA et al., 2002; SOTO et al., 2006). 
Analisando os grupos filogenéticos dos 34 isolados clínicos de E. coli produtores de ESBL, 12\% (4/34) eram do grupo B2 e 18\% (06/34) do grupo D. Dentre os isolados clínicos de urina, apenas um (01) (5\% - 1/19) era do grupo B2 e quatro (04) $(21 \%$ - 4/19) do grupo D (Tabela 7 e Figura 8). Estes resultados concordam com os de Johnson e Russo (2005) que afirma que estes grupos filogenéticos mostram um perfil de virulência com potencial de patogenia e freqüentemente são responsáveis por infecções aguda do trato urinário, pois ocorreram em menor freqüência nos isolados de urina estudados.

Considerando todos os isolados clínicos estudados verificou-se que 18 (53\% - 18/34) eram do grupo filogenético B1 e seis (18\% - 06/34) do grupo A, ou seja, $71 \%$ destes isolados eram de grupos filogenéticos encontrados na maioria das $E$. coli comensais (LECOINTRE et al., 1998; PICARD; GARCIA; GOURIOU, 1999; JOHNSON et al., 2001; JOHNSON et al., 2003b; KARISIK et al., 2008). Entre os isolados clínicos de urina, $11(58 \%$ - 11/19) e três (03) (16\% - 3/19), eram dos grupos B1 e A, respectivamente.

Rodriguez-Siek et al. (2005) estudaram Escherichia coli patogênica para aves (APEC) e Escherichia coli uropatogênicas (UPEC), verificaram que entre as APEC, $38 \%$ eram dos grupos A, $15,5 \%$ do grupo B1, $18,5 \%$ do grupo $\mathbf{B 2}$ e $28,1 \%$ do grupo D. Nos isolados de UPEC de humanos, 10,5\% eram dos grupos A, $6 \%$ do grupo B1, $65 \%$ do grupo B2 e $18,5 \%$ do grupo D, assim, $83,5 \%$ dos isolados de infecções do trato urinário eram dos grupos B2 e D. Os resultados encontrados neste estudo não corroboram estes resultados, pois se detectou nos isolados clínicos de infecção do trato urinário que 74\% (14/19) eram dos grupos B1 e A e 26\% (05/19) dos grupos B2 e D (Tabela 7). Dessa forma, os isolados dos grupos B1 e A, possivelmente eram microrganismos oportunistas e da microbiota intestinal, embora $47 \%$ destes apresentassem um potencial de virulência pela presença de genes iss em nove isolados (09/19).

Ron et al. (2006) sugeriram que amostras de ExPEC isoladas de aves poderiam ser patógenos zoonóticos e Rodriguez-Siek et al. (2005) levantaram a hipótese de que certas amostras de APEC têm o potencial para infectar humanos e/ou aves domésticas, podendo atuar como um reservatório para os genes de virulência para ExPEC, podendo haver uma relação entre os fatores de virulência que uma cepa possui e o grupo filogenético a que ela pertence (JOHNSON e 
STELL, 2000; JOHNSON et al., 2001). Tais similaridades no perfil de virulência encontrados em amostras de APEC e em outros subpatotipos de ExPEC fomentam o potencial desse risco zoonótico (MOULIN-SCHOULEUR et al., 2006; JOHNSON et al., 2008; MORA et al., 2009), e estes podem ter sido transmitidos por alimentos causando doenças em humanos (JOHNSON et al., 2006; JOHNSON et al., 2007b; MANGES et al., 2007; JOHNSON et al, 2009), pois amostras de ExPEC foram encontradas em alimentos no varejo e produtos avícolas (JOHNSON et al., 2003a; JOHNSON et al., 2003b; JOHNSON e RUSSO, 2005; HANNAH et al., 2009; JOHNSON et al., 2009), e pelo menos um estudo encontrou amostras isoladas de aves, idênticas as isoladas de humanos (JOHNSON et al., 2006).

Entretanto, outro estudo mostra que ExPEC isoladas de humanos são distintas das amostras isoladas de aves (GRAZIANI et al., 2009) e que o consumo de produtos avícolas ou o contato com aves não estão correlacionados com a colonização de E.coli exibindo perfil de multiresistência aos antimicrobianos (JOHNSON et al., 2007a).

Considerando que existe uma correlação entre as cepas de E. coli com os grupos filogenéticos e a presença de genes de virulência, e que a aquisição desses genes ocorreu através de mecanismos de transferência horizontal em períodos de pressão seletiva do uso dos antimicrobianos (PICARD; GARCIA; GOURIOU, 1999; JOHNSON e STEEL, 2000), é possível que cepas comensais tenham adquirido esses genótipos de virulência e resitência, passando a ser amostras patogênicas em potencial (JOHNSON e RUSSO, 2002).

Além disso, amostras de ExPEC constituem um problema de saúde pública, especialmente devido a alta incidência de resistência antimicrobiana que na maioria das vezes são mediadas por plasmídeos (ANANIAS e YANO, 2008). Esses plasmideos carregando genótipos de resistência, com possibilidade de estarem disseminando genes de multiresistência em um hospital requer um melhor monitoramento, para que se possam estabelecer medidas preventivas que são extremamente necessárias contra a morbidade e o impacto econômico destas infecções (BINGEN-BIDOIS et al., 2002).

Este estudo mostrou que 6\% (34/562) dos isolados clínicos de E. coli eram produtores de beta-lactamases de espectro estendido, 100\% possuíam o gene de resistência CTX-M, e em 65\% (22/34) destes isolados carregavam dois genes de 
resistência. Os grupos filogenéticos B1 e A (baixa virulência) foram determinados em 71\% (24/34) destes, sendo que dois genes de resistência aos $\beta$-lactâmicos foram encontrados em $47 \%$ (16/34) dos isolados. Como estes isolados classificaram-se no grupo de microrganismos comensais, é possível que este fenômeno tenha ocorrido pela pressão do uso de antimicrobianos, como conseqüência da automedicação, uma prática bastante difundida em nossa sociedade, ou também pelo fato de que $53,5 \%$ (15/28) dos pacientes eram idosos e provavelmente já tenham recebido medicamentos antimicrobianos ao longo de suas vidas. A detecção de dois genes de resistência mostra a importância do monitoramento da resitência aos $\beta$-lactâmicos em Escherichia coli. 


\section{CONCLUSÕES}

1. Escherichia coli produtoras de beta-lactamases de espectro estendido isoladas de pacientes (ambulatoriais e hospitalizados) com infecções extra-intestinais foram encontradas em um Hospital Universitário de São Paulo.

2. Os isolados clínicos de Escherichia coli produtores de ESBL carreavam os genes bla $a_{\mathrm{CTX}-\mathrm{M}-2}, b / a_{\mathrm{CTX}-\mathrm{M}-1}, b / a_{\mathrm{CTX}-\mathrm{M}-15}, b / a_{\mathrm{TEM}}$, bla $a_{\mathrm{SHV}}$.

3. Os grupos filogenéticos B1 e A (baixa virulência) ocorreram com maior freqüência entre os isolados clínicos de Escherichia coli ESBL.

4. O sorogrupo $\mathrm{O} 25$ (internacional), subtipo molecular $b$, foi isolado de secreção traqueal, sendo de baixa ocorrência entre os isolados clínicos de $E$. coli estudados.

5. A análise por PFGE demonstrou que existiu uma grande diversidade genotípica entre os 34 isolados clínicos de E. coli produtores de beta-lactamases de espectro estendido recuperados de pacientes com infecções do trato urinário e outras infecções de um Hospital Universitário de São Paulo.

6. A alta incidência de isolados clonalmente não relacionados, pertencentes aos grupos filogenéticos $\mathrm{A}$ e $\mathrm{B} 1$, de baixa virulência, sugere que cepas comensais de $E$. coli podem adquirir genes de resistência do tipo bla contribuindo no estabelecimento e no prognóstico de infecções extra-intestinais, principalmente do trato urinário. 


\section{REFERÊNCIAS*}

AGÜERO, M. E.; CABELLO, F. C. Relative Contribution of ColV Plasmid and K1 Antigen to the Pathogenicity of Escherichia coli. Infection and Immunity, v. 40, n. 1, p. 359-368, 1983.

AGUERO, M. E.; DE LA FUENTE, G.; VIVALDI, E.; CABELLO, F. C ColV increases the virulence of Escherichia coli K1 strains in animal models of neonatal meningitis and urinary infection. Medical Microbiology Immunology, v. 178, n. 4, p. 211-216. 1989.

ALMEIDA, M. C.; SIMÕES, M. J. S.; RADDI, M. S. G. Ocorrência de infecção urinária em pacientes de um hospital universitário. Revista de Ciências Farmacêuticas Básica e Aplicada, v. 28, n. 2, p. 215-219, 2007.

AMBLER, R. P. The structure of b-lactamases. Philos. Trans. R. Soc. London Ser.(Biol), v. 289, p. 321-331, 1980.

ANDERSON, G. G.; DODSON, K. W.; HOOTON, T.M.; HULTGREN S. J. Intracellular bacterial communities of uropathogenic Escherichia coli in urinary tract pathogenesis. TRENDS in Microbiology, v. 12, n. 9, p. 424-430, 2004.

ANDRADE, S. S.; JONES, R. N.; GALES, A. C.; SADER, H. S. Increasing prevalence of antimicrobial resistance among Pseudomonas aeruginosa isolates in Latin American medical centres: 5 year report of the SENTRY Antimicrobial Surveillance Program (1997-2001). Journal of Antimicrobial Chemotherapy, v. 52, n. 1, p. 140-141, 2003.

ANDREU, A.; ALÓS J.I.; GOBERNADO, M.; MARCO, F.; LA ROSA, M.; GARCÍARODRIGUES, J.A. Etiologia y sensibilidad a los antimicrobianos de los uropatogenos causantes de la infeccion urinaria baja adquirida en la comunidad. Enfermedades Infecciosas y Microbiología, v. 23, n. 1, p. 4-9, 2005.

ANANINAS, M.; YANO, T. Serogroups and virulence genotypes of Escherichia coli isolated from patients with sepsis. Brazilian Journal of Medical and Biological Research, v. 41, n. 10, p. 877-883, 2008.

*De acordo com: ASSOCIAÇÃO BRASILEIRA DE NORMAS TÉCNICAS. NBR 6023: informação e documentação: referências: elaboração. Rio de Janeiro, 2002. 
BABIC, M.; HUJER, A.; BONOMO, R. What's new on antibiotic resistance? Focus on beta-lactamases. Drug Resistance Updates, v. 9, n. 3, p. 142-156, 2006.

BABINI, G. S.; LIVERMORE, D. M. Antimicrobial resistance amongst Klebsiella spp. Collected from intensive care units in Southern and Western Europe in 19971998. Journal of Antimicrobial Chemotherapy, v. 45, n. 2, p. 183-189. 2000.

BACHUR. R.; HARPER, M.B. Reliability of the Urinalysis for Predicting Urinary Tract Infections in Young Febrile Children. Archives of Pediatrics Adolescent Medicine, v. 155, n. 1, p. 60-65, 2001.

BAHRANI-MOUGEOT, F. K.; GUNTHER IV, N. W.; DONNENBERG, M. S.; MOBLEY, H. L. T. Uropathogenic Escherichia coli. In: DONNENBERG, M.S (Ed), Escherichia coli: virulence mechanisms of a versatile pathogen. Academic Press, San Diego, Calif, v. 5, p. 23-268, 2002.

BAILEY, R. R. Vesicoureteric reflux and reflux nephropathy. Kidney Internacional, v. 44, n. 42, p. 80-85, 1993.

BAUER A. W.; KIRBY, W. M. M.; SHERRIS, J. C. Antibiotic susceptibility testing by a standardized single disk method. American Journal of Clinical Pathology, v. 45, n. 4, p. 493-496, 1966.

BAUER, R. J.; ZHANG, L.; FOXMAN, B.; SIITONEN, A.; JANTUNEN, M.E.; SAXEN, H.; MARRIS, C. F. J. Molecular epidemiology of 3 putative virulence genes for Escherichia coli urinary tract infection - usp, iha and iro $\mathrm{N}$ ( $E$. coli). The Journal of Infectious Diseases, v. 185, n. 10, p. 1521-1524, 2002.

BAUERNFEIND, A.; GRIMM, H.; SCHWEIGHART, S. A new plasmidic cefotaximase in a clinical isolate of Escherichia coli. Infection, v. 18, n. 5, p. 294298, 1990.

BAUERNFEIND, A.; STEMPLINGER, I.; JUNGWIRTH,R.; MANGOLD, P.; AMANN,S.; AKALIN, E.; ANG O.; BAL, C.; CASELLAS, J. M.Characterization of b-Lactamase Gene blaPER-2, Which Encodes an Extended-Spectrum Class A bLactamase. Antimicrobial Agents and Chemotherapy, v. 40, n. 3, p. 616-620, 1996.

BIANCO, G.; MACHADO, A. L.; PETRY, J. L. Padrões de sensibilidade e resistência da Escherichia coli frente a nove antimicrobianos em comunidades no Rio Grande do Sul. Revista Pharmácia Brasileira, v. 14, n. 10, p. 82-87, 2002. 
BIEDENBACH, D.; MOET, G.; JONES, R. Occurrence and antimicrobial resistance pattern comparisons among bloodstream infection isolates from the SENTRY Antimicrobial Surveillance Program (1997-2002). Diagnostic Microbiology and Infectious Disease, v. 50, n. 1, p. 59-69, 2004.

BINNS, M. M.; DAVIES, D. L.; HARDY, K. G. Cloned fragments of the plasmid ColV,I-K94 specifying virulence and serum resistance. Nature, v. 279, n. 5716, p. 778-781, 1979.

BINGEN-BIDOIS, M.; CLERMONT, O.; BONACORSI, S.; TERKI, M.; BRAHIMI, N.; LOUKIL, C.; BARRAUD, D.; BINGEN, E. Phylogenetic analysis and prevalence of urosepsis strains of Escherichia coli bearing pathogenicity islandlike domains. Infection and Immunity, v. 70, n. 6, p. 3216-3226, 2002.

BISSON, G.; FISHMAN, N. O.; PATEL, J. B.; EDELSTEIN, P. H.; LAUTENBACH, E. Extended spectrum beta-lactamase-producing Escherichia coli and Klebsiella species: risk factors for colonization and impact of antimicrobial formulary interventions on colonization prevalence. Infection Control and Hospital Epidemiology, v. 23, n. 5, p. 254-260, 2002.

BLANCO, J.; BLANCO, M. Escherichia coli enterotoxigenicos, necrotoxigenicos y verotoxigenicos de origen humano y bovino: patogénesis, epidemiologia y diagnóstico microbiológico. Edita: Lugo, 1993. $361 \mathrm{p}$.

BLANCO, M.; BLANCO, J. E.; BLANCO, ALONSO, M. P.; BLANCO, J. Virulence factors and $O$ groups of Escherichia coli isolates from patients with acute pyelonephritis, cystitis and asymptomatic bacteriuria. European Journal of Epidemiology, v. 12, n. 2, p. 191-198, 1996.

BLANCO, M.; BLANCO, J. E.; ALONSO, M.P.; MORA, A.; BALSALOBRE, C.; MUÑOA, F.; JUAREZ, A.; BLANCO, J. Detection of pap, sfa and afa adhesinencoding operons in uropathogenic Escherichia coli strains: relationship with expression of adhesins and production of toxins. Research in Microbiology, v. 148, n. 9, p. 745-755, 1997.

BLUM, G.; OTT, M. ; LISCHEWSKI, A.; RITTER, A. ; IMRICH, H.; TSCHAPE, H. ; HACKER, J. Excision of large DNA regions termed pathogenicity islands from tRNA-specific loci in the chromosome of an Escherichia coli wild-type pathogen. Infection and Immunity, v. 62, n. 2, p. 606-614, 1994. 
BLUM, G.; FALBO, V.; CAPRIOLI, A.; HACKER, J. Gene clusters encoding the cytotoxic necrotizing factor type 1, fimbriae and a-hemolysin from the pathogenicity island II of the uropathogenic Escherichia coli strain J96. FEMS Microbiology Letters, v. 126, n. 2, p. 189-196, 1995.

BOEBM, D. F.; WELCH, R. A.; SNYDER, I.S. Domains of Escherichia coli hemolysin (HlyA) involved in binding of calcium and erythrocyte membranes. Infection and Immunity, v. 58, n. 6, p. 1959-1964, 1990.

BONNET,R.; SAMPAIO, J. L. M.; LABIA, R.; DE CHAMPS, C.; SIROT, D.; CHANAL, C.; SIROT, J. A Novel CTX-M $\beta_{\text {-Lactamase (CTX-M-8) in Cefotaxime- }}$ Resistant Enterobacteriaceae Isolated in Brazil. Antimicrobial Agents and Chemotherapy, v. 44, n. 7, p. 1936-1942, 2000.

BONNET, R. Growing group of extended-spectrum $\beta$-lactamases: the CTX-M enzymes. Antimicrobial Agents and Chemotherapy, v. 48, n. 1, p. 1-14, 2004.

BOQUET, P. The cytotoxic necrotizing factor 1 (cnf1) from Escherichia coli. Toxicon, v. 39, n. 11, p. 1673-1680, 2001.

BOU, G.; CARTELLE, M.; TOMAS, M.; CANLE, D.; MOLINA, F.; MOURE, R.; EIROS, J. M.; GUERRERO, A. Identification and broad dissemination of the CTXM-14 B lactamase in different Escherichia coli strains in the northwest area of Spain. Journal of Clinical Microbiology, v. 40, n. 11, p. 4030-4036, 2002.

BOWER, P. A.; SCOPEL, C. O.; JENSEN, E. T.; DEPAS, M. M.; MCLELLAN, S. $\mathrm{L}$. Detection of genetic markers of fecal indicator bacteria in lake michigan and determination of their relationship to Escherichia coli densities using standard microbiological methods. Applied and Environmental Microbiology, v. 71, n. 12, p. 8305-8313, 2005.

BOYD, D. A.; TYLER, S.; CHRISTIANSON, S.; MCGEER, A.; MATTHEW, P. M.; WILLEY B. M.; BRYCE E.; GARDAM, M.; NORDMANN, P.; MULVEY, M. R.; Canadian Nosocomial Infection Surveillance Program, Health Canada. Complete nucleotide sequence of a 92-kilobase plasmid harbouring the CTX-M-15 extended-spectrum b-lactamase involved in an outbreak in long-term-care facilities in Toronto, Canada. Antimicrobial Agents and Chemotherapy, v. 48, n. 10, p. 3758-3764, 2004.

BRADFORD, P. A.; CHERUBIN, C. E.; IDEMYOR, V.; RASMUSSEN, B. A.; $\mathrm{BUSH}, \mathrm{K}$. Multiply resistant Klebsiella pneumoniae strains from two Chicago hospitals: identification of the extended-spectrum TEM-12 and TEM-10 ceftazidime-hydrolyzing beta-lactamases in a single isolate. Antimicrobial Agents and Chemotherapy, v. 38, n. 4, p. 761-766, 1994. 
BRADFORD, P. A.; URBAN, C.; MARIANO, N.; PROJAN, S. J.; RAHAL, J. J.; $\mathrm{BUSH}, \mathrm{K}$. Imipenem resistance in Klebsiella pneumoniae is associated with the combination of ACT-1, a plasmid mediated AMP C beta-lactamase and the loss of an outer membrane protein. Antimicrobial Agents and Chemotherapy, v. 41, n. 3, p. 563-569, 1997.

BRADFORD, P. A. Extended-spectrum beta-lactamases in the 21st century: characterization, epidemiology, and detection of this important resistance threat. Clinical Microbiology, v. 14, n. 4, p. 933-951, 2001.

BRIAN, S. A.; CURRY, S. H. M. D. Urinary Tract Infection in Children. American Family Physician, v. 72, n. 12, p. 2483-2488, 2005.

BROWN, P.; FREEMAN, A.; FOXMAN, B. Prevalence and predictors of trimethoprim sulfametaxazole resistance among uropathogenic Escherichia coli isolates in Michigan. Clinical Infectious Diseases, v. 34, n. 8, p. 1061-1066, 2002.

BUSH, K. B-lactamase inhibitors from laboratory to clinic. Clinical Microbiology, v.1, n. 1, p. 109-123, 1988.

BUSH, K.; MACALINTAL, C.; RASMUSSEN, B. A.; LEE, V. J.; YANG, Y. Kinetic interactions of tazobactam with beta-lactamases from all major structural classes. Antimicrobial Agents and Chemotherapy, v. 37, n. 4, p. 851-858, 1993.

BUSH, K.; JACOBY, G. A.; MEDEIROS, A. A. A functional classification scheme for $b$-lactamases and its correlation with molecular structure. Antimicrobial Agents and Chemotherapy, v. 39, n. 6, p. 1211-1233, 1995.

CAMARGO, I. L.; BARATELLA C; MASCHIETO, A. Diagnóstico bacteriológico de infecção do trato urinário: uma revisão técnica. Revista Medicina, v. 34, n. 1, p. 70-78, 2001.

CANTÓN, R.; COQUE, T. M. The CTX-M $\beta$-lactamases pandemic. Current Opinion in Microbiology, v. 9, n. 5, p. 466-475, 2006.

CANTÓN R.; NOVAIS, A.; VALVERDE, A.; MACHADO, E.; PEIXE, L.; BAQUERO, F.; COQUE, T.M. Prevalence and spread of extended-spectrum $\beta$ lactamase-producing Enterobacteriaceae in Europe. Clinical Microbiology and Infection, v. 14, n. 1, p. 144-153, 2008. 
CARBONETTI, N. H.; BOONCHAI, S. L.; ROBERTS, P.L.; STAMM, W.E. Aerobactin-mediated iron uptake by Escherichia coli isolates from human extraintestinal infections. Infection and Immunity, v. 51, n. 3, p. 966-968, 1986.

CERGOLE-NOVELLA, M. C.; GUTH, B. E.; CASTANHEIRA, M.; PIGNATARI, A. C. First description of bla(CTX-M-14)- and bla(CTX-M-15)-producing Escherichia coli isolates in Brazil. Microbial drug resistance, v. 16, n. 3, p. 177-184, 2010.

CHAPMAN, P. A.; ELLIN, M.; ASHTON, R.; SHAFIQUE, W. Comparison of culture, PCR and immunoassays for detecting Escherichia coli 0157 following enrichment culture and immunomagnetic separation performed on naturally contaminated raw meat products. International Journal of Food Microbiology, v. 68 , n. 1-2, p. 11-20, 2001.

CHUBA, P. J.; LEON, M. A.; BANERJEE, A.; PALCHAUDHURI, S. Cloning and DNA sequence of plasmid determinant iss, coding for increased serum survival and surface exclusion, which has homology with lambda DNA. Molecular \& general genetics, v. 216, n. 2-3, p. 287-292, 1989

CLERMONT, O.; BONACORSI, S.; BINGEN, E. Rapid and simple determination of the Escherichia coli phylogenetic group. Applied and Environmental Microbiology, v. 66, n. 10, p. 4555-4558, 2000.

CLERMONT, O.; JOHNSON, J. R.; MENARD, M.; DENAMUR, E. Determination of Escherichia coli $O$ types by allele-specific polymerase chain reaction: application to the $O$ types involved in human septicemia. Diagnostic Microbiology and Infectious Disease, v. 57, n. 2, p.129-136, 2007.

CLERMONT, O.; LAVOLLAY, M.; VIMONT, S.; DESCHAMPS, C.; FORESTIER, C.; BRANGER, C.; DENAMUR, E.; ARLET, G. The CTX-M-15-producing Escherichia coli diffusing clone belongs to a highly virulent B2 phylogenetic subgroup. Journal of Antimicrobial Chemotherapy, v. 61, n. 5, p. 1024-1028, 2008.

CLERMONT, O.; DHANJI, H.; UPTON, M.; GIBREEL, T.; FOX, A.; BOYD, D. A.; MULVEY, M. R.; NORDMANN, P.; RUPPÉ, E.; SARTHOU, J. L.; FRANK, T.; VIMONT, S.; ARLET, G.; BRANGER, C.; WOODFORD, N.; DENAMUR, E. Rapid detection of the O25b-ST131 clone of Escherichia coli encompassing the CTX-M15-producing strains. Journal of Antimicrobial Chemotherapy, v. 64, n. 2, p. 274-277, 2009.

CLINICAL AND LABORATORY STANDARDS INSTITUTE (CLSI).Performance standards for antimicrobial susceptibility testing, (M100-S16), v. 26, n. 3 , 2006. 16th Informational Supplement. 
CLINICAL AND LABORATORY STANDARDS INSTITUTE (CLSI).Performance standards for antimicrobial susceptibility testing, (M100-S20), v. 30, n. 1, 2010. 20th Informational Supplement.

CORKILL, J. E.; CUEVAS, L. E.; GURGEL, R. Q.; GREENSILL, J.; HART, C. A. SHV-27, a novel cefotaxime-hydrolysing beta-lactamase, identified in Klebsiella pneumoniae isolates from a Brazilian hospital. The Journal of Antimicrobial Chemotherapy, v. 47, n. 4, p. 463-465. 2001.

COSGROVE, S. E.; KAYE, K. S.; ELIOPOULOUS, G. M.; CARMELI, Y. Health and economic outcomes of the emergence of third-generation cephalosporin resistance in Enterobacter species. Archives of Internal Medicine, v. 162, n. 2, p. 185-190, 2002.

COUNDRON, P. E.; MOLAND, E. S.; SANDERS, C. C. Occurrence and detection of extended-spectrum $\beta$-lactamases in members of the family Enterobacteriaceae at a Veterans Medical Centers: seek and you may find. Journal of Clinical Microbiology, v. 35, n. 10, p. 2593-2597, 1997.

D'AGATA, E. M. Rapidly rising prevalence of nosocomial multidrugresistant, Gram-negative bacilli: a 9-year surveillance study. Infection Control and Hospital Epidemiology, v. 25, n. 10, p. 842- 846, 2004.

DALBOSCO, V.; SROUGI, M.; DALL'OGLIO, M. Infecções do trato urinário. Revista Brasileira de Medicina, v. 60, n. 6, p. 320-328, 2003.

DASHE, J. S; GILSTRAP, L. C. Antibiotic use in pregnancy. Obstetetrics \& Gynecology Clinics of North America, v. 24, n. 3, p. 617-629, 1997.

DECOUSSER, J. W.; POIREL, L., NORDMANN, P. Characterization of a chromosomally encoded extended-spectrum class A beta-lactamase from Kluyvera cryocrescens. Antimicrobial Agents and Chemotherapy, v. 45, n. 12, p. 3595-3598, 2001.

DEL PELOSO, P. F.; LEITE, C. C. F.; SILVA, H. P.; FILHO, H. M. T. Importância da utilização de metodologias para a detecção de ESBL em espécies de Enterobactérias. Revista Newslab, n. 61, p. 118-128, 2003.

DICK, P. T.; FELDMAN, W. Routine diagnostic imaging for childhood urinary tract infections: A systematic overview. Journal of Pediatrics, v. 128, n. 1, p. 15-22, 1996. 
DIEKEMA, D. J.; PFALLER, M. A.; JONES, R. N.; DOERN, G. V.; WINOKUR, P. L.; GALES, A. C. Survey of bloodstream infections due to gram-negative bacilli: frequency of occurrence and antimicrobial susceptibility of isolates collected in the United States, Canada, and Latin America for the SENTRY Antimicrobial Surveillance Program, 1997. Clinical Infectious Diseases, v. 29, n. 3, p. 595607, 1999.

DOBRINDT, U.; BLUM-OEHLER, G.; NAGY, G.; SCHNEIDER, G.; JOHANN, A.; GOTTSCHALK, G.; HACKER J. Genetic structure and distribution of four pathogenicity islands (PAI 1536 to PAI IV536) of uropathogenic Escherichia coli strain 536. Infection and Immunity, v. 70, n. 11, p. 6365-6372, 2002.

DOZOIS, C.M.; CURTISS , R. Pathogenic diversity of Escherichia coli and the emergence of "exotic" island in the gene stream. Veterinary Research, v. 30, n. 2-3, p. 157-179, 1999.

DOZOIS, C. M.; DHO-MOULIN, M.; BREE, A.; FAIRBROTHER, J. M.;DESAUTELS, C.; CURTISS, III. R. Relationship between the Tsh autotransporter and pathogenicity of avian Escherichia coli and localization and analysis of the Tsh genetic region Infection and Immunity, v. 68, n. 7, p. 41454154, 2000.

DONNENBERG, M. S.; WELCH, R. A. Virulence determinants in uropathogenic Escherichia coli. In: MOBLEY, H. L. T.; WARREN, J. W. (Ed.). Urinary tract infections: Molecular Pathogenesis and Clinical Management. Washington, DC: ASM Press, 1996. p.135-174.

DRASAR, B. S.; HILL, M. J. (Ed). Human intestinal flora. London: Academic Press, 1974. xii, $263 \mathrm{p}$.

DROPA, M.; BALSALOBRE, L. C.; LINCOPAN, N.; MAMIZUKA, E. M.; MURAKAMI, T.; CASSETTARI, V. C.; FRANCO, F.; GUIDA, S. M.; BALABAKIS, A. J.; PASSADORE, L. F.; SANTOS, S. R.; MATTÉ, G. R.; MATTÉ M. H. Extended-spectrum beta-lactamases among Enterobacteriaceae isolated in a public hospital in Brazil. Revista do Instituto de Medicina Tropical de São Paulo, v. 51, n. 4, p. 203-209, 2009.

DROPA, M.; BALSALOBRE, L. C.; LINCOPAN, N.; MAMIZUKA, E. M.; CASSETARI, V. C.; MATTÉ, M. H. Emergence of Klebsiella pneumoniae carrying the novel extended-spectrum $\beta$-lactamase gene variants blasHV-40, blaTEM-116 and the class 1 integron-associated bla $a_{\text {GES-7 }}$ in Brazil. Clinical Microbiology and Infection, v. 16, n. 6, p. 630-632, 2010. 
DUVAL, V.; MAIGA, I.; MAIGA, A.; GUILLARD, T.; BRASME, L.; FORTE, D.; MADOUX, J.; VERNET-GARNIER, V.; DE CHAMPS, C. High Prevalence of CTXM-Type $\beta$-Lactamases among Clinical Isolates of Enterobacteriaceae in Bamako, Mali. Antimicrobial Agents and Chemotherapy, v. 53, n. 11, p. 4957-4958, 2009.

EDELSTEIN, M.; PIMKIN, M.; PALAGIN, I.; EDELSTEIN, I.; STRATCHOUNSKI, L. Prevalence and molecular epidemiology of CTX-M extended-spectrum betalactamase-producing Escherichia coli and Klebsiella pneumoniae in Russian hospitals. Antimicrobial Agents and Chemotherapy, v. 47, n. 12, p. 3724-3732, 2003.

ELLIS, M. G.; ARP, L. H.; LAMONT, S. J. Serum resistance and virulence of Escherichia coli isolated from turkeys. American Journal of Veterinary Research, v. 49, n. 12, p. 2034-2037, 1988.

ESPARIS, C. M.; TEIXEIRA, L. M.; IRINO K.; GIL P. F.; ALMEIDA M. M. T. B.; LOPES G. S.; BRAVO V. L. R.; PACHECO R. S.; REGUA-MANGIA, A. H. Biological and molecular characteristics of uropathogenic Escherichia coli strains isolated in the City of Rio de Janeiro. Revista da Sociedade Brasileira de Medicina Tropical, v. 39, n. 6, p. 573-576, 2006.

EWERS C.; JANSEN, T.; KIESLING, S.; PHILIPP, H-C.; WIELER, L. Rapid detection of virulence-associated genes in avian pathogenic Escherichia coli by multiplex polymerase chain reaction. Avian Diseases, v. 49, n. 2, p. 269-273, 2005.

EWERS, C.; LI, G.; WILKING, H.; KIESSLING S.; ALT, K.; ANTÁO E, M.; LATURNUS, C.; DIEHL, I.; GLODDE, S; HOMEIER, T.; BÖHNKE, U.; STEINRÜCK, H.; PHILIPP, H. C.; WIELER, L. H. Avian pathogenic, uropathogenic, and newborn meningitis-causing Escherichia coli: how closely related are they? Internacional Journal of Medical Microbiology, v. 297, n. 3, p. 163-176, 2007.

EWERS, C.; ANTÃO E. M., DIEHL, I.; PHILIPP H. C.; WIELER L. H. Intestine and environment of the chicken as reservoirs for extraintestinal pathogenic Escherichia coli strains with zoonotic potential. Applied Environmental Microbiology, v. 75, n. 1, p. 184-192, 2009.

EYKYN, S.; JENKINS, C.; KING, A.; PHILLIPS, I. Antibacterial activity of cefamandole, a new cephalosporin antibiotic, compared with that of cephaloridine, cephalothin, and cephalexin. Antimicrobial Agents and Chemotherapy, v. 3, n. 6, p. 657-661, 1973. 
EYKYN, S. J.; PHILLIPS, I Community outbreak of multiresistant invasive Escherichia coli infection. Lancet, v. 2, n. 1454, p. 8521-8522, 1986.

FANTINATTI, F.; SILVEIRA, W. D.; CASTRO, A. F. P. Characteristics associated with pathogenicity of avian septicaemic Escherichia coli strains. Veterinary.Microbiology, v. 41, n. 1-2, p. 75-86, 1994.

FARHAT, W.; KHOURY, A. Constipação e infecção do trato urinário. Urologia Pediátrica, v. 1, p. 275-283, 2004.

FERNANDEZ-BEROS, M. E.; KISSEL, V.; LIOR, H.; CABELLO, F C. Virulencerelated genes in ColV plasmids of Escherichia coli isolated from human blood and intestines. Journal of Clinical Microbiology, v. 28, n. 4, p. 742-746, 1990

FERREIRA, A. L. S. Classificação filogenética de Escherichia coli patogênica para aves (APEC) e correlação com a presença de fatores de virulência. Londrina: Departamento de Microbiologia, Universidade Estadual de $\quad 2010.2$ Disponível em: $<$ http://www.scribd.com/doc/29807069/Classificacao-filogenetica-de-escherichiacoli-APEC>. Acesso em: 10 dez. 2010.

FLUIT, A. C.; JONES, M. E.; SCHMITZ, F. J.; ACAR, J.; GUPTA, R.; VERHOEF. Antimicrobial susceptibility and frequency of occurrence of Clinical blood isolates in Europe from The Sentry Antimicrobial Surveillance Program, 1997 and 1998. Clinical Infectious Diseases, v. 30, n. 3, p. 454-460, 2000.

FLUIT, A. C.; VERHOEF, J.; SCHMITZ, F. J. Frequency of isolation and antimicrobial resistance of gram-negative and gram-positive bacteria from patients in intensive care units of 25 European university hospitals participating in the European arm of the SENTRY Antimicrobial Surveillance Program 1997-1998. European Journal of Clinical Microbiology \& Infectious Diseases, v. 20, n. 9, p. 617-625, 2001.

GALES, A. C.; BOLMSTROM, A.; SAMPAIO, J.; SADER, H. S. Antimicrobial susceptibility of Klebsiella pneumoniae producing extended spectrum Blactamase (ESBL) isolated in hospitals in Brazil. The Brazilian Journal of Infectious Diseases, v. 1, n. 4, p. 196-203, 1997.

GALES, A. C.; JONES, R. N.; TURNIDGE, J.; RENNIE, R.; RAMPHAL, R. Characterization of Pseudomonas aeruginosa isolates: occurrence rates, antimicrobial susceptibility patterns, and molecular typing in the global SENTRY Antimicrobial Surveillance Program, 1997-1999. Clinical Infectious Diseases, v. 32, n. 2, p. 146-155, 2001. 
GALES, A. C.; SADER, H. S.; JONES, R. N. Urinary tract infection trends in Latin American hospitals: report from the SENTRY antimicrobial surveillance program (1997-2000). Diagnostic Microbiology and Infectious Disease, v. 44, n. 3, p. 289-299, 2002.

GALES, A. C.; MENEZES, L. C.; SILBERT, S.; SADER, H. S. Dissemination in distinct Brazilian regions of an epidemic carbapenem-resistant Pseudomonas aeruginosa producing SPM metallo- $\beta$-lactamases. Journal of Antimicrobial Chemotherapy, v. 52, n. 4, p. 699-702, 2003.

GARCIA, M. I.; LE BOUGUÉNEC, C. Role of adhesion in pathogenicity of human uropathogenic and diarrheogenic Escherichia coli. Bulletin de I'Institut Pasteur, v. 94, n. 3, p. 201-236, 1996.

GARCIA, P. C.; CAMPONOVO, R. C.; TRIANTAFILO, V., Encuesta sobre los métodos de diagnóstico microbiológico de la infección urinaria. Revista Chilena de Infectología, v. 18, n. 1, p. 35-40, 2001.

GARCIA, M. I. G.; BELLIDO, J. L. M.; RODRIGUEZ, J. A. G; Spanish Cooperative Group for the Study of Anitimicrobial susceptibiltiy of Community Uropathogens. In vitro susceptibility of community-acquired urinary tract pathogens to commonly used antimicrobial agents in Spain: a comparative multicenter study (2002-2004). Journal of Chemotherapy, v. 19, n. 3, p. 263-270, 2007.

GIAMARELLOU, H. Multidrug resistance in Gram negative bacteria that produce estendedspectrum- $\beta$-lactamases (ESBLs). Clinical Microbiology Infectious, v. 11, p. 1-16, 2005.

GILBERT, P; ALLISON, D. G.; LAMBERT, P. A. Antibiotics that act on nucleic acids and protein biosynsthesis. In: SUSSMAN, M. (Ed.). Molecular Medical Microbiology. London: Academic Press, 2001. p. 599-608.

GINSBURG, C. M.; McCRACKEN, G. H. Urinary tract infections in young infants. Pediatrics, v. 69, n. 4, p. 409-412, 1982.

GNIADKOWSKI, M.; SCHNEIDER, I.; PAŁUCHA, A.; JUNGWIRTH, R.; MIKIEWICZ, B.; BAUERNFEIND, A. Cefotaxime-resistant Enterobacteriaceae isolates from a hospital in Warsaw, Poland: identification of a new CTX-M-3 cefotaxime-hydrolyzing $\beta$-lactamase that is closely related to the CTX-M-1/MEN-1 enzyme. Antimicrobial agents and Chemotherapy, v. 42, n. 4, p. 827-832, 1998 
GOERING, R. V. Pulsed-field electrophoresis. In: PERSING, D. H. (Ed.) Molecular Microbiology: Diagnostic Principles and Practice. Washington: ASM Press, 2004. p. 185-196.

GRAHAM, J. C.; LEATHART, J. B. S.; KEEGAN, S. J.; PEARSON, J.; BINT, A.; GALLY, D. L. Analysis of Escherichia coli strains causing bacteriuria during pregnancy:Selection for strains that do not express type 1 fimbriae. Infection and Immunity, v. 69, n. 2, p. 794-799, 2001.

GRAZIANI, C.; LUZZI, I.; CORRO, M.; TOMEI, F.; PARISI, G.; GIUFRE, M.; MORABITO, S.; CAPRIOLI, A.; CERQUETTI, M. Phylogenetic background and virulence genotype of ciprofloxacin-susceptible and ciprofloxacin-resistant Escherichia coli strains of human and avian origin. Journal of Infectious Diseases, v. 199, n. 8, p. 1209-1217, 2009.

GREENE, C. E. (Ed.). Infectious diseases of the dog and cat. 3rd ed. Canada: Saunders/Elsevier, 2006. 1387 p.

GUPTA, K.; HOONTON, M. T.; WOBBE, C. L.; STAMM, W. E. The prevalence of antimicrobial resistance among uropathogens causing acute uncomplicated cystitis in young women. International Journal of Antimicrobial Agents, v. 11, n. 3-4, p. 305-308, 1999.

GUPTA, K.; SCHOLES, D.; STAMM, W. E. Increasing prevalence of antimicrobial resistance among uropathogens causing acute uncomplicated cystitis in women. Journal of American Medical Association, v. 281, n. 8, p. 736-738, 1999a.

GUPTA, K.; HOOTON, T. M.; ROBERTS, T. L.; STAMM, W. E. PatientInitiatedTreatment of Uncomplicated Recurrent Urinary Tract Infections in Young Women. Annals of Internal Medicine, v. 135, n. 1, p. 9-16, 2001.

GUYER, D. M.; HENDERSON, I. R.; NATARO J. P.; MOBLEY H. L. T. Identification of Sat, an autotransporter toxin produced by uropathogenic Escherichia coli. Molecular Microbiology, v. 38, n. 1, p. 53-66, 2000.

GUYER, D. M.; RADULOVIC, S.; JONES, F.E.; MOBLEY, H. L. Sat, the secreted autotransporter toxin of uropathogenic Escherichia coli, is a vacuolating cytotoxin for bladder and kidney epithelial cells. Infectious and Immunity, v. 70, n. 8, p. 4539-4546, 2002.

GYLES, C. L. Escherichia coli. In: GYLES, C. L.; THON, C. O. (Ed.) Pathogenesis of bacterial infections in animals. 2nd ed. Ames: lowa University Press, 1993. p. 164-187. 
HACKER, J.; BENDER, L.; OTT, M.; WINGENDER, J.; LUND, B.; MARRE, R.; GOEBEL, W. Deletions of chromosomal regions coding for fimbriae and hemolysin occurr in vitro and in vivo in various extraintestinal Escherichia coli. Microbial Pathogenesis, v. 8, n. 3, p. 213-225, 1990.

HACKER, J.; BLUM-OEHLER, G.; MUHLDORFER, I.; TSCHAPE, H. Pathogenicity islands of virulent bacteria: structure, function and impact on microbial evolution. Molecular Microbiology, v. 23, n. 6, p. 1089-1097, 1997.

HACKER, J.; KAPER, J. B. Pathogenicity islands and the evolution of microbes. Annual review of microbiology, v. 54, p. 641-679, 2000.

HANNAH, E. L.; JOHNSON, J. R.; ANGULO, F.; HADDADIN, B.; WILLIAMSON, J.; SAMORE, M. H. Molecular Analysis of Antimicrobial-Susceptible and Resistant Escherichia coli from Retail Meats and Human Stool and Clinical Specimens in a Rural Community Setting. Foodborne Pathogens and Disease, v.6, n. 3, p. 285-295, 2009.

HEILBERG I. P.; SCHOR, N. Abordagem diagnóstica e terapêutica na infecção do trato urinário - ITU. Revista da Associação Médica Brasileira, São Paulo, v. 49, n. 1, p. 109-116, 2003.

HENDERSON, I. R.; NATARO, J. Virulence Functions of Autotransporter Proteins. Infection and Immunity, v. 69, n. 3, p. 1231-1243, 2001.

HENDERSON, I. R.; NAVARRO-GARCIA, F.; DESVAUX, M., FERNANDEZ, R. C.; ALA'ALDEEN, D. Type V Protein Secretion Pathway: the Autotransporter Story. Microbiology and Molecular Biology Reviews, v. 68, n. 4, p. 692-744, 2004.

HIRSH, D. C.; ZEE Y. C. Veterinary Microbiology \& Immunology. 2nd ed. Rio de Janeiro: Guanabara Koogan, 2003.

HOCHHUT, B.; WILDE, C.; BALLING, G.; MIDDENDORF, B.; DOBRINDT, U.; BRZUSZKIEWICZ, E.; GOTTSCHALK, G.; CARNIEL, E.; HACKER, J. Role of pathogenicity island-associated integrases in the genome plasticity of uropathogenic Escherichia coli strain 536. Molecular Microbiology, v. 61, n. 3, p. 584-595, 2006.

HORNE, S. M.; PFAFF-MCDONOUGH, S. J.; GIDDINGS, C. W.; NOLAN, L. K. Cloning and sequencing of the iss gene from a virulent avian Escherichia coli. Avian Diseases, v. 44, n. 1, p. 179-184, 2000. 
HOU, Y. M. Transfer RNAs and pathogenicity islands. Trends Biochemistry Science, v. 24, n. 8, p. 295-298, 1999.

HUGHES, C.; PHILLIPS, R.; ROBERTS, A. P. Serum resistance among E. coli strains causing urinary tract infection in related $O$ type and carriage of hemolysin, colicin, and antibiotic resistance determinants. Infection and Immunity, v. 35, n. 1, p. 270-275, 1982.

HUMENIUK, C.; ARLET, G.; GAUTIER, V.; GRIMONT,P.; LABIA, R.; PHILIPPON, A. B-Lactamases of Kluyvera ascorbata, Probable Progenitors of Some Plasmid-Encoded CTX-M Types. Antimicrobial Agents and Chemotherapy, v. 46, n. 9, p. 3045-3049, 2002.

ISLAND, M. D.; CUI, X.; FOXMAN, B.; MARRS, C. F.; STAMM, W. E.; STAPLETON, A.E; WARREN, J.W. Cytotoxicity of Hemolytic, Cytotoxic Necrotizing Factor 1-Positive and -Negative Escherichia coli to Human T24 Bladder Cells. Infection and Immunity, v. 66, n. 7, p. 3384-3389, 1998.

ISHII, Y.; OHNO. A.; TAGUCHI, H.; IMAJO, S.; ISHIGURO, M.; MATSUZAWA, H. Cloning and sequence of the gene encoding a cefotaxime-hydrolyzing class $A \beta-$ lactamase isolated from Escherichia coli. Antimicrobial Agents and Chemotherapy, v. 39, n. 10, p. 2269-2275, 1995.

IKE, K.; KUME, K.; KAWAHARA, K.; DANBARA, H. Serotyping of $O$ and Pilus antigens of Escherichia coli strains isolated from chicks with colisepticemia. Japanese Journal of Veterinary Science, v. 52, n. 5, p.1023-1027, 1990.

JACOBY, G. A.; SUTTON, I. $\beta$-lactamases and $\beta$-lactam resistance in Escherichia coli. Antimicrobial . Agents and Chemotherapy, v. 28, n. 5, p. 703-705, 1985.

JACOBY, G. A. Desenvolvimento da resistência em patógenos Gramnegativos. Relatório especial de Hospital Practice "Patógenos emergentes nas doenças infecciosas”. São Paulo: McGraw-Hill Company, 2000.

JALIER, V.; NICOLAS, M. H.; FOURNIER, G.; PHILIPPON. Extended broadspectrum beta-lactamases conferring transferable resistance to newer betalactam agents in Enterobacteriaceae: hospital prevalence and susceptibility patterns. Infectious Diseases, v. 10, n. 4, p. 867-878, 1988.

JOHNSON, J. R.; ROBERTS, P. L.; STAMM, W. E. Aerobactin and other virulence factor genes among strains of Escherichia coli causing urosepsis: association with patient characteristics. Infection and Immunity, v. 56, n. 2, p. 405-412, 1988. 
JOHNSON, J. R.; GOULLET, P.; PICARD, B. Association of carboxylesterase B eletrophoretic pattern with presence and expression of urovirulence factor determinants and antimicrobial resisitance among strains of Escherichia coli that cause urosepsis. Infection and Immunity, v. 59, n. 7, p. 2311-2315, 1991.

JOHNSON, J. R.; STELL, A. L. Extended virulence genotypes of Escherichia coli strains from patients with urosepsis in relation to phylogeny and host compromise. The Journal of Infectious Diseases, v. 181, n. 1, p. 261-272, 2000.

JOHNSON, J. R.; DELAVARI, P.; KUSKOWSKI, M.; STELL, A. L. Phylogenetic Distribution of Extraintestinal Virulence-Associated Traits in Escherichia coli. The Journal of Infectious Diseases, v. 183, n. 1, p. 78-88, 2001.

JOHNSON, J. R.; RUSSO, T. Extraintestinal pathogenic Escherichia coli: "The other bad E. coli". The Journal of Laboratory and Clinical Medicine, v. 139, n. 3, p. 155-162, 2002.

JOHNSON, J. R. Microbial virulence determinants and pathogenesis of urinary tract infection. Infectious Disease Clinics of North America, v. 17, n. 2, p. 261 278, 2003.

JOHNSON, J. R.; MURRAY, A. C.; GAJEWSKI, A.; SULLIVAN, M.; SNIPPES, P.; KUSKOWSKI, M. A.; SMITH, K. E. Isolation and Molecular Characterization of Nalidixic Acid-Resistant Extraintestinal Pathogenic Escherichia coli from Retail Chicken Products. Antimicrobial Agents and Chemotherapy, v. 47, n. 7, p. 2161-2168, 2003a.

JOHNSON, J. R.; KUSKOWSKI, M. A.; OWENS, K.; GAJEWSKI, A.; WINOKUR, P. L. Phylogenetic Origin and Virulence Genotype in Relation to Resistance to Fluoroquinolones and/or Extended-Spectrum Cephalosporins and Cephamycins among Escherichia coli Isolates from Animals and Humans. The Journal of Infectious Disease, v. 188, n. 1, p. 759-768, 2003b.

JOHNSON, J. R.; RUSSO T. A. Molecular epidemiology of extraintestinal pathogenic (uropathogenic) Escherichia coli. International Journal of Medical Microbiology, v. 295, n. 6-7, p. 383-404, 2005.

JOHNSON, T. J.; SIEK, K. E.; JOHNSON, S. J.; NOLAN, L. K. DNA sequence of a ColV plasmid and prevalence of selected plasmid-encoded virulence genes among avian Escherichia colistrains. Journal of Bacteriology, v. 188, n. 2, p. 745-758, 2006. 
JOHNSON, T. J.; WANNEMUEHLER, Y. M.; JOHNSON, S. J.; LOGUE, C. M.; WHITE, D. G.; DOETKOTT, C., et al. Plasmid replicon typing of commensal and pathogenic Escherichia coli isolates. Applied and Environmental Microbiology, v. 73, n. 6, p. 1976-1983, 2007a.

JOHNSON, J. R.; SANNES, M. R.; CROY, C.; JOHNSTON, B.; CLABOTS, C.; KUSKOWSKI, M. A.; BENDER, J.; SMITH, K. E.; WINOKUR, P. L.; BELONGIA E. A. Antimicrobial drug-resistent Escherichia coli from humans and poultry products, Minnesota and Wisconsin, 2002-2004. Emerging Infectious Diseases, v. 13, n. 6, p. 838-845, 2007b.

JOHNSON, T. J.; WANNEMUEHLER, Y.M.; JOHNSON, S. J.; STELL, A. L.; DOETKOTT, C.; JOHNSON, J. R.; KIM, K. S.; SPANJAARD, L.; NOLAN, L. K. . Comparison of extraintestinal pathogenic Escherichia coli strains from human and avian sources reveals a mixed subset representing potential zoonotic pathogens. Applied and Environmental Microbiology, v. 74, n. 22, p. 7043-7050, 2008.

JOHNSON, T. J.; WANNEMUEHLER, Y. M.; NOLAN, L. K. Evolution of the iss gene in Escherichia coli. Applied and Environmental Microbiology, v. 74, n. 8, p. 2360-2369, 2008a.

JOHNSON, T. J.; LOGUE, C. M.; WANNEMUEHLER, Y.; KARIYAWASAM, S.; DOETKOTT, C.; DEBROY, C.; WHITE, D. G.; NOLAN, L. K. Examination of the Source and Extended Virulence Genotypes of Escherichia coli Contaminating Retail Poultry Meat. Foodborne Pathogens and Disease, v. 6, n. 6, p. 657-667, 2009.

JONES, R. N.; KEHRBERG, E. N.; ERWIN, E. E.; ANDERSON, S. C. Prevalence of important pathogens and antimicrobial activity of parenteral drugs at numerous medical centers in the United States: I. Study on threat of emerging resistances: real or perceived? Diagnostic Microbiology and Infectious Disease, v. 19, p. 203-215, 1994.

JONES, R. N.; CROCO, M. A.; KUGLER, K. C.; PFALLER, M. A.; BEACH, M. L. Respiratory tract pathogens isolated from patients hospitalized with suspected pneumonia:frequency of occurrence and antimicrobial susceptibility patterns from the SENTRY Antimicrobial Surveillance Program (United States and Canada, 1997). Diagnostic Microbiology and Infectious Disease, v. 37, n. 2, p. 115$125,2000$.

KAISER, G. V.; GORMAN, M.; WEBBER, J. A. Cefamandole- a review of chemistry and microbiology. Journal Infectious Diseases, v. 137, p. 10-16, 1978 
KALSI, J.; ARYA, M.; WILSON P.; MUNDY A. Hospital-acquired urinary tract infection. International Journal of Clinical Practice, v. 57, n. 5, p. 388-391, 2003.

KAPER, J. B.; NATARO, J. P.; MOBLEY, H. L. T. Pathogenic Escherichia coli. Nature Reviews Microbiology, v. 2, n. 2, p. 123-140, 2004.

KARISIK, E.; ELLINGTON, M. J.; LIVERMORE, D. M.; WOODFORD, N. Virulence factors in Escherichia coli with CTX-M-15 and other extended-spectrum B-lactamases in the UK. Journal of Antimicrobial Chemotherapy, v. 61, n. 1, p. 54-58, 2008.

KARIYAWASAM, S.; JOHNSON, T. J.; DEBROY,C.; NOLAN, L. K. Occurrence of pathogenicity island I (APEC-01) genes among Escherichia coli implicated in avian colibacillosis. Avian Diseases, v. 50, p. 405-410, 2006.

KARIYAWASAM, S.; SCACCIANOCE, J. A.; NOLAN, L. K. Common and specific genomic sequences of avian and human extraintestinal pathogenic Escherichia coli as determined by genomic subtractive hybridization. BMC Microbiology, v. 7, n. 81, 2007, doi:10.1186/1471-2180-7-81.

KAUFFMANN, F. The serology of the coli group. The Journal of Immunology, v. 57, p. 71-100, 1947.

KEANE, W. F.; WELCH, R.; GEKKER, G.; PETERSON, P. K. Mechanism of Escherichia coli alpha-hemolysin-induced injury to isolated renal tubular cells. American Journal of Pathology, v. 126, n. 2, p. 350-357, 1987.

KIFFER C.; HSIUNG, A.; OPLUSTIL. C.; SAMPAIO, J.; SAKAGAMI, E.; TURNER, P.; MENDES, C. Antimicrobial susceptibility of Gram-negative bacteria in Brazilian hospitals: the MYSTIC Program Brazil 2003. The Brazilian Journal of Infectious Diseases, v. 9, n. 3, p. 216-224, 2005.

KLIEBE, C.; NIES, B. A.; MEYER, J.F.; TOLXDORFF-NEUTZLING, R. M.; WIEDEMANN, B. Evolution of plasmid-coded resistance to broad spectrum cephalosporins. Antimicrobial Agents Chemotherapy, v. 28, p. 302-307, 1985.

KNOTHE, H.; SHAH, P.; KRCMERY, V.; ANTAL, M.; MITSUHASHI, S.; Transferable resistance to cefotaxime, cefoxitin, cefamandole and cefuroxime in clinical isolates of Klebsiella pneumoniae and Serratia marcescens. Infection and Immunity, v. 11, n. 6, p. 315-317, 1983. 
KOCH, V. H.; ZUCCOLOTTO, S. M. C. Infecção do trato urinário: em busca das evidências. Jornal de Pediatria, v. 79, n. 1, p. S97-S106, 2003.

KONEMAN, E. W. et al. Diagnóstico Microbiológico: Texto e Atlas Colorido. 5. ed. São Paulo: Medsi. 2001. 586 p.

KUKKONEN, M.; KORHONEN, T. K. The omptin family of enterobacterial surface proteases/adhesins: from housekeeping in Escherichia coli to systemic spread of Yersinia pestis. International Journal of Medical Microbiology, v. 294, n. 1, p. 7-14, 2004.

KUNIN, C. M. Detection, prevention and management of urinary tract infections. 2nd ed. Philadelphia: Lea \& Febiger, 1987.

KUSECEK, B.; WLOCH, H.; MERCER, A.; VAISÄNEN, V.; PLUSCHKE, G.; KORHONEN, T.; ACHTMAN, M. Lipopolysaccharide, capsule, and fimbriae as virulence factors among $\mathrm{O} 1, \mathrm{O} 7, \mathrm{O} 16, \mathrm{O} 18$, or $\mathrm{O} 75$ and $\mathrm{K} 1, \mathrm{~K} 5$, or $\mathrm{K} 100$ Escherichia coli. Infection and Immunity, v. 43, n. 1, p. 368-379, 1984

LAGO, A.; FUENTEFRIA, S. R.; FUENTEFRIA, D. B. ESBL-producing enterobacteria in Passo Fundo, State of Rio Grande do Sul, Brazil. Revista da Sociedade Brasileira de Medicina Tropical, v. 43, n. 4, p. 430-434, 2010

LAU, S.H.; KAUFMANN, M. E.; LIVERMORE, D. M. UK epidemic Escherichia coli strains A-E, with CTX-M-15 lactamases, all belong to the O25:H4 ST 131 clone. Journal of Antimicrobial Chemotherapy, v. 62, n. 6, p. 1241-1244, 2008.

LAUTENBACH, E.; STROM, B. L.; BILKER, W. B.; PATEL, J. B.; EDELSTEIN, P. H.; FISHMAN, N. O. Epidemiological investigation of fluoroquinolone resistance in infections due to extended-spectrum B-lactamase producing Escherichia coli and Klebsiella pneumoniae. Clinical Infectious Diseases, v. 33, n. 8, p. 1288-1294, 2001.

LAUTENBACH, E.; PATEL, J. B.; BILKER, W. B.; EDELSTEIN, P. H.; FISHMAN, N. O. Extended-spectrum beta-lactamase-producing Escherichia coli and Klebsiella pneumonia: risk factors for infection and impact of resistance on outcomes. Clinical Infectious Diseases: an official publication of Infectious Diseases Society of America, v. 32, n. 8, p. 1162-71, $2001 \mathrm{a}$.

LECOINTRE, G. et al. Escherichia coli Molecular Phylogeny Using the Incongruence Length Difference Test. Molecular Biology and Evolution, v. 15, n. 12, p. 1685-1695, 1998. 
LINCOLN, K. Epidemiology of symptomatic urinary tract infection in children. Acta Pediatrica Scandinavica, v. 252, p. 2-20, 1974.

LINCOPAN, N.; MCCULLOCH, J. A.; REINERT, C.; CASSETTARI, V. C.; GALES, A. C.; MAMIZUKA, E. M. First isolation of metallo-ß-lactamaseproducing multiresistant Klebsiella pneumoniae from a patient in Brazil. Journal of Clinical Microbiology, v. 43, n. 1, p. 516-19, 2005.

LINCOPAN, N.; LEIS, R.; VIANELLO, M. A.; ARAÚJO, M. R. E.; RUIZ, A. S.; MAMIZUKA, E. M. Enterobacteria producing extended-spectrum beta-lactamases and IMP-1 metallo-beta-lactamases isolated from Brazilian hospitals. Journal of Medical Microbiology, v. 55, n. 11, p. 1611-13, 2006.

LIU, P. Y. F.; GUR, D.; HALL, L. M. C.; LIVERMORE, D. M. Survey of the prevalence of beta-lactamase amongst 1000 gram-negative bacilli isolated consecutively at the Royal London Hospital. Journal of Antimicrobial Chemotherapy, v. 30, n. 4, p. 429-447, 1992.

LIVERMORE, D. M.; YANG, Y. J. $\beta$-lactamase hability and inducer power of newer $\beta$-lactam antibiotics in relation to their activity against $\beta$-lactamase inducibility mutants of Pseudomonas aeruginosa. Journal of Infectious Diseases, v. 155, p. 775-782, 1987.

LIVERMORE, D. M. $\beta$-lactamases in laboratory and clinical resistance. Clinical Microbiology Reviews, v. 8, p. 557-584, 1995.

LIVERMORE, D. M.; WILLIAMS, J. D. Mode of action and mechanisms of bacterial resistance. In: LORIAN, V. (Ed.). Antibiotics in laboratory medicine. 4th ed. Baltimore, Md.: The Williams \& Wilkins Co., 1996. p. 502-578.

LIVERMORE, D. M.; HAWKEY, P. M. CTX-M: changing the face of ESBLs in the UK. Journal of Antimicrobial Chemotherapy, v. 56, p. 451-454, 2005.

LIVERMORE, D. M. Introduction: the challenge of multiresistance. Journal of Antimicrobial Chemotherapy, v. 29, p. 1-7, 2007. Supplement 3.

LIVERMORE, D. M.; CANTON, R.; GNIADKOWSKI, M.; NORDMANN, P.; ROSSOLINI, G. M.; ARLET, G.; AYALA, J.; COQUE, T. M.; KERN-ZDANOWICZ, I.; LUZZARO, F.; POIREL, L.; WOODFORD, N. CTX-M: changing the face of ESBLs in Europe. Journal of Antimicrobial Chemotherapy, v. 59, p. 165174, 2007. 
LLOYD, A. L.; RASKO, D. A.; MOBLEY, H. L. T. Defining Genomic Islands and Uropathogen-Specific Genes in Uropathogenic Escherichia coli. Journal of Bacteriology, v. 189, n. 9, p. 3532-3546, 2007.

LUZZARO, F.; MEZZATESTA, M.; MUGNAIOLI, C.; PERILLI, M.; STEFANI, S.; AMICOSANTE, G. Trends in Production of Extended-Spectrum-Lactamases among Enterobacteria of Medical Interest: Report of the Second Italian Nationwide Survey. Journal of Clinical Microbiology, v. 44, p. 1659-1664, 2006.

MADIGAN, M. M.; MARTINKO, J.; PARKER, J. E. Brock biology of microorganisms. 10th ed. New York: Prentice Hall, 2003. 1104 p.

MAJD, M.; RUSHTON, H. G.; JANTAUSCH, B. et al. Relationship among vesicoureteral reflux, P-firnbriated Escherichia coli, and acute pyelonephritis in children with febrile urinary tract infection. Journal of Pediatrics, v. 119, p. 578, 1991.

MAMLOUK, K.; BOUBAKER, I. B-B.; GAUTIER, V.; VIMONT, S.; PICARD, B.; REDJEB, S.B.; ARLET, G. Emergence and Outbreaks of CTX-M B-LactamaseProducing Escherichia coli and Klebsiella pneumoniae Strains in a Tunisian Hospital Journal of Clinical Microbiology, v. 44, n. 11, p. 4049-4056, 2006.

MANGES, A. R.; SMITH, S. P.; LAU, B. J.; NUVAL, C. J.; EISENBERG, J. N.S.; DIETRICH, P. S.; RILEY, L. W. Retail meat consumption and the acquisition of antimicrobial resistant Escherichia coli causing urinary tract infections: a casecontrol study. Foodborne Pathogens and Disease, v. 4, n. 4, p. 419-431, 2007

MARCADÉ, G.; DESCHAMPS, C.; BOYD, D. A.; GAUTIER, V.; PICARD, B.; BRANGER, C.; DENAMUR, E.; ARLET, G. Replicon typing of plasmids in Escherichia coli producing extended-spectrum $\beta$-lactamases. Journal of Antimicrobial Chemotherapy, v. 63, n. 1, p. 67-71, 2009.

MARRS, C. F.; ZHANG, L.; FOXMAN, B. Escherichia coli mediated urinary tract infections: are there distinct uropathogenic $E$. coli (UPEC) pathotypes?. FEMS Microbiology Letters, v. 252, p. 183-190, 2005.

MARTINS, I. S.; PESSOA-SILVA, C. L.; NOUER, S. A.; PESSOA DE ARAUJO, E. G.; FERREIRA, A. L.; RILEY, L. W.; MOREIRA, B. M. Endemic extendedspectrum beta-lactamase-producing Klebsiella pneumoniae at an intensive care unit: risk factors for colonization and infection. Microbiology and Drug Resistance, v. 12, n. 1, p. 50-58. 2006. 
MAURER, J. J.; BROWN, T. P.; W. L. STEFFENS, W. L.; THAYER, S. G. The Occurrence of Ambient Temperature-Regulated Adhesins, Curli, and the Temperature-Sensitive Hemagglutinin Tsh among Avian Escherichia coli. American Association of Avian Pathologists, v. 42, n. 1, p. 106-118, 1998.

MEDEIROS, A. A. $\beta$-Lactamases. British Medical Bulletin, v. 40, n. 1, p. 18-27, 1984.

MEDEIROS, A. A. Evolut ion and dissemination of beta -lactamases accelerated by generat ions of beta -lactam ant ibiot ics. Clinical Infectious Diseases, v. 24, p.19-45, 1997. Suppl. 1.

MEDEIROS, E. A. et al. Infecção hospitlar em pacientes cirúrgicos de um Hospital Universitário. Revista Acta Cirúrgica Brasileira, v. 18, n. 1, p. 15-18, 2003.

MENDES, C.; HSIUNG, A.; KIFFER, C.; OPLUSTIL, C.; SINTO, S.; MIMICA, I.; ZOCCOLI, C. Evaluation of in vitro Activity of 9 Antimicrobials Against Bacterial Strains Isolated From Patients in Intensive Care Units in Brazil: MYSTIC Antimicrobial Surveillance Program. Brazilian Journal of Infectious Diseases, v. 4, n. 5, p. 236-244, 2000.

MENDES, C.; SINTO, S.; SAMPAIO J. et al . $P$. aeruginosa clonal dissemination in Brazilian intensive care units during 2002. Clinical Microbiology and Infection, v. 10, n. 3, p. 300, 2004a.

MENDES, C.; SINTO, S.; SAMPAIO, J. et al. A. baumannii clonal dissemination in Brazilian intensive care units during 2002. Clinical Microbiology and Infection, v. 10, n. 3, p. 439, 2004b.

MENEZES, E. A.; ARAÚJO, G. N.; LOPES, H. M.; COSTA, E. P.; NASCIMENTO, I. R. O.; CUNHA, F. A. Perfil de Susceptibilidade a Norfloxacina e ao Sulfazotrim no tratamento de Infecções Urinárias causadas por Escherichia coli no Laboratório de Análises Clínicas de Esquadrão de Saúde da Base Aérea de Fortaleza. NewsLab, v. 49, p. 150-156, 2001.

MENEZES, E. A; MELO, O. F.; OLIVEIRA, I. R. N.; SANTOS, A. S.; FARIAS, R. B.; GUERRA, A. C. P.; CUNHA, F. A. Bacteriúria assintomática em gestantes atendias no Hospital da Base Aérea de Fortaleza. Laes \& Haes, v. 140, p. 84-96, 2003. 
MENEZES, E. A.; CARNEIRO H. M.; CUNHA H. M.; OLIVEIRA, F. A.; NASCIMENTO, I. R.; FERREIRA, A. M. R.; CAVALCANTE, S. M. N. Frequency of microorganisms caused of urine infections nosocomiais in patients of the general Fortaleza Hospital. Revista Brasileira de Análises Clínicas, v. 37, n. 4, p. 243-246, 2005.

MIDDENDORF, B.; HOCHHUT, B; LEIPOLD, K; DOBRINDT, U; BLUM-OEHLER, M. G.; HACKER, J. Instability of Pathogenicity Island in Uropathogenic Escherchia coli 536. Journal of Bacteriology, p. 3056-3096, 2004.

MINARINI, L. A.; GALES, A. C.; PALAZZO, I. C. V; DARINI, A. L . Prevalence of community-occurring extended spectrum beta-lactamase-producing Enterobacteriaceae in Brazil. Current Microbiology, v. 54, n. 5, p. 335-341, 2007.

MINARINI, L. A. R.; CLÍMACO, E. C.; GUIMARÃES, D. B.; FERREIRA, J. C.; PALAZZO, I. C.; MARTINEZ, R.; DARINI, A. L. Clonal transmission of ESBLproducing Klebsiella spp. at a university hospital in Brazil. Current Microbiology, v. 56 , n. 6 , p. $587-591,2008$.

MINARINI, L. A. R.; POIREL, L.; TREVISANI, N. A. ; DARINI, A. L.; NORDMANN, $P$. Predominance of CTX-M-type extended-spectrum $\beta$-lactamase genes among enterobacterial isolates from outpatients in Brazil. Diagnostic Microbiology and Infectious Disease, v. 65, n. 2, p. 202-206, 2009.

MINSHEW, B. H.; JORGENSEN, J.; COUNTS, G. W.; FALKOW, S. Association of hemolysin production, hemagglutination of human erythrocytes, and virulence for chicken embryos of extraintestinal Escherichia coli isolates. Infection and Immunity, v. 20, n. 1, p. 50-54, 1978.

MOKADY, D.; GOPHNA, U.; RON, E. Z. Extensive gene diversity in septicemic Escherichia coli strains. Journal of Clinical Microbiology, v. 43, n. 1, p. 66-73, 2005.

MOLENDA, J. R. Escherichia coli (including 0157:H7): An environmental health perspective. Diary, Food and Environmental Sanitation, v. 14, n. 12, p. $742-$ 747, 1994.

MONNET, D. L.; BIDDLE, J. W.; EDWARDS, J. R.; CULVER, D. H.; TOLSON, J. S.; MARTONE, W. J.; TENOVER, F. C.; GAYNES, R. P.; The National Nosocomial Infections Surveillance System. Evidence of interhospital transmission of extended-spectrum $\beta$-lactam resistant Klebsiella pneumoniae in the United States, 1986 to 1993. Infection Control and Hospital. Epidemiology, v. 18, p. 492-498, 1997. 
MONTGOMERIE, J. Z.; BINDEREIF, A.; NEILANDS, J. B.; KALMANSON, G. M.; GUZE, L. B. Association of hydroxamate siderophore (aerobactin) with Escherichia coli isolated from patients with bacteremia. Infection and Immunity, v. 46, n. 3, p. 835-838, 1984.

MOULIN-SCHOULEUR, M.; SCHOULER, C.; TAILLIEZ, P.; KAO, M. R.; BRÉE, A.; GERMON, P.; OSWALD, E.; MAINIL, J.; BLANCO, M.; BLANCO, J. . Common virulence factors and genetic relationships between O18:K1:H7 Escherichia coli isolates of human and avian origin. Journal of Clinical Microbiology, v. 44, n. 10, p. 3484-3492, 2006.

MORA, A.; LÓPEZ, C.; DABHI, G.; BLANCO, M.; BLANCO, J.; ALONSO, M.;HERRERA, A.; MAMANI, R.; BONACORSI, S.; MOULIN-SCHOULEUR, M.; BLANCO, J. Extraintestinal pathogenic Escherichia coli $01: \mathrm{K} 1: \mathrm{H} 7 / \mathrm{NM}$ from human and avian origin: detection of clonal groups B2 ST95 and D ST59 with different host distribution. BMC Microbiology, v. 9, n. 1, p.132, 2009.

MORA, A.; HERRERA, A.; MAMANI, R.; LÓPEZ, C.; ALONSO, M. P.; BLANCO, J.; BLANCO, M.; DABHI, G.; GARCÍA-GARROTE, F.; PITA, J. M.; COIRA, A.; BERNÁRDEZ, M. I.; BLANCO, J. Recent Emergence of Clonal Group O25b:K1:H4-B2-ST131 ibeA Strains among Escherichia coli Poultry Isolates, Including CTX-M-9-Producing Strains, and Comparison with Clinical Human Isolates Applied and Environmental Microbiology, v. 76, n. 21, p. 6991-6997, 2010.

MUGNAIOLI, C.; LUZZARO, F.; DE LUCA, F.; BRIGANTE, G.; PERILLI, M.; AMICOSANTE, G.; STEFANI, S.; TONIOLO, A.; ROSSOLINI, G. M. CTX-M-Type Extended-Spectrum B-Lactamases in Italy: Molecular Epidemiology of an Emerging Countrywide Problem. Antimicrobial Agents and Chemotherapy, v. 50, n. 8, p. 2700-2706, 2006.

MULVEY, M. A.; SCHILLING, J. D.; MARTINEZ, J. J.; HULTGREN, S. J. Bad bugs and beleaguered bladders: Interplay between uropathogenic Escherichia coli and innate host defenses. Proceedings of the National Academy of Sciences of the United States of the America, v. 97, n. 16, p. 8829-8835, 2000.

MULVEY, M. R.; BRYCE, E.; BOYD, D. A.; OFNER-AGOSTINI, M.; CHRISTIANSON, S.; SIMOR, A. E.; PATON, S.; CANADIAN HOSPITAL EPIDEMIOLOGY COMMITTEE; CANADIAN NOSOCOMIAL INFECTION SURVEILLANCE PROGRAM, HEALTH CANADA. Ambler class A extendedspectrum beta-lactamase-producing Escherichia coli and Klebsiella spp. in Canadian hospitals. Antimicrobial Agents and Chemotherapy, v. 48, n. 4, p. 1204-1214, 2004. 
MULVEY, M. R.; BRYCE, E.; BOYD, D. A.; OFNER-AGOSTINI, M.; LAND, A. M.; SIMOR, A. E.; PATON, S. Molecular characterization of cefoxitin-resistant Escherichia coli from Canadian hospitals. Antimicrobial Agents and Chemotherapy, v. 49, n. 1, p. 358-365, 2005.

NATARO, J. P.; KAPER, J. B. Diarrheagenic Escherichia coli. Clinical Microbiology Reviews, v. 11, n. 1, p. 142-201, 1998.

NATIONAL COMMITTEE FOR CLINICAL LABORATORY STANDARDS. Supplemental Tables. Performance Standards for Antimicrobial Susceptibility Testing. NCCLS Publication (M100-S12), v. 22, n. 1, 2002. 12th Informational Supplement.

NAUMOVSKI, L.; QUINN, J. P.; MIYASHIRO, D.; PATEL, M.; BUSH, K.; SINGER, S. B.; GRAVES, D.; PALZKILL, T.; ARVIN, A. M. Outbreak of ceftazidime resistance due to a novel extended-spectrum beta-lactamase in isolates from cancer patients. Antimicrobial Agents and Chemotherapy, v. 36, n. 9, p. 1991-1996, 1992.

NICOLAS-CHANOINE, M. H. Impact of $\beta$-lactamases on the clinical use of $\beta$ lactam antibiotics. Journal of Antimicrobial Agents, v. 7, n. 1, p. 21-26, 1996.

NICOLAS-CHANOINE, M. H.; BLANCO, J.; LEFLON-GUIBOUT, V.; DEMARTY, R.; ALONSO, M. P.; CANIÇA, M. M.; PARK, Y. J.; LAVIGNE, J. P.; PITOUT, J. D.; JOHNSON, J. R. Intercontinental emergence of Escherichia coli clone O25:H4-ST131 producing CTX-M-15. Journal of Antimicrobial Chemotherapy, v. 61 , n. 2, p. 273-281, 2008.

NICOLLE, L. E. Epidemiology of urinary tract infection. Infections in Medicine, v. 18, p. 153-162, 2001.

NGELEKA, M.; KWAGA, J. K. P.; WHITE, D. G.; WITTAM, T. S.; RIDDELL, C.; GOODHOPE, R.; POTTER, A. A.; ALLAN, B. Escherichia coli cellulitis in broiler chickens: Clonal relationships among strains and analysis of virulence-associated factors of isolates from diseased birds. Infection and Immunity, v. 64, n. 8, p. 3118-3126, 1996.

NOGUEIRA, K. S.; HIGUTI, I. H.; NASCIMENTO, A. J.; TERASAWA, L. B.; OLIVEIRA, S.; MATOS, A. P.; SOUZA, H. A. P. H. M.; COGO, L. L.; COSTA, L. M. D. Occurrence of extended-spectrum beta-lactamases in Enterobacteriaceae isolated from hospitalized patients in Curitiba, southern Brazil. Brazilian Journal of Infectious Diseases, v. 10, n. 6, p. 390-395, 2006. 
NOLAN, L. K.; HORNE, S. M.; GIDDINGS, C. W.; FOLEY, S. L.; JOHNSON, T. J.; LYNNE, A. M.; SKYBERG, J. Resistance to serum complement, iss and virulence of avian Escherichia coli. Veterinary Research Communications, v. 27, n. 2, p. 101-110, 2003.

NOUGAYRÈDE, J.; FERNANDES, P. J.; DONNENBERG, M. S. Adhesion of enteropathogenic Escherichia coli to host cells. Cellular Microbiology, v. 5, n. 6, p. 359-372, 2003.

OELSCHLAEGER, T. A.; DOBRINDT, U.; HACKER, J. Pathogenicity islands of uropathogenic $E$. coli and the evolution of virulence. International Journal of Antimicrobial Agents, v. 19, n. 6, p. 517-521, 2002a.

OELSCHLAEGER, T. A.; DOBRINDT, U.; HACKER, J. Virulence factors of uropathogens. Current Opinion in Urology, v. 12, n. 1, p. 33-38, 2002b.

OLIVER, A.; PEREZ-DIAZ, J. C.; COQUE, T. M.; BAQUERO, F.; CANTON, R. Nucleotide sequence of a novel cefotaximehydrolyzing b-lactamase (CTX-M-10) isolated in Spain. Antimicrobial Agents and Chemotherapy, v. 45, n. 2, p. 616620, 2001.

OLSON, A. B.; SILVERMAN, M.; BOYD, D. A.; MCGEER, A.; WILLEY, B. M.; PONG-PORTER, V.; DANEMAN, N.; MULVEY, M. R. Identification of a Progenitor of the CTX-M-9 Group of Extended-Spectrum $\beta$-Lactamases from Kluyvera georgiana Isolated in Guyana. Antimicrobial Agents and Chemotherapy, v. 49, n. 5, p. 2112-2115, 2005.

ORSKOV, F.; ORSKOV, I. Escherichia coli serotyping and disease in man and animals of. Can. The Journal of Microbiology, v. 38, p. 699-704, 1992.

OSUGUI, L. Pesquisa e caracterização de amostras de ExPEC ("Extraintestinal Pathogenic Bacteria") isoladas de infecções do trato urinário (ITU) de cães e gatos. 2008. 76 f. Dissertação (Mestrado em Ciências Biológicas) - Instituto de Ciências Biológicas, Universidade de São Paulo, São Paulo, 2008.

OTTO, B. R.; VAN DOOREN, S. J. M.; HUIJENS, J. H.; LUIRINK, J.; OUDEGA, $B$. Characterization of a hemoglobin protease secreted by the pathogenic Escherichia coli strain EB1. Journal of Experimental Medicine, v. 188, n. 6, p. 1091-1103, 1998. 
PAGANI, L.; DELL'AMICO, E.; MIGLIAVACCA, R.; D'ANDREA, M. M.; GIACOBONE, E.; AMICOSANTE, G.; ROMERO, E.; ROSSOLINI, G. M. Multiple CTX-M-Type Extended-Spectrum B-Lactamases in Nosocomial Isolates of Enterobacteriaceae from a Hospital in Northern Italy. Journal of Clinical Microbiology, v. 41, n. 9, p. 4264-4269, 2003.

PARHAM, N. J.; SRINIVASAN, U.; DESVAUX, M.; FOXMAN, B.; MARRS, C. F.; HENDERSON, I. R.; PICU. A second serine protease autotransporter of uropathogenic Escherichia coli. FEMS Microbiology Letters, v. 230, p. 73-83, 2004.

PARREIRA, V. R.; GYLES, D. C. L. A Novel Pathogenicity Island Integrated Adjacent to the thrW tRNA Gene of Avian Pathogenic Escherichia coli Encodes a Vacuolating Autotransporter Toxin. Infection and Immunity, v. 71, n. 9, p. 50875096, 2003.

PARREIRA, V. R.; ARNS, C. W.; YANO, T. Virulence factors of avian Escherichia coli associated with swolle head syndrome. Avian Pathology, v. 27, p.148-154, 1998.

PATERSON, D. L.; BONOMO, R. L. Extended-spectrum B-lactamases: a clinical update. Clinical Microbiology Reviews, v. 18, n. 4, p. 657-686, 2005.

PATERSON, D. L. Resistance in gram-negative bacteria: Enterobacteriaceae. American Journal of Infection Control, v. 34, n. 5, p. 20-28, 2006.

PEIRANO, G.; PITOUT, J. D. Molecular epidemiology of Escherichia coli producing CTX-M $\beta$-lactamases: the worldwide emergence of clone ST131 $\mathrm{O} 25: \mathrm{H} 4$. International Journal of Antimicrobial Agents, v. 35, n. 4, p. 316-321, 2010.

PEIRANO, G.; RICHARDSON, D.; NIGRIN, J.; MCGEER, A.; LOO, V.; TOYE, B.; ALFA, M.; PIENAAR, C.; KIBSEY, P.; PITOUT, J. D. High Prevalence of ST131 Isolates Producing CTX-M-15 and CTX-M-14 among Extended-Spectrum- $\beta$ Lactamase-Producing Escherichia coli Isolates from Canada Antimicrobial Agents and Chemotherapy, v. 54, n. 3, p. 1327-1330, 2010.

PEREZ, F.; ENDIMIANI, A.; HUJER, K. M.; BONOMO, R. A. The continuing challenge of ESBLS. Current Opinion in Pharmacology, v. 7, n. 5, p. 459-469, 2007. 
PERUGINI, M. R. E.; VIDOTTO, M. C. Características clínicas e virulência deEscherichia coli infecções do trato urinário. Semina: Cências Biológicas e da Saúde, v. 13, n. 2, p. 33-39, 1992.

PFALLER, M. A.; JONES, R. N.; DOERN, G. Y.; KUGLER, K. Bacterial pathogens isolated from patients with bloodstream infection: frequencies of occurrence and antimicrobial susceptibility patterns from The Sentry Antimicrobial Surveillance Program (United States and Canada, 1997). Antimicrobial Agents Chemotherapy, v. 42, n. 7, p. 1762-1770, 1998.

PFAFF-MCDONOUGH, S. J.; HORNE, S. M.; GIDDINGS, C. W.; EBERT, J. O.; DOETKOTT, C.; SMITH, M. H.; NOLAN, L. K. Complement resistance-related traits among Escherichia coli isolates from apparently healthy birds and birds with colibacillosis. Avian Diseases, v. 44, n. 1, p. 23-33, 2000.

PHILIPPON, A.; LABIA, R.; JACOBY, G. Extended-spectrum B-lactamases. Antimicrobial Agents Chemotherapy, v. 33, p. 1131-1136, 1989.

PHILIPPON, A.; ARLET, G.; LAGRANGE, P. H. Origin and impact of plasmidmediated extend-spectrum $\beta$-lactamases. European Journal of Clinical Microbiology \& Infectious Diseases, v. 13, p. 17-29, 1994. Supplement 1.

PICÃO, R. C.; POIREL, L.; NORDMANN, P. Diversity of beta-lactamases produced by ceftazidime-resistant Pseudomonas aeruginosa isolates causing bloodstream infections in Brazil. Antimicrobial Agents and Chemotherapy, v. 53, n. 9, p.3908-3913, 2009.

PICARD, B.; GARCIA, J. S.; GOURIOU, S. The link between pylogeny and virulence in Escherichia coli extraintestinal infection. Infection and Immunity, v. 67, n. 2, p. 546-553, 1999.

PITOUT. J. D.; LAUPLAND, K. B. Extended-spectrum $\beta$-lactamase-producing Enterobacteriaceae: an emerging public-health concern. The Lancet Infectious Diseases, v. 8, n. 3, p. 159-166, 2008.

PITOUT, J. D. D.; LAUPLAND, K. B.; CHURCH, D. L.; MENARD, M. L.; JOHNSON, J. R. Virulence factors of Escherichia coli isolates that produce CTXM-Type extended-spectrum beta-lactamases. Antimicrobial Agents and Chemotherapy, v. 49, n. 11, p. 4667-4670. 2005. 
PITOUT, J. D. D.; CHURCH, D. L.; GREGSON, D. B.; CHOW, B. L.; MCCRACKEN, M.; MULVEY, M, R.; LAUPLAND, K. B. Molecular Epidemiology of CTX-M-Producing Escherichia coli in the Calgary Health Region: Emergence of CTX-M-15-Producing Isolates. Antimicrobial Agents and Chemotherapy, v. 51, n. 4, p. 1281-1286, 2007.

PITOUT, J. D. D.; LAUPLAND, K. B. Extended-spectrum $\beta$-lactamase-producing Enterobacteriaceae: an emerging public-health concern. The Lancelet Infectious Diseases, v. 8, n. 3, p. 159-166, 2008.

PITOUT, J. D. D. Recent changes in the epidemiology and management of extended-spectrum $\beta$-lactamase-producing Enterobacteriaceae. F1000 Medicine Reports, v. 6, n. 5, p. 657-669, 2009.

POIREL, L.; NAAS, T.; LE THOMAS, I.; KARIM, A.; BINGEN, E.; NORDMAN, P. CTX-M-type extended-expectrum $\beta$ - lactamase that hydrolyzes ceftazidime through a single amino acid substitution in the omega loop. Antimicrobial Agents and Chemotherapy, v. 45, n. 12, p. 3355-3361, 2001.

POLETTO, K. Q.; REIS, C. Antimicrobial susceptibility of the uropathogens in out patients in Goiânia City, Goiás State. Revista da Sociedade Brasileira de Medicina Tropical, v. 38, n. 5, p. 416-420. 2005.

POWERS, J. H. Antimicrobial drug development - the past, the present, and the future. Clinical Microbiology and Infection, v. 10, n. 4, p. 23-31, 2004.

PROVENCE, D. L.; CURTISS, R. Isolation and characterization of a gene involved in hemagglutination by an avian pathogenic Escherichia coli strain. Infection and Immunity, v. 62, n. 4, p.1369-1380, 1994.

QUINN, J. P.; MIYASHIRO, D.; SAHM, D.; FLAMM, R.; BUSH, K. Novel plasmidmediate $\beta$-lactamase (TEM-10) conferring selective resistance to ceftazidime and aztreonam in clinical isolates of Klebsiella pneumoniae. Antimicrobial Agents and Chemotherapy, v. 33, n. 9, p. 1451-1456, 1989.

REITER, W. D.; PALM, P.; YEATS, S. Transfer RNA genes frequently serve as integration sites for prokaryotic genetic elements. Nucleic Acids Research, v. 17, n. 5, p. 1907-1914, 1989. 
RIBOT, E. M.; FAIR, M. A.; GAUTOM, R.; CAMERON, D. N.; HUNTER, S. B.; . SWAMINATHAN, B.; BARRETT, T. J. Standardization of Pulsed-Field Gel Electrophoresis Protocols for the Subtyping of Escherichia coli O157:H7, Salmonella, and Shigella for PulseNet. Foodborne Pathogens and Disease, v. 3, n. 1, p. 59-67, 2006.

RICE, L. B.; WILLEY, S.H.; PAPANICOLAOU, G.A.; MEDEIROS, A.A.; ELIOPOULOS, G. M.; MOELLERING Jr, R. C.; JACOBY, G. A. Outbreak of ceftazidime resistance caused by extended-spectrum beta-lactamases at a Massachusetts chronic-care facility. Antimicrobial Agents and Chemotherapy, v. 34, n. 11, p. 2193-2199, 1990.

RICE, L. B.; ECKSTEIN, E.C.; DEVENTE, J.; SHLAES, D. M. Ceftazidimeresistant Klebsiella pneumoniae isolates recovered at the Cleveland Department of Veterans Affairs Medical Center. Clinical Infectious Diseases, v. 23, n. 1, p. 118-124, 1996.

RICE, L. B. Successful interventions for gram-negative resistance to extended spectrum $\beta$-lactam antibiotics. Pharmacotherapy, v. 19, n. 8, pt. 2, p. 120S$128 \mathrm{~S}, 1999$.

RODRIGUEZ, M. M.; POWER, P.; RADICE, M.; VAY, C.; FAMIGLIETTI, A.; GALLENI, M.; AYALA, J. A.; GUTKIND, G. Chromossome-encoded CTX-M-3 from Kluyvera ascorbata: a possible origin of plasmid-borne CTX-M-1-derived cefotaximases. Antimicrobial Agents and Chemotherapy, v. 48, n. 12, p. 48954897, 2004.

RODRIGUEZ-SIEK, K. E.; GIDDINGS, C. W.; DOETKOTT, C.; JOHNSON, T.J.; FAKHR, M.K.; NOLAN, L. K. Comparison of Escherichia coli isolates implicated in human urinary tract infection and avian colibacillosis. Microbiology, v. 151, pt. 6, p. 2097-2110, 2005.

RON, E. Z. Host specificity of septicemic Escherichia coli: human and avian pathogens. Current Opinion in Microbiology, v. 9, n. 1, p. 28-32, 2006.

RONALD, A. The etiology of urinary tract infection: traditional and emerging pathogens. Disease-a-Month, v. 49, n. 2, p. 71-82, 2003.

ROSSOLINI, G. M. Acquired Metallo-b-Lactamases: An Increasing Clinical Threat. Clinical Infectious Diseases. v. 41, p. 1557-1558, 2005. 
RUIZ, J.; SIMON, K.; HORCAJAA, J. P.; VELASCO, M.; BARRANCO, M.; ROIG, G.; MARTÍNEZ, A. M.; MARTÍNEZ, J. A.; ANTA, T. J.; MENSA, J.; VILA, J. Diferences in virulence factors among clinical isolates of Escherichia coli causing cystitis na pyelonephritis in women na prostatitis in men. Journal of Clinical Microbiology, v. 40, n. 12, p. 4445-4449, 2002.

RUSHTON, H. G. Urinary tract infections in children: epidemiology, evaluation, and management. Pediatric Clinics of North America, v. 44, n. 5, p. 1133-1169, 1997.

RUSSO, T. A.; JOHNSON, J. R. A proposal for an inclusive designation for extrainstestinal pathogenic Escherichia coli: ExPEC. The Journal of Infectious Diseases, v. 181, n. 5, p. 1753-1754, 2000.

RUSSO, T. A.; JOHNSON, J. R. Medical and economic impact of extraintestinal infections due to Escherichia coli: focus on an increasingly important endemic problem. Microbes and Infection, v. 5, n. 5, p. 449-456, 2003.

SADER, H. S.; JONES, R. N. Antimicrobial activity of the new carbapenem biapenem compared to imipenem, meropenem and other broad - spectrum betalactam drugs. European Journal of Clinical Microbiology and Infectious Diseases, v. 12, n. 5, p. 384-391, 1993.

SADER, H. S.; JONES, R. N.; GALES, A. C.; WINOKUR, P.; KUGLER, K. C.; PFALLER, M. A. Antimicrobial susceptibility patterns for pathogens isolated from patients in Latin American medical centers with a diagnosis of pneumonia: analysis of results from the SENTRY Antimicrobial Surveillance Program (1997). SENTRY Latin America Study Group. Diagnostic Microbiology and Infectious Disease, v. 32, n. 4, p. 289-301, 1998.

SADER, H. S.; JONES, R. N.; WINOKUR, P. L.; PFALLER, M. A.; DOERN, G. V.; BARRETT, T. the SENTRY Study Group, Latin America. Antimicrobial susceptibility of bacteria causing urinary tract infections in Latin American hospitals: results from the SENTRY Antimicrobial Surveillance Program (1997). Clinical Microbiology and Infection: the official publication of the European society of Clinical Microbiology and Infectious Diseases, v. 5, n.8, p. 478487, 1999a.

SADER, H. S.; SAMPAIO, J. L.; ZOCCOLI, C.; JONES, R. N. Results of the 1997 Sentry Antimicrobial Surveillance Program in three Brazilian Medical Centers. The Brazilian Journal of Infectious Diseases: an official publication of the Brazilian Society of Infectious Diseases, v. 3, n. 2, p. 63-79, 1999b. 
SADER, H. S.; GALES, A. C.; PFALLER, M. A.; MENDES, R. E.; ZOCCOLI, C.; BARTH, A.; JONES, R. N. Pathogen frequency and resistance patterns in Brazilian hospitals: summary of results from three years of the SENTRY Antimicrobial Surveillance Program. The Brazilian Journal of Infectious Diseases: an official publication of the Brazilian Society of Infectious Diseases, v. 4, p. 200-214, 2001.

SADER, H. S.; MENDES, R. E.; CASTANHEIRA, M.; GORDON, K. A.; WALSH, T. R.; DESHPANDE, L. M.; JONES, R. N. The emergence of metallo- $\beta$ lactamases and increasing carbapenem resistance among $P$. aeruginosa and Acinetobacter spp. from bloodstream infections (BSI): Report from the SENTRY Antimicrobial Surveillance Program. In: INTERSCIENCE Conference on Antimicrobial Agents and Chemotherapy, 43., 2003, Chicago. Abstract Book of the 43rd Interscience Conference on Antimicrobial Agents and Chemotherapy. Chicago: ICAAC, 2003. p. 43. Resumo. C2-2028.

SADER, H. S.; JONES, R. N.; GALES, A. C.; SILVA, J. B.; PIGNATARI, J. B. Sentry Participants Group (Latin America). Sentry Antimicrobial Surveillance Program Report: Latin American and Brazilian Results For 1997 Through 2001. The Brazilian Journal of Infectious Diseases: an official publication of the Brazilian Society of Infectious Diseases, v. 8, n. 1, p. 25-79, 2004.

SADER, H. S.; BIEDENBACH, D. J.; JENNIFER, M.; STREIT, M.; JONES, R. N. Cefdinir activity against contemporary North American isolates from communityacquired urinary tract infections. International Journal of Antimicrobial Agents, v. 25, n.1, p. 89-92, 2005.

SADOWSKA, B.; OSEK, J.; BONAR, A.; WIECKOWSKA-SZAKIEL, M.; RUDNICKA, W.; RÓZALSKA, B. Phenotypic and molecular characteristics of typical and atypical Escherichia coli 0157 , clinical and food isolates. Acta Microbiologica Polonica, v. 52, n. 2, p. 149-158, 2003.

SALZER, W. Infecções do trato urinário. In: GATES, R. H. Segredos de infectologia: respostas necessárias ao dia a dia em rounds, na Clínica em Exames Orais e Escritos. Porto Alegre: Artes Médicas Sul, 2000.

SANDERS, C. C.; SANDERS Jr, W. E. Emergence of resistance to cefamandole: possible role of cefoxitin-inducible beta-lactamases. Antimicrobial Agents and Chemotherapy, v. 15, n. 6, p. 792-797, 1979.

SANGER, F.; NICKLEN, S.; COULSON, A. R. DNA sequencing with chainterminating inhibitors. 1977. Biotechnology, v. 24, p. 104-108, 1992. 
SCHWARTZ, D. C.; SAFFRAN, W.; WELSH, J.; HAAS, R.; GOLDENBERG, M.; CANTOR, C. R. New techniques for purifying large DNAs and studying their properties and packaging. Cold Spring Harbor Symposia on Quantitative Biology, v. 47, n. 1, p. 189-195, 1983.

SCHEUTZ, F.; CHEASTY, T.; WOODWARD, D.; SMITH, H. R. Designation of O174 and $\mathrm{O} 175$ to temporary $\mathrm{O}$ groups $\mathrm{OX} 3$ and $\mathrm{OX7}$, and six new Escherichia coli $\mathrm{O}$ groups include verocytotoxin - producing E.coli (VTEC): O176, O177, 0178, O179, O180 an O181. Acta pathologica, micobiologica et immunologica Scandinavica, v. 112, n. 9, p. 569-584, 2004.

SCHOULER, C.; KOFFMANN, F.; AMORY, C.; LEROY-SETRIN, S.; MOULINSCHOULEUR, M. Genomic subtraction for the identification of putative new virulence factors of an avian pathogenic Escherichia coli strain of $\mathrm{O} 2$ serogroup Microbiology. v. 150, n. 9, p. 2973-2984, 2004.

SCHUBERT, S.; RAKIN, A.; FISCHER, D.; SORSA, J.; HEESEMANN, J. Characterization of the integration site of Yersinia high-pathogenicity island in Escherichia coli. FEMS Microbiology Letters, v. 179, n. 2, p. 409-414, 1999.

SCHITO, G. C.; NABER, K. G., BOTTO, H.; PALOU, J.; MAZZEI, T.; GUALCO, L.; MARCHESE, A. The ARESC study: an international survey on the antimicrobial resistance of pathogens involved in uncomplicated urinary tract infections. Journal of Antimicrobial Agents, v. 34, n. 5, p. 407-413, 2009.

SMITH, H. W.; HUGGINS, M. B. The association of the O18, K1 and H7 antigens and the Co1V plasmid of a strain of Escherichia coli with its virulence and immunogenicity. Journal of General Microbiology, v. 121, n. 2, p. 387-400, 1980.

SMITH, J. L.; FRATAMICO, P. M.; GUNTHER, N. W. Extraintestinal pathogenic Escherichia coli. Foodborne Pathogens and Disease, v. 4, n. 2, p. 134-163, 2007.

SOTO, S. M.; SMITHSON, A.; HORCAJADA, J. P.; MARTINEZ, J. A.; MENSA, J. P.; VILA, J. Implication of biofilm formation in the persistence of urinary tract infection caused by uropathogenic Escherichia coli. Clinical Microbiology and Infection, v. 12, n. 10, p. 1034-1036, 2006.

STEHLING, E. G.; YANO, T.; BROCCHI, M.; SILVEIRA, W. D. Characterization of a plasmid-encoded adhesin of an avian pathogenic Escherichia coli (APEC) strain isolated from a case of swollen head syndrome (SHS). Veterinary Microbiology, v. 95, n. 1-2, p. 111-120, 2003. 
STRAHILEVITZ, J.; JACOBY, G. A.; HOOPER, D. C.; ROBICSEK, A. Plasmidmediated quinolone resistance: a multifaceted threat. Clinical Microbiology Reviews, v. 22, n. 4, p. 664-689, 2009.

SOUSA JÚNIOR, M. A.; FERREIRA, E.S.; CONCEICÃO, G.C. Beta-lactamases de Espectro Ampliado (ESBL): um Importante Mecanismo de Resistência Bacteriana e sua Detecção no Laboratório Clínico. NewsLab, n. 63, p. 38-55, 2004.

SOUSA, J. C. Manual de antibióticos antimicrobianos. Porto: Universidade Fernando Pessoa, 2005.

SOUSA, C. P. The versatile strategies of Escherichia coli pathotypes: a mini review. Journal of Venomous Animals and Toxins including Tropical Diseases, v. 12, n. 3, p. 363-373, 2006.

STAWSKI, G.; NIELSEN, L.; ORSKOV, F.; ORSKOV, I. Serum sensitivity of a diversity of Escherichia coli antigenic reference strains. Acta pathologica, micobiologica et immunologica Scandinavica, v. 98, n. 7-12, p. 828-838, 1990.

STROM, L. B.; COLLINS, M.; WEST, S. L.; KREISBERG, J.; WELLER, S. Sexual activity, contraceptive use and other risk factors for symptomatic and asymptomatic bacteriuria. A case-control study. Annals of internal medicine, v. 107, n. 6, p. 816-823, 1987.

STÜRENBURG, E.; MACK, D. Extended-spectrum beta-lactamases: implications for the clinical microbiology laboratory, therapy, and infection control. Journal of Infectious Diseases, v. 47, n. 4, p. 273-295, 2003.

SUPERTI, S. V.; AUGUSTI, G.; ZAVASCKI, A. P. Risk factors for and mortality of extended-spectrum- $\beta$-lactamase-producing Klebsiella pneumoniae and Escherichia coli nosocomial bloodstream infections. Revista do Instituto de Medicina Tropical de São Paulo, v. 51, n. 4, p. 211-216, 2009.

SWENSON, D. L.; BUKANOV, N. O.; BERG, D. E.; WELCH, R. A. Two pathogenicity islands in uropathogenic Escherichia coli J96: cosmid cloning and sample sequencing. Infection and Immunity. v. 64, n. 9, p. 3736-3743, 1996. 
TALBOT, G. H.; BRADLEY, J.; EDWARDS JR, J. E.; GILBERT, D.; SCHELD, M.; BARTLETT, J. G.; ANTIMICROBIAL AVAILABILITY TASK FORCE OF THE INFECTIOUS DISEASES SOCIETY OF AMERICA. Bad bugs need drugs: an update on the development pipeline from the Antimicrobial Availability Task Force of the Infectious Diseases Society of America. Clinical Infectious Diseases: an official publication of the Infectious Diseases Society of America, v. 42, n. 5, p. 657-668, 2006.

TENG, L. J.; HSUEH, P. R.; LIAW, S. J.; HO, S. W.; TSAI, J. C. Genetic detection of diarrheagenic Escherichia coli isolated from children with sporadic diarrhea. Journal of Microbiology, Immunology and Infection. v. 37, n. 6, p. 327-334, 2004.

TENOVER, F. C.; ARBEIT, R. D.; GOERING, R. V.; MICKELSEN, P. A.; MURRAY, B. E.; PERSING, D. H.; SWAMINATHAN, B. Interpreting chromosomal DNA restriction patterns produced by pulsed-field gel electrophoresis: criteria for bacterial strain typing. Journal of Clinical Microbiology, v. 33, n. 9, p. 22332239, 1995

TERAI, A.; YAMAMOTO, S.; MITSUMORI, K.; OKADA, Y.; KURAZONO, H.; TAKEDA, Y.; YOSHIDA, O. Escherichia coli virulence factors and serotypes in acute bacterial prostatitis. International Journal of Urology : official journal of the Japanese Urological Association, v. 4, n. 3, p. 289-294, 1997.

THOMSON, K. S.; PREVAN, A. M.; SANDERS, C. C. Novel plasmid-mediated beta-lactamases in enterobacteriaceae: emerging problems for new beta-lactam antibiotics. Current Clinical Topics in Infectious Diseases, v. 16, p. 151-163. 1996

THOMSON, K. S., SANDERS, C. C. A simple and reliable method to screen isolates of Escherichia coli and Klebsiella pneumoniae for the production of TEMand SHV-derived extended-spectrum $\beta$-lactamases. Clinical Microbiology and Infection, v. 3, n. 5, p. 549-554, 1997

TIBA, M. R.; YANO, T.; LEITE, S. Genotypic characterization of virulence factors in Escherichia coli strains from patients with cystitis. Revista do Instituto de Medicina Tropical de São Paulo, v. 50, n. 5, p. 255-260, 2008.

TODAR, K. The Microbial World. Bacterial Resistance to Antibiotics: mechanisms of antibiotic resistance in bacteria. Department of Bacteriology, University of Wisconsin, Madison, 2009. Disponível em:<http:/textbookofbacteriology.net/themicrobialworld/bactresanti.html>. Acesso em: 10 dez. 2010. 
TOLLENTINO, F. M.; POLOTTO, M.; NOGUEIRA, M. L.; LINCOPAN, N.; NEVES, P.; MAMIZUKA, E. M.; REMELI, G. A.; DE ALMEIDA, M. T.; RUBIO, F. G.; NOGUEIRA, M. C. High prevalence of bla(CTX-M) extended expectrum betalactamase genes in Klebsiella pneumonia isolates from a Tertiary Care Hospital: first report of bla (SHV - 12), bla (SHV-31), bla (SHV - 38), and bla (CTX - M 15) in Brazil. Microbial Drug Resistance, 2010. doi: 10.1089/mdr.2010.0055.

TRABULSI, L. R.; ALTERTHUM, F. Microbiologia. 4. ed. São Paulo: Atheneu, 2004.

TUMBARELLO, M.; SPANU, T.; SANGUINETTI, M.; CITTON, R.; MONTUORI, E.; LEONE, F.; FADDA, G.; CAUDA, R. Bloodstream infections caused by extended-spectrum-ß-lactamase-producing Klebsiella pneumoniae: risk factors, molecular epidemiology, and clinical outcome. Antimicrobial Agents Chemotherapy, v. 50, n. 2, p. 498-504, 2006.

TWAIJ, M. Urinary tract infection in children: a review of its pathogenesis and risk factors. The Journal of the Royal Society for the Promotion of Health, v. 120, n. 4, p. 220-226, 2000.

TZOUVELEKIS, L. S.; VATOPOULOS, A. C.; KATSANIS, G.; TZELEPI, E. Rare case of failure by and automated system to detect extended-spectrum betalactamase in a cephalosporin-resistant Klebsiella pneumonia isolate. Journal of Clinical Microbiology, v. 37, n. 7, p. 2388, 1999.

URBAN, C.; MEYER, K. S.; MARIANO, N.; RAHAL, J. J.; FLAMM, R.; RASMUSSEN, B. A.; BUSH, K. Identification of TEM-26 $\beta$-Lactamase responsible for a major outbreak of Ceftazidime-Resistant Klebsiella pneumoniae. Antimicrobial Agents and Chemotherapy, v. 38, n. 2, p.392-395, 1994.

VIDAL, M.; KRUGER, E.; DURAN, C.; LAGOS, R.; LEVINE, M.; PRADO, V. Single multiplex PCR assay to identify simultaneously the six categories of diarrheagenic Escherichia coli associated with enteric infections. Journal of Clinical Microbiology, v. 43, n. 10, p. 5362-5365, 2005.

VILA, J.; SIMON, K.; RUIZ, J.; HORCAJADA, J. P.; VELASCO, M.; BARRANCO, M.; MORENO A.; MENSA J. Are Quinolone-Resistant Uropathogenic Escherichia coli Less Virulent? Journal of Infectious Diseases, v. 186, n. 7, p. 1039-1042, 2002.

WALTHER-RASMUSSEN, J.; HOIBY, N. Cefotaximases (CTX - M - ases), an expanding family of extended-spectrum beta-lactamases. Canadian Journal of Microbiology, v. 50, n. 3, p. 137-165, 2004. 
WICK, W. E.; PRESTON, D. A. Biological Properties of three 3-heterocyclicthiomethyl cephalosporin antibiotics. Antimicrobial Agents and Chemotherapy, v. 1, n. 3, p. 221-234, 1972.

WILLIAMS, J. D. $\beta$-lactamases and $\beta$-lactamase inhibitors. International Journal of Antimicrobial Agents, v. 12, n. 1, p. 3-7, 1999.

WILSON, M. L.; GAIDO, L. Laboratory diagnosis of urinary tract infections in adult patients. Clinical Infectious Diseases: an official publication of the Infectious Diseases Society of America, v. 38, n. 8, p. 1150-1158, 2004.

WOOLEY, R. E.; NOLAN, L. K.; BROWN, J.; GIBBS, P. S.; GIDDINGS, C. W.; TURNER, K. S. Association of K-1 capsule, smooth lipopolysaccharides, traT gene, and Colicin $\mathrm{V}$ production with complement resistance and virulence of avian Escherichia coli. Avian Diseases, v. 37, n. 4, p. 1092-1096, 1993.

WYCKOFF, E. E.; DUNCAN, D.; TORRES, A. G.; MILLS, M.; MAASE, K.; PAYNE, S. M. Structure of the Shigella dysenteriae haem transport locus and its phylogenetic distribution in enteric bacteria. Molecular Microbiology, v. 28, n. 6, p. 1139-1152, 1998.

YAMAMOTO, S.; TERAI, A.; YURI, K.; KURAZONO, H.; TAKEDA, Y.; YOSHIDA. $O$. Detection of urovirulence factors in Escherichia coli by multiplex polymerase chain reaction. FEMS Immunology and Medical Microbiology, v. 12, n. 2, p. 85-90, 1995.

YAMAMOTO, S. Molecular epidemiology of uropathogenic Escherichia coli. Journal of Infection and Chemotherapy: official journal of the Japan Society of Chemotherapy, v. 13, n. 2, p. 68-73, 2007. 